\title{
AN EXAMINATION OF AN ENVIRONMENTAL CHANGE IN BEVERAGES \\ AVAILABLE TO HIGH SCHOOL STUDENTS IN SANTA MARIA, CALIFORNIA ON THEIR CONSUMPTION BEHAVIOR
}

\author{
A Thesis \\ presented to \\ the Faculty of California Polytechnic State University, \\ San Luis Obispo \\ In Partial Fulfillment \\ of the Requirements for the Degree \\ Master of Science in Agriculture \\ with Specialization in Food Science and Nutrition
}

by

Susan Eileen Klucker

May 2014 
(C) 2014

Susan Eileen Klucker

ALL RIGHTS RESERVED 


\section{COMMITTEE MEMBERSHIP}

TITLE: $\quad$ An Examination of an Environmental Change in Beverages Available to High School Students in Santa Maria,

California on their Consumption Behavior

AUTHOR: $\quad$ Susan Eileen Klucker

DATE SUBMITTED: May 2014

COMMITTEE CHAIR: $\quad$ Mary E. Pedersen, Ph.D.

Associate Vice Provost

Academic Programs and Planning

COMMITTEE MEMBER: Lisa M. Nicholson, Ph.D., R.D.

Associate Professor

Food Science and Nutrition Department

COMMITTEE MEMBER: Marianne McGarry Wolf, Ph.D.

Professor

Agribusiness Department 


\section{ABSTRACT \\ An Examination of an Environmental Change in Beverages Available to High School Students in Santa Maria, California on their Consumption Behavior Susan Eileen Klucker}

Hypothesis: "By an environmental change in high school vending machines, making water available, students will choose water over the sugar sweetened sodas."

This document highlights a case study analysis of vendor-provided refill data for forty-five beverage vending machines at two campus sites in one high school district in 2003 and 2004. The innovative study and publicized negotiated soda contract of a 50:50 (healthy to unhealthy) beverage ratio stipulation became the "Win-Win-WEAN" compromise, in which exposure to healthier beverage options for students might prove to provide the same income opportunity for the school district.

An overview of the political climate in California leading to this local advocacy for reduced availability of sodas on school campuses, which began in 1999 before the passage of Senate Bill 19- Pupil Nutrition, Health Achievement Act of October 2001 (SB-19) is also addressed. The quagmire to generate and implement this unique pilot of a 5-year contract stipulating a 50:50 ratio, with strategic placement of qualified healthy beverages in the top slots of the 45 machines, is discussed to give context of the beverage industry practices. The ratio stipulation was intended to target one significant area of empty calories in students' daily environments in attempt to help reverse the unprecedented obesity epidemic among adolescents. The agreement voted upon by the Santa Maria Joint Union School District's Board of Trustees in a public meeting, as noted in the minutes of August 14, 2002, was not implemented as originally approved and thus a series of negotiation meetings began, prompting this data analysis. The 50:50 ratio, per 
SB-19, was not achieved during the performance life of the contract between the school district and the beverage vendor.

School district administration fiscal year-end data in March 2005 confirmed that the hypothesis of a net profit sales quota of $\$ 60,000$ was rejected, as there was a $\$ 7,300$ shortfall. The data analyzed did determine that the highest selling, single beverage product was un-flavored (plain) water with a $65 \%$ share. This information was contrary to the beverage vendor and school district business superintendents' pre-conceived ideas that water in the machines would cause them to lose money. In reality water was the highest revenue generator beverage. The $\$ 60,000$ minimum guaranteed annual commission, which was in actuality a sales quota projection, was still acknowledged as a contractual commitment by the vendor so no actual deficiency in fund payments was experienced by the school district. The profit margin for both water and other products was 40 cents per can.

The data analysis showed that water was indeed the highest selling beverage regardless of equipment malfunction, restocking failures, and misrepresentation of drinks as healthy by vending machine placement and clever advertising with label changes for the same beverage. When water was included in the vending machines, students responded with immediate purchasing of water, demonstrating the $4^{\text {th }}$ of five distinct stages of readiness for behavior change as "Action" following the principles of Drs' Prochaska and Di Clemete's Trans-Theoretical model. This model outlines different levels toward sustained behavior change and typical timelines of each relative stage of change. Keywords: beverage consumption, sodas, obesity, empty calories. 


\section{ACKNOWLEDGMENTS}

The most significant outcome of writing this thesis, for this author, is that the final result is not a solo effort. I now understand why books have sections referred to by such names as "dedications", "forewords" and "prefaces". A manuscript of this magnitude requires the acceptance of assistance and necessary submission of any excessive personal pride for it to be worthy of professional credentials and subsequent publishing.

I fully acknowledge my Graduate Advisory Team. They took their role seriously. In particular, Dr. Lisa Nichols and Dr. Marianne McGarry-Wolf had the insight to point out to me successes contained in the manuscript when I was concentrating on perceived disappointment in the data results.

I wish to thank my husband, Kurt Klucker, for his love and support throughout this process. I know he looks forward to having the garage boxes cleared out of the background history that is no longer essential.

Alison Okada Wollitzer, Ph.D., became the editor to refine components when I was unable to delete extraneous information of this multifaceted topic. I cannot ever appropriately express in words my gratitude for her patience as this document was refined. Her ongoing support is the primary reason this document was finally submitted in the newly college revised required format. Her follow up on the proper electronic citing of the sources, without question, fostered the completion of this manuscript. She definitely has earned the privilege of being a co-publisher of this research study.

Finally, Dr. Mary Pedersen, my graduate advisor on this journey, is the ultimate example of professional advising. She went "above and beyond" as she was promoted multiple times during the course of the writing, which one would have expected would result in her resigning as graduate advisor. She came along side me during this process 
and continued even though those promotions placed such advising beyond the scope of her duties. She was keenly aware of the subject matter at the core of this thesis and believed in my ability to complete it in the face of multiple challenges. 


\section{TABLE OF CONTENTS}

Page

LIST OF FIGURES

xiii

\section{CHAPTER}

I. INTRODUCTION 1

II. LITERATURE REVIEW

Establishment of "Win-Win-WEAN"

Unprecedented "Globesity"

$\begin{array}{ll}\text { Obesity Youth Definitions } & 7\end{array}$

$\begin{array}{lr}\text { International Adolescent Obesity Rates } & 8\end{array}$

United States Youth Obesity Rates 9

$\begin{array}{ll}\text { California Childhood Obesity Rates } & 10\end{array}$

Santa Barbara County Youth Obesity Data 12

Potential Role of Soda Consumption in Overweight Children 14

Soda Consumption Replacing Necessary Milk 15

Soda Consumption as an Independent Obesity Risk Factor 16

$\begin{array}{ll}\text { Other Overweight Compounding Factors for Youth } & 17\end{array}$

National Carbohydrate Consumption Data and Recommendations 17

$\begin{array}{ll}\text { National Soft Drink Consumption Data and Parallels } & 18\end{array}$

Advocating for Government Recommended "Added Sugar Limits" 20

High Fructose Corn Syrup in Sodas as Added Sugar 20

Government Data for Soft Drink Intake 22

Soft Drink Production Data 22

California Soda Consumption Data 22

viii 
Santa Barbara High School Soda Consumption Data

Overconsumption of Calories Studied as "Energy Gap" 24

High Schools Resort to Soda Sales for Budget Needs 25

California's Initial L.E.A.N. Project 27

CA Dept of Health Services Expands Project L.E.A.N.'s Goals 27

School Environment Exposed for Conflicting Messages 28

Presence of Advertising on School Campuses $\quad 29$

$\begin{array}{ll}\text { Advertising Tactics Targeting Youth } & 30\end{array}$

New Research on Advertising Messages 32

Beverage Industry Tactics $\quad 32$

Vending Beverage Marketing Practices $\quad 34$

The Santa Maria School Soda Study 34

Knowledge Alone is Not Enough to Change Behavior 34

School Environment as an Opportunity to Reverse Obesity Trend 35

Overweight Data Parallels Lack of Federal Regulations Enforcement 36

Legislation to Improve School Nutrition Standards 37

California State School Board Rules Introduced 38

Project L.E.A.N.’s Legislative Involvement Strategy 39

Public Health Responds to Obesigenic Environment 39

Schools as Chosen Institution of the Socio-Ecological Model 40

Behavior Modification Theories $\quad 41$

Trans-theoretical Model Approach $\quad 42$

Techniques for Behavior Modification 43

ix 
Efficacy of Environmental Change Strategies 44

III. MATERIALS AND METHODS 45

Data Source Overview $\quad 45$

Data Procurement Challenges $\quad 45$

Data Challenges Caused by Faulty RFP Definitions 47

Preliminary Data Calculation Methods $\quad 48$

Projections of Water Sales $\quad 49$

Calculation Methods Utilized $\quad 49$

$\begin{array}{ll}\text { District Year-end Data Process } & 50\end{array}$

$\begin{array}{ll}\text { Sales Commission Calculations } & 50\end{array}$

Annual Guaranteed Commission $\quad 51$

Estimated Energy Consumption 51

IV.RESULTS

Availability of Water on Campus $\quad 52$

Beverage Sales $\quad 52$

Water versus Pepsi $\quad 54$

Intended Healthy Beverages $\quad 54$

Financial Impact Data $\quad 55$

Energy Calculation $\quad 55$

V. DISCUSSION AND CONCLUSIONS 57

$\begin{array}{ll}\text { Hypothesis } & 57\end{array}$

Intended Healthy Beverages $\quad 57$

Unhealthy Beverage Options $\quad 58$ 
$\begin{array}{lr}\text { Differential Cost of Beverages } & 58\end{array}$

Ramifications of Revenue Shortfall on School District 59

Healthy Beverage Replacement Concerns $\quad 61$

$\begin{array}{ll}\text { Program Accomplishments } & 62\end{array}$

$\begin{array}{ll}\text { Teen Choices } & 62\end{array}$

Student Activities at Righetti High School Prior to the 50:50 Program 62

$\begin{array}{ll}\text { A Springboard for Change } & 63\end{array}$

$\begin{array}{ll}\text { Affirming Behavioral Science Theory } & 64\end{array}$

Adolescent Elective Behavior $\quad 65$

First Beverage Compromise in California $\quad 66$

$\begin{array}{ll}\text { Conclusions } & 66\end{array}$

$\begin{array}{ll}\text { The Ongoing Need for Education and Application } & 68\end{array}$

$\begin{array}{ll}\text { Taking Responsibility } & 68\end{array}$

$\begin{array}{ll}\text { REFERENCES } & 71\end{array}$

$\begin{array}{ll}\text { ACRONYMS } & 81\end{array}$

$\begin{array}{ll}\text { APPENDICES } & 83\end{array}$

A. "Is Your Child's Health for Sale?” Paid Advertisement, April 14, 200284

B. “Where's The School Soda?" Santa Maria Times, January 20, $2003 \quad 85$

C. "Local Schools Put the Cap on Sodas" Santa Maria Sun, February 6-13, $2003 \quad 86$

D. Annual Guaranteed Commission Calculations 87

$\begin{array}{ll}\text { E. Shortfall Vending Machines } & 88\end{array}$

F. Santa Maria High School Refill Data (2/2/03-5/31/03) 89

G. Santa Maria High School Refill Data (6/1/03-9/30/03) 95

$\mathrm{xi}$ 
H. Santa Maria High School Refill Data (9/1/03-1/21/04) 99

I. Righetti High School Refill Data (2/2/03-5/31/03) 108

J. Righetti High School Refill Data (6/1/03-8/30/03) 110

K. Righetti High School Refill Data (9/1/03-1/21/04) 115

L. Prochaska and DiClemente's Stages of Change Model 127 


\section{LIST OF FIGURES}

Figure $\quad$ Page

1. Consumption of Various Beverages 1970-2000........................... 19

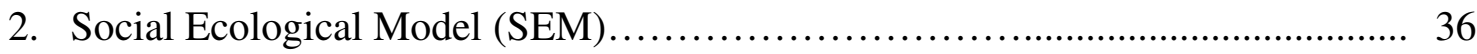

3. Breakdown of Beverages Purchased From Vending Machines (Number)....... 53

4. Breakdown of Beverages Purchased From Vending Machines (Percentage)..... 53

5. Number of Bottles of Water Versus Pepsi Sold ......................... 54

6. Percentage of Water, Intended Healthy Choices, and Known Not Unhealthy Choices (Total Bottles: 91,238).................................... 55 


\section{CHAPTER I}

\section{INTRODUCTION}

Santa Barbara County's Public Health Department received grant funds from the Cancer Prevention and Nutrition Section of the California Dept. of Health Services (CDHS). The grant was administered through a statewide program called Project L.E.A.N. (Leaders Encouraging Activity and Nutrition), in order to provide nutrition education for local high school youth. The primary objective of the Project L.E.A.N. grant was to empower youth to make healthier food choices and actually learn how to request such items on their respective campuses. This program initially began at Ernest Righetti High School in 1998 in the school's Health Education classes. A companion objective was to recruit students for a health club to become peer advocates. The students chose the name and logo as the L.E.A.N. and Mean Club, holding weekly meetings during the lunch period. Ernest Righetti High School was the initial site chosen for this intervention project. The author personally led the on-campus program from 1998 until 2000.

The original objective of Project L.E.A.N. on high school campuses was supporting peer advocacy regarding school food choices. Research had determined that soda consumption was a factor contributing to the obesity concern in adolescents (Ludwig, Peterson, \& Gortmaker, 2001). For this reason, the sale of sodas through vending machines was decided to be the focus for the goal to improve nutrition. If an environmental change could be made by decreasing the availability of sodas, while increasing the availability of healthy beverages in vending machines, would this result in a change in buying behavior of the high school student? 
The Santa Maria Joint Union High School District (SMJUHSD) School

Superintendents, both the Executive and Business, along with the individual Santa Maria Joint Union High School District School Board members were contacted to negotiate a change in the proposed beverage April 2002 contract to decrease sodas available in machines. At the same time, statewide in California legislation was pending restricting the sale of high added sugar beverages on $\mathrm{K}-8^{\text {th }}$ school campuses. This study discusses the negotiation to implement an environmental change in high school vending machine capacity from current $86 \%$ empty calorie beverages to $50 \%$, with the remaining $50 \%$ capacity being filled with healthy beverages. The context of this School Board approved compromise in Santa Maria, CA was before State legislation was passed including high school beverage regulations. Also, for historical distinction, this social experiment was a complex, public community process that occurred before the internationally known soda ban of the Los Angeles Unified School District in August of 2002.

On April 4, 2002, the non-profit Public Health Institute released a study (Purcell, 2002) that examined soda contracts at California's 25 largest school districts. The study concluded that marketing methods and contract mandates of beverage companies were directly affecting the health of students by limiting the availability of healthier on campuses. A controversial press ad placed in the Sunday edition of the local Santa Maria Times on April 14, 2002 (see Appendix A) by the Santa Barbara Public Health Department challenged the public to attend the next school board meeting regarding an impending contract with Pepsi. This prompted a defensive school board reaction with corresponding intense public media exposure (see Appendices B and C) that culminated in an innovative compromise implementation agreement on August 17, 2002. 
This localized grassroots effort was spearheaded by the Santa Barbara County Public Health Department's Project L.E.A.N. grant with political support from the Partners for Fit Youth coalition. Key informant data from school administrators in preceding years supported strong advocacy and revealed motivations for schools to accept unhealthy revenue sources. An overview of the political climate in California that led to this local advocacy effort to negotiate a 5-year contract before the other statewide legislation was scheduled to go into effect is addressed below.

The "Win-Win-WEAN" beverage compromise preceded the internationally publicized school board decisions by the Los Angeles Unified School District in August 2002. The innovative 50:50 compromise ratio became a model for future legislation in California (Escutia, 2005) and nationwide. Under the agreement, healthy beverages were to be strategically placed in the top slots of the 45 machines on the two campus sites pursuant to stipulations included in the passage of California Senate Bill-19 Pupil Nutrition, Health Achievement Act of 2001 (Escutia, 2001). Also, Win-Win-WEANnegotiated terms included vend fronts marketing only the promotionally targeted health beverages (Rooks, 2003).

Due to the sales of high sugar beverages (i.e. sodas) as major revenue for high school campuses, the reduction of soda and potential sales was a significant financial concern for the Santa Maria Joint Union School Board. At the beginning of this study, water was only available in $14 \%$ of the vending machine slots available and often sold out. In addition, most drinking fountains were non-functional. Nutrition education programs targeting the high school students were already in process to encourage limiting calories with healthier food and beverage choices to address weight issues, with a focus on bone growth "window of opportunity" during adolescent years. 
The hypothesis for this study was: By an environmental change in high school vending machines, making water available, students will choose water over sugarsweetened sodas. The environmental change was replacing high sugar beverages with qualifying healthy drinks in $50 \%$ of the available slots in vending machines on two Santa Maria Joint Union High School District campuses. The behavioral change was for students to substitute high-sugar beverages with the healthier beverages, specifically water. The behavioral change was measured by disappearance data by beverage type through summation analysis of the vendor provided refill data sheets. 


\section{CHAPTER II}

\section{LITERATURE REVIEW}

\section{Establishment of "Win-Win-WEAN"}

Public Health Institute (PHI) released and publicized, the School Soda Study in April of 2002, revealing motivations for schools to resort to such unhealthy revenue sources (Purcell, 2002). The pivotal research study, performed by Samuels and Associates as commissioned by The California Endowment, highlighted the factors that had placed cash strapped schools into the business of promoting fast food and beverage sales (Samuels \& Associates, 2000). The identified need to reduce soft drink consumption among children and adolescents (Center for Science in the Public Interest, 1999; Jacobson, 2005) became the impetus for the PHI research study. The environmental change experiment outcome of this study became the "Win-Win-WEAN" 50:50 beverage ratio concept as an idea whose time had come to change beverage industry practices.

Negotiation and adoption of the local beverage ratio compromise preceded the internationally publicized School Board decisions by the Los Angeles Unified School District in August 2002. The innovative 50:50 compromise ratio became a model for future legislation in California (Escutia, 2005) and nationwide. The healthy beverages were to be strategically placed in the top slots of the 45 machines on the two campus sites pursuant to stipulations included in the passage of California Senate Bill-19 Pupil Nutrition, Health Achievement Act of 2001 (Escutia, 2001). Also, Win-Win-WEAN negotiated terms to include vending machine fronts to market only the promotionally targeted health beverages (Rooks, 2003). 


\section{Unprecedented "Globesity"}

Unprecedented obesity, by any current weight definition, has caused public health officials in many countries to declare an epidemic. Worldwide, 300 million adults are obese and 750 million are overweight, a statistic captured in the term "globesity" (International Association for the Study of Obesity Task Force [IASOTF], 2008). Even in countries where people die of malnutrition, the populations are gaining weight. The worldwide trend of increasing obesity makes it clear that powerful societal behavior changes are a major factor. According to Neville Rigby, Public Affairs Director of the London-based International Obesity Task Force (IOTF), "Many people are taken in by the idea that you only have to make a choice to be healthy, but the environment they live in provides a constant stimulus to consume more"(Creager, 2003).

In the United States, U.S. Surgeon General Dr. Richard Carmona referred to the obesity epidemic as the fastest growing cause of illness and death, deserving more attention than any other epidemic (Carmona, 2003). In May 2003, former Surgeon General David Satcher addressed Harvard conference attendees stating that 300,000 deaths per year are associated with excessive weight and obesity and explained the annual public health cost of this condition is approximately $\$ 117$ billion due to lifethreatening complications of diabetes, hypertension, heart disease, cancer, kidney failure, and many other ailments (Newswise, 2003). Health policy analysts maintain the U.S. epidemic increases the burden on taxpayers because it required the Medicare and Medicaid programs to cover the treatment of diseases caused by obesity. Another report stated \$39 billion was spent in America for the treatment of conditions attributable to obesity (Derenzy, 2005). Defendable estimates for the number of adolescent deaths associated with these specific causes have not been established due to a variety of factors, 
including far fewer autopsies, juvenile confidentiality reporting concerns, and state-tostate differences in classification methodologies of deaths (Mokdad, Marks, Stroup, \& Gerberding, 2004).

\section{Obesity Youth Definitions}

$\mathrm{BMI}$ is a ratio of weight to height that is used to categorize individuals as underweight, normal, overweight, or obese. It is a useful, although still imperfect, way for health care providers to screen for risk of health problems associated with excess weight in children aged 2-20 years. "Healthy Weight" status is defined as a PercentileBMI that falls between the $5^{\text {th }}$ percentile to less than the $85^{\text {th }}$ percentile for the child's age and sex using the CDC 2000 growth charts. A BMI percentile above or below the range indicates a higher risk of health problems (Centers for Disease Control, 2006). The CDC 2000 growth charts were developed using statistical and data exclusion procedures to correct for oversampling of overweight children in recent surveys and therefore reflect standards for healthy weights (Kuczmarski, Ogden, Guo, Grummer-Strawn, Flegal, Mei \& Johnson, 2002; Ogden, Kuczmarski, Flegal Mei, Guo, Wei \& Johnson, 2002).

Children's body fatness changes over the years as they grow, and girls and boys differ in their body fatness as they mature (Gold Coast Collaborative, 2003). A broad range of experts and organizations including the American Medical Association (AMA), the American Academy of Pediatrics (AAP), the IOTF and, among others, the CDC have endorsed use of Percentile-BMI-for-age categorizations (Barlow \& Dietz, 1998).

Percentile-BMI for age and sex are a more accurate categorization for children in terms of risk than just BMI (Himes \& Dietz, 1994). Classification differences also are useful because, although the goal for most adults is to decrease BMI as a means of addressing obesity, the goal for growing children is often to maintain their current weight with the 
intent of reaching a healthy height/weight ratio through growth (Amador, Ramos, Morono \& Hermelo, 1990). BMI can best be evaluated in relation to a child's own growth history and has been considered a poor indicator of body fat in individual kids (Society for Nutrition Education, 2000). Many federal programs and pediatricians utilize Percentile-BMI measurement to account for growth spurts that are usually preceded by an increase in body fat for children.

International Adolescent Obesity Rates. Dr. Mikael Fogelholm, the Chairman of the $12^{\text {th }}$ European Congress on Obesity, which occurred in Helsinski, Finland in June 2003, said the prevalence of obesity among adolescents has increased more rapidly than among the middle-age population. "Most obese adults now had not been obese children," Fogelholm stated. He also serves as the Director of the Independent UK Institute for Health Promotion and Research and he has been published in Obesity Reviews, an official journal of the International Association for the Study of Obesity (IASO) (Fogelholm \& Kukkonen-Harjula, 2000). He continued, "They obtained their extra kilos after they were 25 or 30 years old, but now we have more and more people who are already obese at the age of 10, 15 or 20 (Reaney, 2003). Canada reports for 2004 showed $32.3 \%$ of boys and $25.8 \%$ of girls at $25.8 \%$ aged 12 to 17 years old were considered overweight or obese by International Obesity Task Force (IOTF) criteria, which developed smoothed sex-specific BMI curves that intersected with BMI cut-points for adults (Shields \&Tremblay, 2010; Cole, Bellizzi, Flegal \& Dietz, 2000). Australia used the same IOTF criteria in its 2007 Australian National Children's Nutrition and Physical Activity Survey and found that $25 \%$ of the 9 to 13 year old boys and $30 \%$ of the girls were considered overweight or obese. Qatar, in the Eastern Mediterranean region, was also listed as a country for this adolescent overweight and obese epidemic and their 2003 data, supplied by the World 
Health Organization (WHO), for ages 12 to 17 , showed body mass index exceeded the $85^{\text {th }}$ percentile in $36.5 \%$ of boys and at $23.6 \%$ of girls (Bener, 2006).

United States Youth Obesity Rates. The prevalence of obese (BMI $>95^{\text {th }}$

percentile for age and sex) among children aged 6 to 11 years (15.3\%), represents a nearly four-fold increase from 1966 to 2000 according to the National Health and Nutrition Examination Survey (NHANES). For teens (ages12-19 years), the prevalence of obesity increased more than three fold to 15.5\% from 1966 to 2000 (Damery, 2004). These percentages represent almost 9 million youth who are obese. This is especially distressing as more than two-thirds of "obese/overweight" children will become obese adults (Whitaker, Wright, Pepe, Seidel \& Dietz, 1997). The United States reports 35.1\% of boys and $36 \%$ of girls aged 6 to 17 years are considered overweight $\left(\cdot 85^{\text {th }}\right.$ percentile $)$ or obese according to 2003 and 2004 data (IASOTF, 2008). Overall, male students $(15.5 \%)$ were significantly more likely than female students (11.7\%) to be overweight per the Youth Risk Behavior Survey (YRBS) published results from the CDC in 2003. Disturbingly, 2007 YRBS data show increases in these percentages for both adolescent males and females and, worse still, reflect that female percentages have closed the gap on their male counterparts in likelihood for becoming obese.

The 2007 data, it should be noted, is somewhat incongruent with data published between 1999 and 2006 in that the CDC and other pertinent health organizations "reintroduced" the obese tracking category, i.e., adopting their earlier definitions of what constitutes the terms for being at risk to become "overweight" or "obese" (Eaton, Kann, Kinchen, Shanklin, Ross, Hawkins\& Wechsler, 2007).

Researchers determined early during this emerging epidemic that overweight adolescents have an $80 \%$ probability of becoming obese adults if one or more parent is 
overweight (Epstein, Wing \& Valoski, 1985). Dr. J. Michael McGinnis of the Robert Wood Johnson Foundation stated on March 10, 2004, "Unless this turns around somehow, we may be seeing the first generation of children who are sicker and will die sooner than their parents"(California Endowment, 2004).

In the last twenty years, the proportion of overweight children between the ages of 6 and 19 has tripled nationally, to nearly one of every three kids. Despite various contradictions in obesity statistics, obesity remains the nation's second-leading cause of death, behind tobacco and ahead of alcohol (Stein, 2004). "Youth of today may, on average, live less healthy and, possibly, even shorter lives than their parents", according to the New England Journal of Medicine (Olshansky, Passaro, Hershow, Layden, Carnes, Brody \& Ludwig, 2005).

California Childhood Obesity Rates. A study showed that $26.5 \%$ of California children are overweight, including as many as $40-50 \%$ in some school districts (California Center for Public Health Advocacy, 2002). California children were already at least 10 pounds heavier than their counterparts 30 years ago according to news reporter Kim Severson of the San Francisco Chronicle. Because percentiles are calculated based on population data, there has also been a shift in the graph that pediatricians and their staff use to plot percentile data. The conversion for the medical and social service professions to this new weight measurement standard has not yet been fully implemented and accepted, yet is the current method that the CDC is using to track the obesity epidemic. As recently as October of 2005, publications such as the Nutrition Action Health Letter produced by the Center for Science in the Public Interest (CSPI) are still noting that BMI should not be used to evaluate the weight of children, the frail elderly, pregnant, or breastfeeding women (Obesity Education Initiative, 1998). The BMI 
measurement is also not a good indicator of obesity for muscular people who exercise a lot (Derenzy, 2005).

The California Children's Healthy Eating and Exercise Practices Survey (CalCHEEPS) was first conducted from April 21 to June 28, 1999 and involved 9 to 11 year-old children (Center for Weight and Health, 1999). This special analysis prompted the Healthy School Environment and Policy and Community Action Summit held in September 2000 in Sacramento, CA. and was performed under contract by FleishmanHillard Research to the Public Health Institute. Findings highlighted potentially serious repercussions since nearly one-third of the children surveyed were overweight or at risk for overweight. African-American, Latino, and Asian/other children were more likely than white children to meet this criterion for this study funded by The California Endowment.

The 2005 California Childhood Obesity conference highlighted prevalence rates of BMI for youth from 1986 to1998, published in the Journal of the American Medical Association in 2001, and illustrated the higher rates for the Hispanic youth population. Several environmental factors were identified as potential contributors to the higher percentages of obesity, especially in lower income neighborhoods, resulting in health disparities in the Mexican border state of California for the substantial Hispanic population who serve the agriculture and hospitality industries that typically provide low wages. Data focusing on the prevalence of obesity by household income for adolescents ages 12-17 in California highlighted a significant difference in 2005 for families below $100 \%$ of the Federal Poverty level at $21 \%$ as compared to more affluent households at $300 \%$ or higher above the Federal Poverty with only $8 \%$ prevalence of obesity rates (Hastert, Babey, Diamant \& Brown, 2008). 
Secretary of California's Health and Human Services Agency Kimberly Belshé reported the obesity epidemic is an economic crisis that cost California $\$ 28$ billion in 2005 in medical bills, injuries, and lost productivity (Medical News Today, 2006). The president and chief executive officer of The California Endowment, Robert Ross, M.D., stated in 2001, "We're alarmed to find that the increased obesity rate in our children mirrors the increase of obesity in the general population (www.calendow.org) (2004)."

The study conducted by the California Endowment (2004) found, through 1,068 telephone interviews (in English and Spanish) that $92 \%$ of California adults consider the problem of obesity among children and teens to be serious; and, $80 \%$ of Californians believe the problem of childhood obesity/overweight has worsened over the past five years. This is greater than the proportions that say the problems of unsafe sexual behaviors (54\%), illegal drug use (52\%), alcohol use (51\%) or smoking (40\%) have worsened among children and teens over the same time period.

Santa Barbara County Youth Obesity Data. For children ages 5-19 years, the 2004 Pediatric Nutrition Surveillance from the Child Health and Disability Program (CHDP) data on SB County children is available. These data represent the 5,288 lowincome children that had CHDP medical exams. Statistical data was reported for the following categories: Under Healthy Weight (1.7\%); Healthy Weight (53.2\%); and, Above Healthy Weight (45.1\%). Santa Barbara County KIDS Network Scorecard data highlighted some improvement with fewer students in Santa Barbara County testing above or below (overweight or underweight) for the Healthy Fitness Zone For Body Composition when comparing 2001 (32.3\%) and 2005 (30.1\%) (Damery, 2004).

The AMA developed 21 Critical Adolescent Objectives for the Healthy Youth 2010 initiative and ranked reducing the proportion of children and adolescents who are 
overweight or obese in the primary critical health outcome section that includes reducing deaths, pregnancies and sexually transmitted diseases as the major other categories. This resource was designed to be a roadmap for the largest physician organization in the United States to encourage physician participation in and support of the national health objectives (Fleming, Towey \& Jarosik 2000).

The Santa Barbara Regional Health Authority (now CenCal Health), which administers Medicaid under a Health Maintenance Organization (HMO) model, sponsored two workshops for health professionals serving youth. Dr. Scott Gee from the Kaiser Permanente Foundation was, in 2005, the featured physician who has developed protocol for practical assimilation in the routine visits of pediatricians with five-minute conversational tools and flow charts to integrate appropriate follow-up. Empowering health officers to develop competency in the area of childhood overweight was the purpose and the conference topic in 2001, Obesity: California's Other Energy Crisis. Best practices as they related to good nutrition promotion and physical activity promotion for obesity reduction was a primary objective for attending health care professionals and physicians.

Despite awareness of the overweight epidemic, pediatricians and nurses expressed a frustration at not having resources for referrals, especially for the low-income patients, according to Oralia Madera, RN, CDE, as recently as February 2009. In response to this unmet medical treatment need, Sansum Medical Foundation in Santa Barbara County developed an innovative approach for a family participation obesity treatment program known as CHAMP (Childhood Health Awareness Mentoring Program) as a resource for physicians to refer youth above the $95^{\text {th }}$ percentile. As funding has been inconsistent, committed dietitians and health educators continue to approach funders in order to 
improve the program and have experienced mild weight reduction success, which is an unusual result according to pediatricians. This small pilot program began in 2003 and has served numerous families in helping them attain moderate yet sustained weight loss. The approach was to change lifestyles of family units, which had other positive outcomes beyond simply weight management for the individual patient (Weiss, 2005).

\section{Potential Role of Soda Consumption in Overweight Children}

Sodas have been identified by several public health organizations to be one probable cause for the current childhood obesity epidemic that has swept the United States. Nearly one in six 9 - 11-year olds have access to vending machines containing soda with a surprising $8 \%$ reporting having vending machines stocked with candy, chips, and cookies on their school campus during these early formative years.

According to a two month study performed in 2003 by Cornell University, children consuming sweetened drinks took in 244 more calories a day than on days when they did not drink these beverages (Mrdjenovic \& Levitsky, 2003). Their solid food intake on these two occasions varied only by about 2 ounces. Over the two months of this study, children who drank more than 16 ounces a day of sweetened beverages gained an average of 2.5 pounds, compared to a $0.7-1.0$ pound gain in children who consumed on the average 6 to 16 ounces of sweetened drinks a day. When given a choice between a sweetened drink and milk, children choose the sweetened drinks. The finding was concluded that children did not reduce how much food they ate at meals to compensate for the calories they consumed in sweetened drinks (Mrdjenovic \& Levitsky, 2003).

Soda Consumption Replacing Necessary Milk. In 1945, according to Dr. Heyman, people drank four times more milk than soft drinks (O'Keefe, 2003). In the last twenty years, children's consumption of soft drinks has doubled while their consumption 
of milk has decreased $40 \%$ (Trager, 2004). With the introduction of vending machines on school campuses in the 1980's, soft drinks are not only a problem for what they contain, but for what they replace from the diet (Ballew, Kuester \& Gillespie, 2000; Jacobson, 2005). The concern for calcium deficiencies due to lack of milk consumption during critical bone growth years is a new problem in America causing the University of San Diego Director of Bone Densitometry, Dr. David Sartoris, to speculate our current youth population is going to become the "wheelchair generation" due to early onset osteoporosis. His mission was for teens to get the word: bone loss is not just grandmother's disease. "We can't afford to take care of the fractures that we are seeing today and with our aging population, 30 years from now it will be impossible; We must prevent this disease now" (Clark, 1998).

Teens drink nearly twice as many carbonated beverages as milk, eliminating a major calcium source from their diets. Carbonated beverages contain carbonic and phosphoric acid, which make blood more acidic. Anything that increases the acidity of blood can weaken bones and cause osteoporosis. To neutralize this acidity, bones release calcium, which then passes from the body through the kidneys. As bones lose calcium, they weaken and can break with minimal trauma.

Sodas are also high in phosphoric acid due to the phosphates and can bind to calcium in the gastrointestinal track or blood, and thus the calcium does not have the opportunity to be absorbed effectively to be transported to the bones for growth, maintenance, or repair. The calcium in the small intestine requires an estimate of six hours for true mineral absorption, without "binding molecular competition with phosphorous". This is especially critical during the "bone growth years" of 11 to 18 years during which $50 \%$ of the skeleton is formed. Although calcium's primary function 
is not as a buffer for excess acid in the blood, it has become necessary due to our high protein American diets and soda consumption. It is recommended that sodas be consumed, independent of other intake, with a two hour window to avoid the phosphorous to calcium binding in the blood or small intestine, making the calcium unavailable for bone use (McGartland, Robson, Murray, Cran, Savage, Watkins \& Boreham, 2003).

Soda Consumption as an Independent Obesity Risk Factor. Regardless of demographics and lifestyle, soda consumption is an independent risk factor for childhood obesity, Ludwig et al. (2001) enrolled 548 ethnically diverse schoolchildren in a prospective study assessing consumption of sugar-sweetened drinks. They found that for each additional serving of sugar-sweetened drink consumed, both body mass index and frequency of obesity increased after adjustment for anthropometric, demographic, dietary and lifestyle variables. Reynolds and Finke (2002) reported that an increase consumption of food energy from sweetened drinks was significantly associated with a reduced probability of meeting the Recommended Daily Allowance (RDA) requirements.

Other Overweight Compounding Factors for Youth. Overweight children and adolescents are often excluded from peer groups and discriminated against by adults, experience psychological stress, often have a poor body image and low self-esteem (Gift, Reisine \& Larach, 1992). They report a quality of life similar to those with cancer and significantly lower than their healthy and healthy-weight peers (Schwimmer, Burwinkle \& Varni, 2003). Also, the strong association of sugar consumption and dental concerns has a social impact of more than 50 million hours of school time lost annually because of dental problems and dental visits (Wadden \& Strunkard, 1985). The 2000 Surgeon General's Report raised that estimate to 51 million hours of lost time. 


\section{National Carbohydrate Consumption Data and Recommendations}

The Institute of Medicine's Food and Nutrition Board recommends that both children and adults consume at least 130 grams of carbohydrates each day. (Institute of Medicine 2002) The report covers Dietary Reference Intakes (DRIs) and replaces the RDAs published in 1989. The 130 grams is based on the minimum amount of carbohydrates needed to produce enough energy for the brain to function. Most Americans consume far more.

The DRI recommends that added sugars not exceed $25 \%$ of the total calories consumed in order to ensure sufficient intake of essential micronutrients. Added sugars are those incorporated into foods and beverages during production. This does not include natural sugars such as lactose in milk and fructose in fruits. For an individual consuming 2,000 calories per day, the suggested maximum intake of added sugars would be 500 calories or 125 grams of carbohydrates. Data from 2,207 youth aged 12-19 years shows they consumed 55\% of their calories as carbohydrates with the average calorie intake being 2,342 per day equaling 585 carbohydrate grams (Wright, Wang, KennedyStephenson \& Ervin, 2003). Specific data was not available on the breakdown of carbohydrates derived from "added sugars".

NHANES data is collected to assist with monitoring the nutritional status of Americans based on a detailed analysis of a 24 hour dietary recall of the U.S. civilian, non-institutionalized, population. For each 2-year data release cycle, the following dietary intake data files are available:

Individual Foods File - Contains one record per food for each survey participant. Foods are identified by USDA food codes. Each record contains information about when and where the food was consumed, whether the food was eaten in combination with other foods, amount eaten, and amounts of nutrients provided by the food. Starting with the data years 2003-2004, 
the source of each food is provided (CDCP, National Center for Health Statistics 2009).

National Soft Drink Consumption Data and Parallels. Various percentage amounts of soft drink consumption in the adolescent diet have been calculated at $7 \%$ of total calories. The government sponsored 1999-2000 NHANES query found carbonated soft drinks as the single most consumed food in the American diet.

According to the U.S. Department of Agriculture (USDA), per capita soft-drink consumption has increased almost $500 \%$ over the past five years. The graph entitled “Sweetened Soda Rules" illustrates gallons per person per year consumed of various beverages from 1970 through 2000 by the USDA (Figure 1). The soft drink supply, measured in gallons per year in 1970 were 24.3 gallons per person per year doubling by the late 1990's to 53 gallons per person per capita (Nestle, 2002). Soft drinks include soda, fruit-flavored and part-juice drinks and sports drinks. Each additional "serving" of sugar-sweetened drinks, which is still not a defined ounce amount, increases the BMI and the frequency of obesity. Half of all Americans consume soft drinks daily, most of which are sugar sweetened, predominantly via corn syrup. 


\section{SWEETENED SODA RULES}

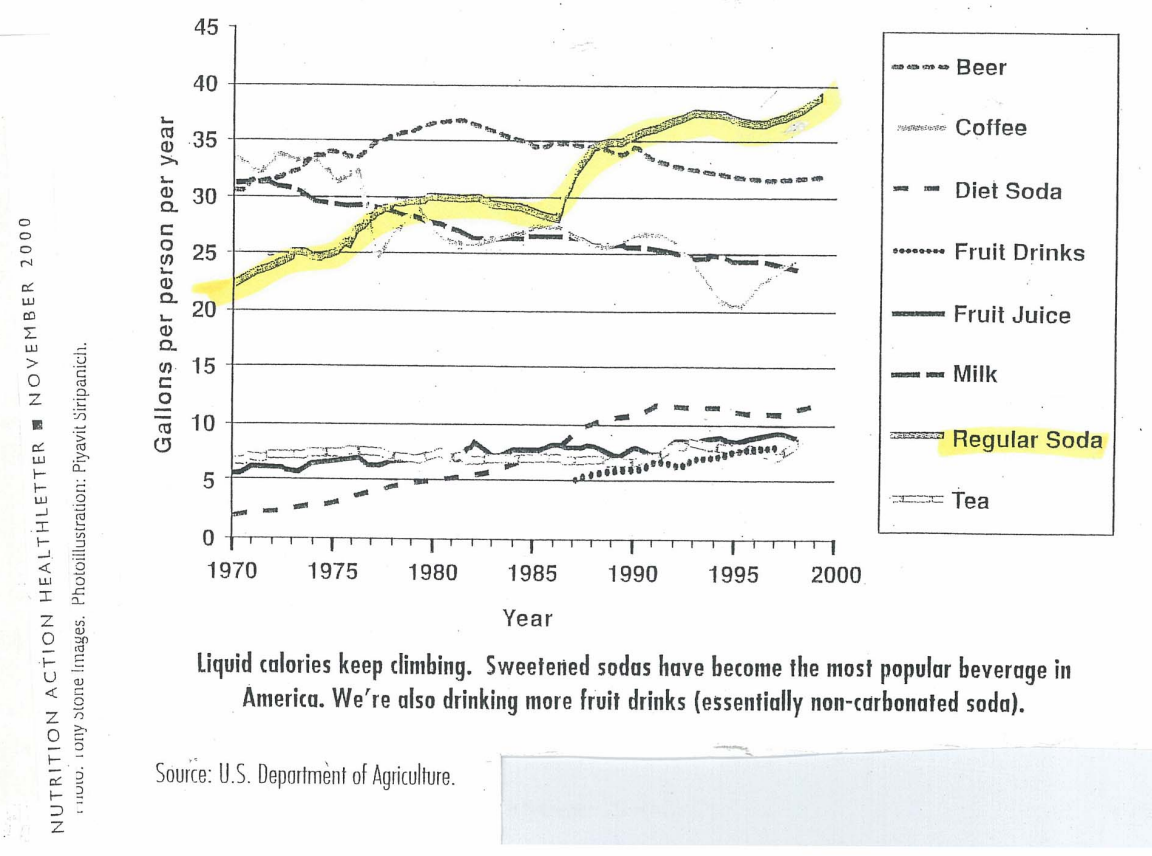

Figure 1: Consumption of Various Beverages 1970-2000

The USDA recommends no more than 10 teaspoons, or 40 grams, of added sugar a day while on a 2000 calorie diet, only $25 \%$, or 10 grams, of which should be table sugar. The average American adult consumes 20 teaspoons of added sugar per day based on a 2000 -calorie diet, which constitutes $16 \%$ of his daily intake from added sugar (when including that taken via sweetened soda beverages).

Michael Jacobson, Executive Director of the Center for Science in the Public Interest (CSPI), stated at a Washington press conference, "Sugar consumption has been going through the roof. It has increased by 28 percent since 1983, fueling soaring obesity rates and other health problems. It's vital that the Food and Drug Administration (FDA) require labels that would enable consumers to monitor—and reduce—-their sugar intake" (2003). 
A teenage male who eats a healthful diet could eat about 18 teaspoons of added sugars, according to the USDA. Most teenage males do not eat a healthful diet, because they consume an average of 34 teaspoons of sugar per day.

Advocating for Government Recommended “Added Sugar Limits”. The CSPI, as a non-profit organization, is asking the FDA to adopt USDA's figure of 10 teaspoons (40 grams) as the $100 \%$ Daily Value amount for added sugars. A 12-ounce Pepsi provides 103 percent of the USDA guidelines.

Daily Values are used on Nutrition Facts labels to indicate the product's specific intakes of fat, sodium, and other nutrients as a percentage of a 2000-calorie diet, and CSPI is proposing listing "Maximum Recommended Amounts" for consumer awareness.

\section{High Fructose Corn Syrup in Sodas as Added Sugar}

The primary ingredient in soft drinks and fruit beverages is high fructose corn syrup and is a leading source of sugar in the American diet. This liquid sweetener is made by treating cornstarch with enzymes and is about half fructose and half glucose. Some experts believe that the body treats high fructose corn syrup more like a fat source than a sugar. According to a study released in the July 2005 issue of Obesity Research, the researchers feeding mice at the University of Cincinnati and the German Institute of Human Nutrition suggest the fructose alters our metabolic rate in a way that favors fat storage. The American Beverage Association stated the study was "seriously flawed" because mice are not humans and fructose is not high fructose corn syrup. In fact, all studies to date have focused on a fabricated fructose fluid and not high fructose corn syrup. The corn refiners group makes the point that obesity rates are escalating throughout the world, including Australia, Mexico and Russia where sucrose is the main 
sweetener, not the typically high fructose mixture of 42 or 55 percent fructose in combination with glucose (Helm, 2005).

Soft drinks are the leading source of added sugars in the daily diet of young Americans. Between 1977-78 and 1994-98 the average daily amount of sugar-sweetened soft drinks consumed by children 6-17 rose from 5 fluid ounces per day to 12 fluid ounces per day (French, Lin, \& Guthrie, 2003).

David Ludwig, co-author of the study and Director of the Optimal Weight for life Program at the Children's Hospital in Boston said, "It is not uncommon for teenagers to receive 500 to 1000 calories per day form sugar-sweetened drinks. These drinks may be easy to over-consume, because the calories in liquid form seem to be less satiating, or less filling than calories in solid form"(Harvard School of Public Health, 2001). In 2004, the average American consumed about 200 calories a day from high fructose corn syrup up from just 2 calories in 1970 according to the USDA, equating to about $12 \frac{1}{2}$ teaspoons daily (Helm, 2005).

\section{Government Data for Soft Drink Intake}

According to the USDA's Continuing Survey of Food Intake by Individuals (U.S. Department of Agriculture, 2005), from 1994 to 1996 adolescents aged 12 to 17 received, on average, $11 \%$ of their calories from soft drinks. Carbonated drinks are the single biggest source of refined added sugars in the American diet. Teenage boys get 44 percent of their 34 teaspoons of refined sugars a day from soft drinks. Teenage girls get 41 percent of the calories with their 24 teaspoons of sugar from soft drinks. Actual intakes are probably higher because dietary surveys tend to underestimate the quantities of food 
people consume, and people may be particularly inclined to underestimate food perceived as being bad for them (Jacobson, 2005).

Soft Drink Production Data. Government data relating to annual production volume of soft drinks may not exactly coincide with consumption data, yet a peak of 56.1 gallons per person per year in 1998 is quite an increase from 24 gallons reported in 1970. It is only in the last 10 years that researchers have begun to find statistical and experimental evidence that soft drinks do, in fact, promote obesity. An analysis of the $1994-1996$ dietary intake data found that obesity rates rose in tandem with soft drink consumption and that heavy consumers of soda pop had higher caloric intakes (Center for Science in the Public Interest, 1999; Jacobson, 2005). Upon simple review of basic graphs of two beverages available in the U.S. food supply, milks and soft drinks, a correlation appeared that soft drinks started to replace milk about 1978 and a wide margin distinction was obvious by 1990 (Figure 1).

California Soda Consumption Data. Based on data from the 2003 report of the California Health Interview Survey of 42,000 households, more than 2 million teens drank soda every day, denoting an average of 1.4 sodas per day. A third of the teens reported drinking two or more sodas a day (UCLA Center for Health Policy Research, 2005). One discrepancy with comparing self- reported data is the variance in serving size containers. The 12-ounce can has been replaced in vending machines with a 20 -ounce bottle, while the self-serve counter at convenience stores offers 44 to 64 ounce containers. The larger the container, the more soda people are likely to drink, especially when they assume they are buying single-serving containers (Jacobson, 2005). Supersizing has definitely occurred with carbonated beverages that were initially introduced in 1942 in 6.5 ounce bottles. This relatively small portion size by today's standards, even a 
year or so ago, prompted the following warning statement from the American Medical Association's Council on Food and Nutrition:

The Council believes it would be in the interest of public health for all practical means to be taken to limit the consumption of sugar in any form in which it fails to be combined with significant proportions of other foods of high nutritive quality (American Medical Association, 1942).

Comparing soft drink serving size data is challenging as even the industry uses different measurements depending on how it is utilized. USDA data reports as availability and consumption in gallons, with research data focusing on international milliliter units, and the consumer in container sizes. According to research published in 1999 in the American Dietetic Association Journal (Harnack, Stang, \& Story, 1999), school children who drank an average of nine ounces or more of soft-drinks a day consumed 188 more calories than those who drank no soft drinks.

Santa Barbara High School Soda Consumption Data. A study survey question performed by Sansum Diabetes Research Institute asked; "How many sodas (cans, bottles, glasses) do you drink in a typical day?" The findings, which included 753 high school students, during academic year 2001-2002, reported that those who consumed 3 or more soft-drinks per day had a higher body mass index (BMI), more body fat, and were more likely to have a BMI at, or above, the $85^{\text {th }}$ percentile than those consuming fewer than three soft drinks per day (Giammattei, Blix, Marshak, Wollitzer \& Pettitt, 2003). This study found $32.6 \%$ total to be overweight plus obese for the $9^{\text {th }}$ to $12^{\text {th }}$ grade students who participated.

As 24-hour dietary recall surveys have limitations, the Youth Food Frequency Questionnaire is an interview survey that uses models for more portion size accuracy. The confusion of serving size may be by industry marketing design. The comparison of 
school consumption of soft drinks cannot be readily compared to grocery purchase consumption as they are also marketed in different sizes to maintain their separate customer bases.

Overconsumption of Calories Studied as the “Energy Gap.” In 2006, a study by researchers at the Harvard School of Public Health (Wang, Gortmaker, Sobel, \& Kuntz, 2006) showed that America's overweight teens over consumed an average of 700 to 1,000 calories each, over a 10-year period. This "energy gap"- or the imbalance between the number of calories children consumed each day and the number required for normal growth, physical activity, and body function -resulted in an average of 58 extra pounds for overweight teens. This study was the first to look at overall calories consumed versus actual calories required each day. The study recommended four strategies to close this "energy gap." One is "reducing the consumption of sugar-sweetened beverages in schools and at home." It specified switching one can of soda for water could mean a difference of 150 calories.

\section{High Schools Resort to Soda Sales for Budget Needs}

Budgetary pressure causes many schools to offer students less nutritious foods since federal reimbursements supported only $30 \%$ to $80 \%$ of the food service budgets. Many schools generate additional revenue from vending machines that can produce up to $12 \%$ of their overall food service budget (O'Keefe, 2003). The position paper of The American Dietetic Association on Child Nutrition Programs in 1996 states that: "Due to federal funding, there is the constant threat of elimination or alteration as the political climate changes. To ensure continued access to food and nutrition programs, we must have reliable funding and national nutrition standards that ensure quality programs for all children and adolescents. It is imperative that barriers to full participation, such as 
competitive foods, inefficient scheduling, negative media advertising and excessive meal prices be identified and eliminated so the programs meet the needs of all children and adolescents (McConnell \& Shaw, 1996).

The School Health and Policies Program Study (SHPPS) is a national survey conducted periodically to assess school health policies and programs at the state, district, school, and classroom levels. Survey data collected in 2000 revealed that $87.8 \%$ of schools participate in the USDA National School Lunch Program, and 63.8\% of schools participate in the USDA School Breakfast Program. It was reported that $83.4 \%$ of schools offer food or beverages other than milk a la carte. The percentage of schools offering soft drinks, sport drinks, or fruit drinks, that are not $100 \%$ juice was $31.6 \%$ (Wechsler, Brener, Kuester, \& Miller, 2001).

The Comprehensive School Health Intervention (CSHI) Pilot was a two-year funded program by the Kansas Department of Health and Environment, implemented in two different sized communities and school districts in Kansas to address research that suggested approximately $50 \%$ of children have at least one modifiable risk factor for coronary heart disease by age 12 . The intervention was designed to change the environment to affect health-related behaviors and outcomes by (1) modifying school lunches, (2) enhancing nutrition education, and (3) increasing opportunities for physical activity. The overarching strategy was to change the environmental context by giving opportunities for selecting (and potentially eating) lower fat foods.

Two registered dietitians worked on the separate school sites for 30 hours per week with the tasks of assisting foodservice staff, classroom teachers, and PE teachers in conducting nutritional analysis of menus, modifying menus, implementing the American 
Cancer's Society's (ACS) nutrition education program, entitled Changing the Course, while also enhancing fitness activities.

The results of the CSHI showed that the project succeeded in reducing fat in school meals from $40 \%$ to the target of $30 \%$ without negatively influencing costs. Review of school records also showed that participation remained relatively constant in the two communities as the menus changed in 1993-1994. The pre and post-tests exhibited an increase in knowledge, skills and attitudes of the fourth and fifth graders. The fundamental tenant of this public health approach was to make healthy choices the easy choices, rather than blame the children (or their parents or teachers) for engaging in health risks (Harris, Paine-Andrews, Richter \& Lewis, 1997).

California's Initial L.E.A.N. Project. The Kaiser Foundation funded the initial California Project L.E.A.N. in which the acronym represented "Low-fat Eating for America Now" due to the high rate of the Latino population becoming increasingly overweight and at a higher risk for diabetes. The target was to reduce the fat in traditional cultural recipes. In 1996, through grant funding from the California Department of Health Services, Cancer Prevention and Nutrition Section, Project L.E.A.N. programs were supported following the American Cancer Society's 10 regional boundaries. The target audience focus shift became teens that now had access at school to a much different food selection than the students in the first L.E.A.N. project of Kansas. At the high school level with open campuses that gave students food choices off site, school cafeterias began competing by bringing the fast food companies on campus for student convenience and to stay solvent.

CA Department of Health Services Expands Project L.E.A.N.'s Goals. Addressing the high school food and beverage environment, the Santa Barbara County Public Health 
Department began to focus on food selection and the development of a support network for healthy eating. In the school environment, classroom lessons alone might not be enough to effect lasting changes in students' eating (Society for Nutrition Education 1995; Centers for Disease Control, 1996). The intent was to empower youth to advocate for healthier choices and be part of the solution of reducing the rising adolescent overweight public health epidemic. The innovative health education program was free to high schools and was integrated as regular nutrition lessons in health education classes and noontime campus clubs in the Santa Maria Joint Union High School District. Project L.E.A.N. developed a curriculum entitled "Jump Start" that enabled students to critically analyze advertising claims, nutrition fact label reading and prompt motivation for advocating for changes on their campuses. As the peer advocacy movement evolved the L.E.A.N. acronym name was replaced to Leaders Encouraging Activity and Nutrition.

\section{School Environment Exposed for Conflicting Messages}

The National Coordinating Committee on School Health (NCCSH) held its $6^{\text {th }}$ meeting of over 30 member organizations, with well over 50 representatives of Federal agencies, attending in 2001. The theme was "Stories and Statistics" and a new mission statement was adopted by consensus including nutrition and health as priorities between the three primary organizations of Department of Education, Department of Health and Human Services and the USDA. The second objective is as follows: To convey a clear vision of the role of school health and safety programs in improving the health, safety, mental health, nutrition, and educational achievement of children and youth through such activities as:

- Reducing barriers to collaboration among health, education, transportation, nutrition, human services, child welfare, and other child-focused systems and 
initiatives, by addressing common elements and joint strategies for program integration.

- "Marketing to children in schools is especially problematic because in schools children are a captive audience and are asked to believe that what they are taught in school will be in their best interest, " according to Professor Alex Molnar as Director of the Education Policies Studies Laboratory at Arizona State University. Many parents and educators do not fully realize the subtle, yet pervasive marketing and advertising practices that students are exposed to on a daily basis at school (Public Health Institute, 2006).

Health advocates with a Santa Barbara County coalition, entitled Partners for Fit Youth, was formed to raise awareness that it was irresponsible to sell sugary drinks to children at school when there is a child obesity epidemic. Mounting evidence linking an increase in school food offerings of trade name high fat food products and soda beverages with the parallel increase of childhood overweight was shared in the Fast Food Survey released by the Public Health Institute in 2000. Through grass root efforts, with support from the California Department of Health Services' program entitled Project L.E.A.N. with local obesity prevention coalition member support, multiple school boards were presented with the facts about the unhealthy school food environments teens face everyday that contributes adversely to the rising public health epidemic of dietpreventable diseases. The environment for successful and convenient healthy eating for the individual student was a daily challenge with peer group and time limit pressures. A quote in 1978 by American philosopher and inventor Buckminster Fuller "Change the Environment; do not try to change man" applies to this generation of "desk jockeys and couch potatoes". As Sue Gilroy, the food services director for San Diego County's 
Sweetwater Union High School District, so aptly stated in a September 2003 Los Angeles Times news article: "We have an obligation to give these kids the nutrition they need. The challenge is to present it in a way that appeals to them."

Presence of Advertising on School Campuses. American children are bombarded daily with dozens of television commercial promoting fast foods, snack foods, and soft drinks. Advertisements for such products are even commonplace in schools thanks to Channel One, a private venture that provides free video equipment and a daily television "news" program in exchange for mandatory viewing of commercials by students and school district contracts for exclusive marketing of one or another soft drink in vending machines and sports facilities. Advertising directly affects the food choices of children who now have far more disposable income than they had several decades ago and far greater influence on their parents' buying behavior (Nestle \& Jacobson, 2000).

Project L.E.A.N grant administrators at the California State level acted on an opportunity to investigate this fundraising stream for school districts as a possible counterproductive relationship for the health of students and a probable contributing environmental factor of the childhood overweight crisis. Through multiple funding sources, such as the California Endowment and the California Department of Justice, Antitrust Law section, the research firm of Samuels and Associates were contracted by the Public Health Institute for several studies to analyze the school food environment. Among their findings for California high schools, was that nearly $72 \%$ allow advertising for fast food and beverages on campus while only 13 percent prohibit such advertising. The most common fast food or beverage advertisements are on vending machines (48 percent), scoreboards or signs (31 percent) and posters (23 percent) (Craypo, 2002). Further study in 2006 found that $65 \%$ of vending advertisements were for sweetened 
beverages, soda, and sports drinks while water accounted for only $21 \%$ of all vending advertisements (Samuels \& Associates, 2006).

Advertising Tactics Targeting Youth. The food industry spends an estimated \$10 billion per year marketing foods and beverages to children and youth in America (Committee on Food Marketing and the Diets of Children \& Youth, 2006). "More and more companies see school-based marketing as the most compelling, memorable, and cost effective way to build share of mind and market into the $21^{\text {st }}$ century," as reported in 1995 in a publication "Giving Kids the Business: The Commercialism of American School Reform” by Joseph Fenton and Alex Molnar. A 2000 report from the federal government's General Accounting Office (GAO) called marketing in schools a "growth industry". The purchase power influence on parental spending increases as children age. Studies based on 1998 dollars reported $\$ 15$ billion for 3 to 5 year olds, to $\$ 80-90$ billion dollars annually for America's youth affecting food purchasing behavior, were published in Family Economics and Nutrition Review (Kraak \& Pelletier, 1998). Advertising's persuasive influence is not understood as intentional by children under 8 years old, leading the American Academy of Pediatrics to call for a ban in 1995 on all advertising to this age-group (Committee on Communications, 1995).

Marketers utilize sophisticated means to infiltrate the lives of youth, from logos on baby bottles, toy products, free school curricula, and other tactics. The newest advertising arena is digital with the un-regulated Internet and numerous accessory electronic products, including cell phones. It is no coincidence that a primary competitor of cola soft drinks "branded" themselves as "The Choice for the New Generation". Marketers often use a tendency to rebel against authority figures as selling points for their products according to the Campaign for a Commercial Free Childhood. 
Many people, some parents and psychologists among them, hold the opinion it is unethical to "brand" consumers under age 2 since association is a limbic emotional response to a logo, etc., and thus automatic association for future purchases. Research shows for children under 8 years old, rational brain processing has still not developed and efforts have been made to follow Britain's example to limit advertising to such age groups. In 2004, California State Senator Sheila Kuehl sponsored (CA) Senate Joint Resolution 129 (SJR-129), a resolution raising awareness of the quantity of advertising messages to young children and a call to action to the American Psychological Association to publically support voluntary monitoring of advertising messages to children under the age of 8 .

New Research on Advertising Messages. A National Institutes of Health news release containing an article compiled by researchers within the National Institute on Drug Abuse (NIDA) highlights numerous brain processes that occur in response to finely-honed messages seeking to impregnate, with ever increasing specificity, their influence upon targeted audiences whether they be smokers, soft drink consumers, or other vulnerable population. The article argues that it is the neurobiological processes that elicit desired responses pursuant to these techniques and neither the products involved nor the audiences subjected to such methodologies are of major consequence insofar as the advertising practice itself.

\section{Beverage Industry Tactics}

The following article was released on December 7, 2006 by the consumer advocacy groups CSPI and Public Health Advocacy Institute (PHAI); as reported by Lorraine Heller, the article claims to be the first ever multi-state analysis of school systems' contracts with beverage companies and reads as follows: The majority of the 
revenue from US school beverage contracts goes to beverage firms and not schools, according to a new report, which claims its findings should encourage schools to replace sodas with healthier drinks. However, its publication has resulted in an immediate reaction from the industry, with trade group American Beverage Association (ABA) calling the report "outdated," "inaccurate," and "uninformed."

Convenient liquid calories became a mainstay on school campuses beginning in the 1980's and 90's, as high school campuses in California and nationwide increasingly resorted to soda sales as an acceptable fundraiser for various program needs. The soda corporations lured struggling schools into contracts with enticements such as significant signing bonuses and athletic kits, along with scoreboards that featured their logos to "brand" their viewers. The motives of these corporate giants was not altruistic, but rather a method to secure direct marketing access to a captive audience (Purcell, 2002).

According to CSPI/PHAI, these deals were generally not very beneficial for schools, raising an average of only $\$ 18$ per student per year, with some schools clearly getting better deals than others. "Selling sugary drinks in vending machines and elsewhere in schools doesn't pump money into the community, it drains it," said CSPI nutrition policy director Margo Wootan. "It's not philanthropic behavior on the part of soft drink companies, it's predatory. When a kid puts a dollar in a soft drink vending machine, the school is lucky to keep 33 cents. And the money comes from parents or kids pocketbooks," she added. Indeed, voluntary guidelines announced in May by former President Clinton, the ABA, the American Heart Association and leading soda firms aim to reduce portion sizes and restrict soda sales in schools over the next three years. But CSPI claims that schools are not a party to that agreement, and "it remains to be seen if schools will comply with the guidelines". According to CSPI's analysis of ABA figures, 
high school students drink the equivalent of about 4020 -ounce bottles of non-diet soft drinks per year, while middle-school students drink about 14 20-ounce bottles.

Vending Beverage Marketing Practices. Beverage vendors had discovered the school campuses to be a lucrative environment with electricity costs for their equipment paid by the schools, not to mention that the machines were an effective advertising medium and method to secure another generation of consumers. For example the signature color recognition of red for Coca Cola even has nostalgic roots in this country. Pepsi strategically selected another color as their subliminal branding to gain a larger market share of a "new generation." These corporate giants began offering schools enticements for this brand loyalty opportunity.

The Santa Maria School Soda Study. In April 2002, the current study was put in place to showcase the actual marketing practices of beverage vendors to generate brand loyalty of young consumers and the impact of changes in school policy regarding such practices. For these corporate giants to make a profit, one astute Santa Maria High School Board Member stated at a School Board meeting, "Vending machines were simply big billboards for the soda companies." The "free" scoreboards would not have been provided without the company logo. The offer of "free" merchandise was conditional and a marketing method to display a logo and develop brand recognition.

\section{Knowledge Alone is Not Enough to Change Behavior}

An Obesity Presentation Summary handout, at the American Public Health Association's 2005 Obesity Conference, revealed that knowledge skill building was sixth on a list of recommendations, with the preceding five being environmental changes. As it relates to the target audience of this study of high school students, a study in March and April of 2004 surveyed 1634 students between the two large campuses of the Santa Maria 
Joint Union High School District. The third question of the six on the local survey, designed by a food service entity, asked the following: "If you knew that by consuming one regular $20 \mathrm{oz}$. soda daily for one year that you could add an additional 25 pounds of weight to your body would you still drink one soda each day?" The survey results for the two campuses showed "Yes" at 45\% and 39\%, with 55\% and 61\% stating "No" respectively. Although these responses seem to reflect that knowledge should change behavior, the developmental stage of the teen years is one of perceived invincibility and is often notorious for risk-taking behaviors, especially as a desire to fit in with their peers (Neumark-Sztainer, Story, Perry \& Casey, 1999). The conclusive proof would be by analyzing real sales data to determine students' actual behavior choices, as actions have always spoken louder than words/surveys.

In a 2001 press release, the Vice President of the Public Health Institute, Carmen Nevarez, M.D., was quoted as saying "Negative health behaviors started in childhood, we can clearly see, continues into adulthood" as a response to a California dietary survey that was unique as it allowed patterns across age groups to emerge.

\section{School Environment as an Opportunity to Reverse Obesity Trend}

In 1998 the Carnegie Council on Adolescent Development issued a statement saying "Schools could do more than perhaps any other single institution in society to help young people-and the adults they will become-live healthier, longer, more satisfying and more productive lives.” In 2000, the U.S. Secretary of Health and Human Services, Donna Shalala, stated "There is no question that our schools have a key role to play in helping our children begin a lifetime of good health." This type of support for disease prevention initiated the national health objectives movement to address and quantify the rising epidemic of overweight American youth. 
Since adolescents spend a third of their day in the school environment, the California Department of Education was positioned perfectly according to the Social Ecological Model (SEM) (Figure 2) for health promotion programs to build an infrastructure of coordinated school health with the California Department of Health Services. A publication in 2000 by the Health Work Group generated "California's Blueprint" document with findings outlining there is no regulation for the nutritional content of foods sold outside of the campus cafeteria and such foods may be of little or no nutritional value.

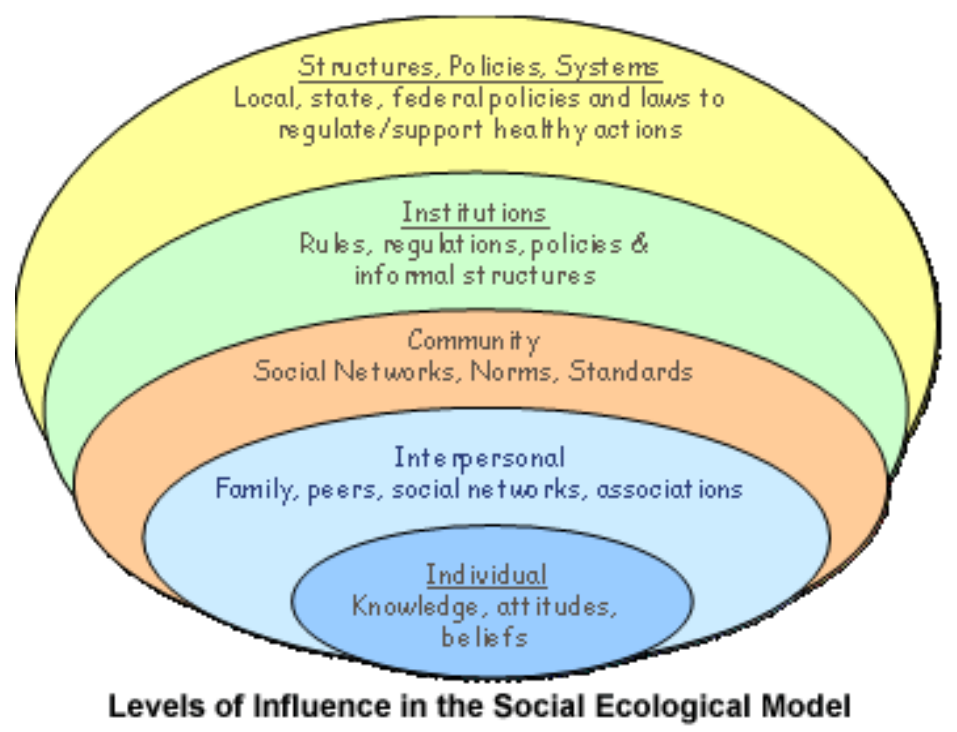

Figure 2: Social Ecological Model (SEM)

\section{Overweight Data Parallels Lack of Federal Regulation Enforcement}

A healthy school environment had originally been supported by federal legislation in several areas, including "other food sales" also known as "a la carte" which are the snack bars, mobile food carts, concession stands, and vending machines, yet site specific audits only occurred typically every three years in California and focused primarily on the cafeteria, not the entire campus food environment. 
Despite already established regulations against "soda water", for example, this lack of enforcement allowed beverage vending machines to invade school campuses. In addition, schools resorted to student customer demands since cafeteria programs were required to be self-supporting and solvent without reliance on school district general fund revenues. A combination of labor costs and students with purchasing capital compromised the integrity intent of the National School Lunch Program. Federal regulation mandates prohibited the sale of foods of minimal nutritional value during the breakfast and lunch periods and are defined in 7 CFR Part 210, with "soda water" at the top of the list as it provides less than 5 percent of the U.S. Recommended Daily Allowance for eight specified nutrients (Berends, Gonzalez, Purcell \& Robertson, 2003). Creative loopholes were "discovered" to operate ala cart snack bars and food courts that were not required to meet the USDA nutrient regulations, thereby introducing vending machines on school campuses with stipulations that they were located at least 500 feet from the USDA Reimbursable Food Service Delivery area, commonly known as the cafeteria line. The parallel of this environmental change and the rise in childhood obesity became a potential intervention point for revisiting existing regulations and improving them with reinforced legislative efforts.

\section{Legislation to Improve School Nutrition Standards}

A major legislative effort began to address the empty calorie temptations on school campuses to address whether or not the school environment was the appropriate venue for the beverage companies to routinely market to students who were often on campuses without operational drinking water fountains. The childhood obesity epidemic became a call to action for improved school food and beverage regulations prompting such legislation as that introduced by California Senator Escutia which, after multiple and 
varied negotiations, finally became law in 2001 as SB-19. It contained a requirement that the state increase funding to the federal meal program before implementing nutrition standards for competitive foods. It also excluded high schools. SB-12 was subsequently written to strengthen and implement the competitive food standards originally described without funding in SB 19 (Escutia, 2001). SB-12 now included requirements for high schools.

To provide context for this high school regulation inclusion, the Los Angeles Unified School District passed its own internationally publicized total soda ban in August 2002, and "Win-Win-WEAN" was negotiated in April of 2002 with positive localized publicity culminating on August 14, 2002. These school districts utilized their local jurisdiction authority and rallied the community to encourage their individual school boards to initiate the healthy beverage changes. SB-12 had not yet passed through the California State Legislature in 2002.

Yet another bill specifying beverage regulations for high schools was passed as SB-965, since there were slightly different stipulations between the elementary, middle and high schools. Los Angeles County Public Health Department developed a worksheet in 2007 to assist with implementation of these varying standards for school personnel and fundraising organizations.

California State School Board Rules Introduced. In 2008, California adopted new food and beverage regulations for schools that clarified some of the ambiguous areas of law governing the foods and beverages sold on public school properties. The new food and beverage regulations worked in conjunction with, but did not take the place of, existing state law. The new laws set nutrition standards for the foods that schools can sell outside of the cafeteria. 
Project L.E.A.N.'s Legislative Involvement Strategy. A successful method of educating teenagers on the various aspects of advertising strategies was incorporated into a statewide intervention for California high school students beginning in 1996. "Exposing marketing lies" was an effective teaching strategy employed by Project L.E.A.N. to "sell health" to adolescents through the "Jump Start" curricula developed with funding from the California Department of Health Services. This program funded a student task force that educated themselves on upcoming legislation and made recommendations directly to elected officials and made official effective endorsements to support their fellow students with healthy behavior choices.

Carol Schecter, the director of health communications for the Academy of Educational Development, a Washington, D.C.-based non-profit organization, was quoted in the LA Times in 2006, "Very few behaviors change because someone saw an ad. You need social norms in place, environmental supports, the products, the placement, all the things that make the right decisions easy."

\section{Public Health Responds to Obesigenic Environment}

According to an article entitled Fat Nation, "Our obesity epidemic is an issue of public health and not personal virtue." The decades of trends have overwhelmed the significant social impact of high fat convenience foods and declining levels of physical activity. According to Professor Farley of public health at Tulane University and Senior Natural Scientist, Cohen, of the RAND corporation; "The desk job, the television, the Internet and suburban housing developments and their roads to nowhere all conspire against us" (Steiner, 2002).

Part of the obesity discussion language change to "crisis" stems from Americans' view of fat as an issue of individual virtue, not public health. Farley and Cohen make a 
comparison to the $19^{\text {th }}$ century epidemic of cholera, which once was believed caused by poor personal hygiene and intemperate drinking and eating habits of the urban poor. They had only themselves to blame, according to many social reformers of the time. Cholera turned out to be more susceptible to clean water than moral uplift; the disease rate declined after the introduction of better sewage and water supply systems. Modern obesity, like cholera in $19^{\text {th }}$ century New York and London, is more common among the poor and disenfranchised. Rather than making people ashamed that they indulge and seldom exercise, they proposed recommendations for public policies to help Americans keep off the extra pounds, fashioning public education campaigns to promote healthy eating and exercise and banning soft drinks from school grounds along with restoring daily physical education in schools as logical areas of opportunity.

\section{Schools as the Chosen Institution of the Socio-Ecological Model}

Behavior change requires more than knowledge as doctors and schools have known for years, resulting in a shift from cognitive focused curricula. Schools function as the institution that can teach students how to resist social pressures. Eating is a socially learned behavior that is influenced by social pressures. School-based programs can directly address peer pressure that discourages healthy eating and harness the power of peer pressure to reinforce healthy habits (Centers for Disease Control, 1996). Public Health officials for decades have grappled with education methods that appropriately motivate a positive action or replacement behavior and now employ teaching strategies based on social learning theory.

Behavior Modification Theories. In Social Learning Theory (SLT), human behavior is explained in terms of a three-way, dynamic, reciprocal theory in which personal factors, environmental influences, and behaviors continually interact. A basic 
premise of SLT is that people learn not only through their own experiences, but also by observing the actions of others and the results of those actions. In the 1970s, Albert Bandura published a comprehensive framework for understanding human behavior, based on a cognitive formulation, which he named the Social Cognitive/Learning Theory. This framework is currently the dominant version used in health behavior and health promotion and is still referred to as SLT (Glanz \& Rimer, 1997).

The Health Belief Model (HBM) was one of the first models that adapted theory from the behavioral sciences to health problems and it is one of the most widely recognized conceptual frameworks of health behavior. Psychologists working in the U.S. Public Health Service originally introduced it in the 1950's. Their focus was on increasing use of then-available preventive services, such as chest $\mathrm{x}$-rays for tuberculosis screening and immunizations such as flu vaccines. They assumed that people feared diseases, and that health actions were motivated in relation to the degree of fear (perceived threat) and expected fear-reduction potential of actions, as long as that potential outweighed practical and psychological obstacles to taking action (net benefits).

The HBM was spelled out in terms of four constructs representing the perceived threat and net benefits: perceived susceptibility, perceived severity, perceived benefits, and perceived barriers. These concepts were proposed as accounting for people's "readiness to act." It was originally developed to help explain health related behaviors and could guide in the search for "why" to help identify leverage points for change. It has been a useful application for developing messages that are likely to persuade individuals to make healthy decisions.

Most health behavior theories involve some "motivation" component criteria to distinguish along with concrete "maintenance factors". From the well-known Maslow's 
hierarchy of needs to the latest "Information, Motivation Behavior" (IMB) theory utilized for HIV positive patients in 2009 , the relevant catalysts to successful behavior changes are significantly beyond only presentation of the information. Pre-establishing a desired outcome and approach is its own task based on the target audience, learning styles, with clearly stated objectives needed to outline what performance is expected, conditions and cues, and criterion for measurement.

Trans-theoretical Model Approach. Another behavior change model that involves an intra-personal approach, ("within individuals") level, includes characteristics of individuals such as their knowledge, attitudes, beliefs, motivation, self-concept, and development history, past experience, skills, and behavior. The Stages of Change Model concerns individuals' readiness to change or attempt to change toward healthy behaviors. It evolved from work with smoking cessation and the treatment of drug and alcohol addiction and has recently been applied to a variety of other health behaviors. The basic premise is that behavior is a process and not an event, and individuals are at varying levels of motivation, or readiness, to change. Five distinct stages are identified in the Stages of Change Model: pre-contemplation, contemplation, decision/determination, action and maintenance.

It is important to note that this is a spiral, not linear model. People don't necessarily go through the stages and enter and exit at any point; they often recycle. Changing eating behaviors works best when the individual is in the "Action" or "Maintenance" stage. The "Preparation" stage research has been identified to be an average of 30 days before the "intended action" is pursued. Six months has been identified as the typical length of time for the "Action" phase before a newly adopted behavior is technically considered to be in the "Maintenance" stage. 
Techniques for Behavior Modification. Since "Change" is a process, studying the person's environment is useful for determining the conditions and events that precede, and follow, the eating choice. Multiple factors beyond physiological needs are involved, especially psychological and social in a peer environment.

To intervene, to break the response chain of behavior choices involves identifying the Antecedents, Behavior, and Consequences. Antecedents options would be to control, limit, or remove the stimuli cues, whether internal or external. For example, eating speed would be the actual behavior. Consequences are reinforcement rewards or punishments and can also be neutral. The theory is that never reinforcing a behavior should lead to it's extinction, yet the environment repeatedly intervenes either subliminally or overtly. An environmental point of note is the media's influence on eating behavior that is so pervasive in American culture. Modifying cognitive processes, which are automatic thoughts and self-dialogue, requires an approach that anticipates the intense experiential stimuli and responds with coping strategies to address the visceral intrinsic response $(\mathrm{Ni}$ Mhurchu, Margetts \& Speller, 1997).

\section{Efficacy of Environmental Change Strategies}

Knowledge is necessary, but not sufficient for behavior change. The change should have a "relative advantage" (Prochaska \& DiClemente, 1992). The motivation for change requires a preference to what a person is doing currently and can be based on efficiency, health, pleasure, economics, and prestige among peers, with consideration that each aspect being individually relevant. Pleasure, or lack of pleasure, affects rate of acceptance of change, especially with dietary adherence. Dietary regimens have more success, an average of about $30 \%$, with short term and flexible goals. 
Factors influencing adherence include an individual's behavioral attitude and stage of self-monitoring, as well as contingency plans. The relationship between the health care provider and the "patient" is interrelated. Positive reinforcement and rewards can be the primary motivations to substitute, replace, or abandon a behavior. The goal of self-efficacy of getting patients to perform a behavior on their own is enhanced by a tailored environment to support a different stimulus response.

Social marketing techniques have been utilized to address this epidemic since the stimulus can be a flood of advertising messages (Lefebvre \& Rochlin, 1997). It has been proven successful in the health field and had limited success in conjunction with traditional programs. Social marketing is not education alone, nor attitude changes alone, or social advertising alone, media advocacy alone or peer pressure alone. It is a multilevel advertising approach that responds to the current environment by including policy makers and retailers, beyond the individuals and health care providers, to increase success rates necessary for societal change in attitudes (Lefebvre \& Rochlin, 1997). 


\section{CHAPTER III}

\section{MATERIALS AND METHODS}

\section{Data Source Overview}

The data analyzed in this study were taken from weekly refill data sheets from 45 individual vending machines on the two primary SMJUHSD high school campuses in Santa Maria, California; these vendors provided tabulations from the period of February, 2003 through January 21, 2004, that were converted into spreadsheets. A vending machine inventory conducted at Santa Maria High School in November 2001, prior to the beginning of the study period, provided a breakdown of designated beverage slots per machine, serving as baseline information for this study. Pre-contract data was not obtained, so direct analysis measuring an increase or decrease in specific beverages was not ascertained. The contracted beverage vendor was instructed to provide refill data sheets with specific dates referenced, which included varying formats at the intervals of 8/27/03, 8/29/03, 10/21/03, 11/18/03 and 1/22/04.

\section{Data Procurement Challenges}

The beverage account sales representative could not, in numerous meetings, decipher the multiple formats he provided in the refill data sheets. Students, along with the public, had been told that the drinks in the top half of every vending machine on both campuses were "qualifying as healthy" by defined sugar amount standards, but the ratio of beverages was not implemented as publicized and different sales target amounts were given for the $4^{\text {th }}$ and $5^{\text {th }}$ promised healthy slots.

Since the actual ratio implementations were inaccurate, health advocates thus headed efforts to correct the misleading action of the vendor and school administration. Therefore each machine's number of available vending slots needed to be assessed as 
they varied from 8 to 10 per machine with some older machines containing 9 slots. The spreadsheets also included overlapping data that needed to be excluded from the summation for assessing ratio calculations while developing a methodology.

The spreadsheets in the appendices represent the beverage vendor's refill data for the 8, 9 and 10 slots for 45 machines, representing sales. From February 3, 2003 to January 21,2004 , the actual number of beverage vending machines was gradually increased from 22 machines to 45 total between the two campuses. The vendor did not share pre-contract data, so it was not possible to assess whether there was an increase or decrease in specific beverages, only an obvious increase in the number of vending units.

It should also be noted the analyses involved 4 separate data sets relating to selective procurement frequencies of 45 vending machines, including beverage refill and specific beverage flavor information provided by the vendor and school district business superintendent. The vending machines were, in aggregate, located throughout two high school campuses.

Although the negotiated five-year contract was approved by the School Board Members on August 17, 2002, there was not a specific contract initiation date as expected, causing significant challenges when initially interpreting data. As mentioned before, a local newspaper's front- page photo of non-compliance in January 2003 (Appendix B) and a strong focus article in February 2003 (Appendix C) initiated the actual implementation and contract finalization.

In spite of this difficulty, "First Fill" date, noted "FF" on the refill datasheets, was eventually determined for new machines. There were a few older vending machines with an odd number of slots, which were not readily apparent since beverage types were combined numbers on the spreadsheets. Due to the fact the vendor's refill data sheets did 
not outline or highlight individual slots, it became very difficult to identify and assess specific beverage slot data.

As noted on the spreadsheets in Appendices F-H (Santa Maria High School) and I-K (Righetti High School), the beverage refill counts of 32, 64, and 108, respectively represented the one, two, and three slots of a certain beverage type. These combined beverage numbers were also used to determine the number of total slots per beverage vending unit. These corresponding numbers became the indicator for the total number of slots per machine to determine the total ratios of the critical beverages of water, $100 \%$ orange juice, "Fruit Works" drinks, with flavor separations calculated to figure compliance with 50:50 ratio agreement positively publicized as "Win-Win-WEAN". On August 14, 2002 local CBS affiliate KCOY-TV once again provided excellent live coverage with critical exposure for the program and what it was trying to accomplish.

\section{Data Challenges Caused by Faulty RFP Definitions}

Upon educating the School Board about the practices of beverage vendors, the board decided to defer voting on the current proposal until they had time to review some of the poignant points. At the following board meeting, the vendors made presentations defending their business practices and the board formally voted to reject the current proposals and requested a new Request for Funding Proposal application be developed to include a 50:50 healthy to unhealthy beverage ratio with vending fronts that only market the qualifying healthy beverages by current standards passed for the middle school level known as SB-19.

SB-19 terms as healthy all milk, $100 \%$ juice, and water, with a typical 20 - ounce beverage only allowed to contain a maximum of 42 grams of added sugar. SB-19 regulations allow carbonation and no limit of added sugar was stipulated in flavored 
milks. Drinks that contained 50\% or more real juice were also qualifying beverages. Diet beverages were not allowed due to artificial sweeteners with controversial health effects still not resolved, despite FDA approval and requests from diabetic students.

There was no option to review the newly revised RFP before it was released to confirm the language met the 50:50 School Board approved beverage ratio. The qualifying beverage stipulation was circumvented with inclusion language of "flavored teas" and other non-carbonated beverages. New formulations of such drinks to meet the under 42 grams of added sugar had not occurred yet. As a result, the RFP was an inaccurate representation of the School Board members' intentions to support students with an equal number of healthy choices by volume, placement and marketing.

\section{Preliminary Data Calculation Methods}

Because of the contract ratio disparity, the initial calculations goal was to be able to highlight that the two slots of "Fruit Works" were displacing healthy drink sales and being chosen as healthy by unsuspecting students, due to placement and misleading labeling. "Asset numbers" listed on the refill data sheets were identified as separate vending machines and initial summations of qualifying separate beverages types were tabulated to be compared to the refill data representing sales of the signature cola flavor.

As refill data sets were given in different formats, it became necessary to decipher and correct for overlapping refill amounts, which was extremely tedious for 45 machines with an average of 10 slots and varying refill dates. The newer cola flavors were not originally totaled, nor were the other non-qualifying beverages in the bottom half of the machines. Only "Fruit Works" flavors were included as non-qualifying beverages to ascertain if students were choosing these beverages based on top slot placement or clever 
label marketing, affecting the ratio goal of $33 \%$ required to request a fourth beverage slot with an official qualifying beverage.

\section{Projections of Water Sales}

It became apparent, due in no small part to implementation delays and display deviations, that the total number of bottles sold of all beverages was not going to compensate for the $\$ 60,000$ Annual Guaranteed Commission as the Health Educator postulated based on case price data in the contract and accounting for the CRV (recycling fee). The number of potential customers listed in the RFP also was utilized to estimate the number of beverages per year that each person would need to buy. Calculations determined, assuming 6,565 possible consumers, a total need of only 23 beverage purchases by each person per school year. The possibility now existed, with double the amount of vending machines and average teen soda consumption data at about two per day, whereby water sales alone could easily meet the $\$ 60,000$ Annual Guaranteed Commission, which in actuality, was a sales projection goal of the vendor to break even on product sales. Net profit to the school on any vended beverage, in 2003 and 2004, was forty cents based on cost of the product and CRV expenses.

\section{Calculation Methods Utilized}

Beverages that qualified as healthy as defined by SB-19-bottled water and 100\% orange juice—were totaled, as were primary signature beverages of the vendor's brand. The misleading "fruit drink" labeled beverages are also included in the tabulations, due to their placement in the top slots designated for the healthy qualifying half promoted by significant earlier media marketing and nutrition education as the "healthy choice half." Furthermore, the data sets divide the beverages into categories of healthy and intended healthy drinks by top slots, with the known high sugar beverages in the lower slots. The 
summations were tripled checked for accuracy and validated by the school district yearend check receipt data.

\section{District Year-end Data Process}

In March 2005, the Health Educator visited the school district administration office to share preliminary data results with the new Business Superintendent and asked permission to highlight the positive information with the media about water outselling all the other beverages. This new employee to the high school district was very willing to share actual commission check history that allowed the Health Educator to fill in the last

quarter of first year data with greater accuracy, since the vendor was no longer providing refill data sheets. The voluminous year-end vendor sales data was made available to the Health Educator several months after its collection.

\section{Sales Commission Calculations}

Pricing per case information from the RFP was utilized to calculate the net profit per beverage including consideration of the recycling rate, referred to as $\mathrm{CRV}$, at 60 cents per case of 24 beverages.

The case prices of the all the beverages the vendor provided for the vending machines were the same, including the water and juice, although the vendor complained the juice was more costly. In fact, the 16-ounce versus 20-ounce packaging, and the resultant fewer bottles per case, compensated for this cost difference at a practical business level. The net profit per beverage sold was calculated to be 40 cents per 20ounce bottle sold. This calculation was reviewed by the Public Health Institute staff to assure accuracy and perused by the authors of the School Soda Study released in April 2002.

\section{Annual Guaranteed Commission}


The Annual Guaranteed Commission of the beverage contract is typically known in the industry as a "signing bonus". This contract specified $\$ 60,000$ per year for the vending portion of the contract. The $\$ 60,000$ figure is a form of a sales quota to the beverage vendor. To break even on the "Annual Guaranteed Commission", 150,000 bottles need to be sold each contract year (Appendix D).

\section{Estimated Energy Consumption}

An energy calculation was conducted to estimate the cost to the District for the electricity required to operate the vending machines on its campuses. Representatives from Pacific Gas and Electric Company worked with study staff to determine the appropriate methodology for these estimates. 


\section{CHAPTER IV}

\section{RESULTS}

\section{Availability of Water on Campus}

A beverage slot inventory taken at Santa Maria High School prior to the environmental change showed that 10 of the $72(14 \%)$ available slots in eight vending machines were designated for water. Only four of the eight machines had any slots designated for water, and the slots were often reported to be sold out. Refill data from the last study period (Fall semester 2003) showed that 32 of the $210(15 \%)$ slots in 21 vending machines on the Santa Maria High School campus were designated for water. There was clearly an increase in the number of vending machines on campus and as well as slots devoted to water, although the percentage devoted to water was essentially the same. At Righetti High School, beverage slot inventory taken prior to the environmental change showed that nine of the 70 available slots in seven vending machines were designated for water (13\%). In the last period of the study, 42 of 180 slots (23\%) in 18 vending machines designated for water, and increase in both the number of machines available and the percentage of slots devoted to water.

\section{Beverage Sales}

Beverage refill data by machine are included in Appendices F-K. Figures 3 and 4 show the breakdown of the 91,238 beverages sold during the study period by number sold and percentage of beverages sold, respectively. 


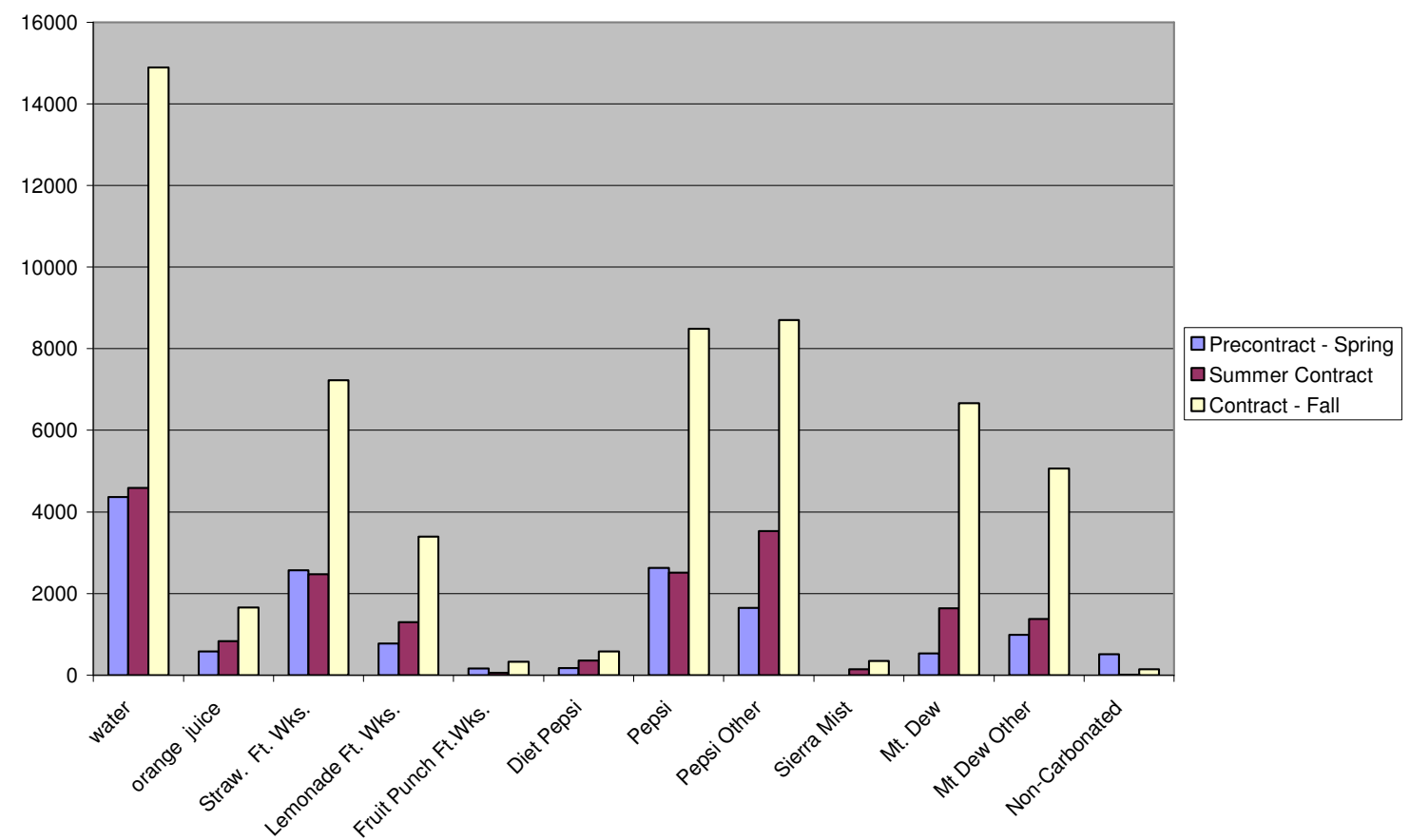

Figure 3: Breakdown of Beverages Purchased From Vending Machines (Number)

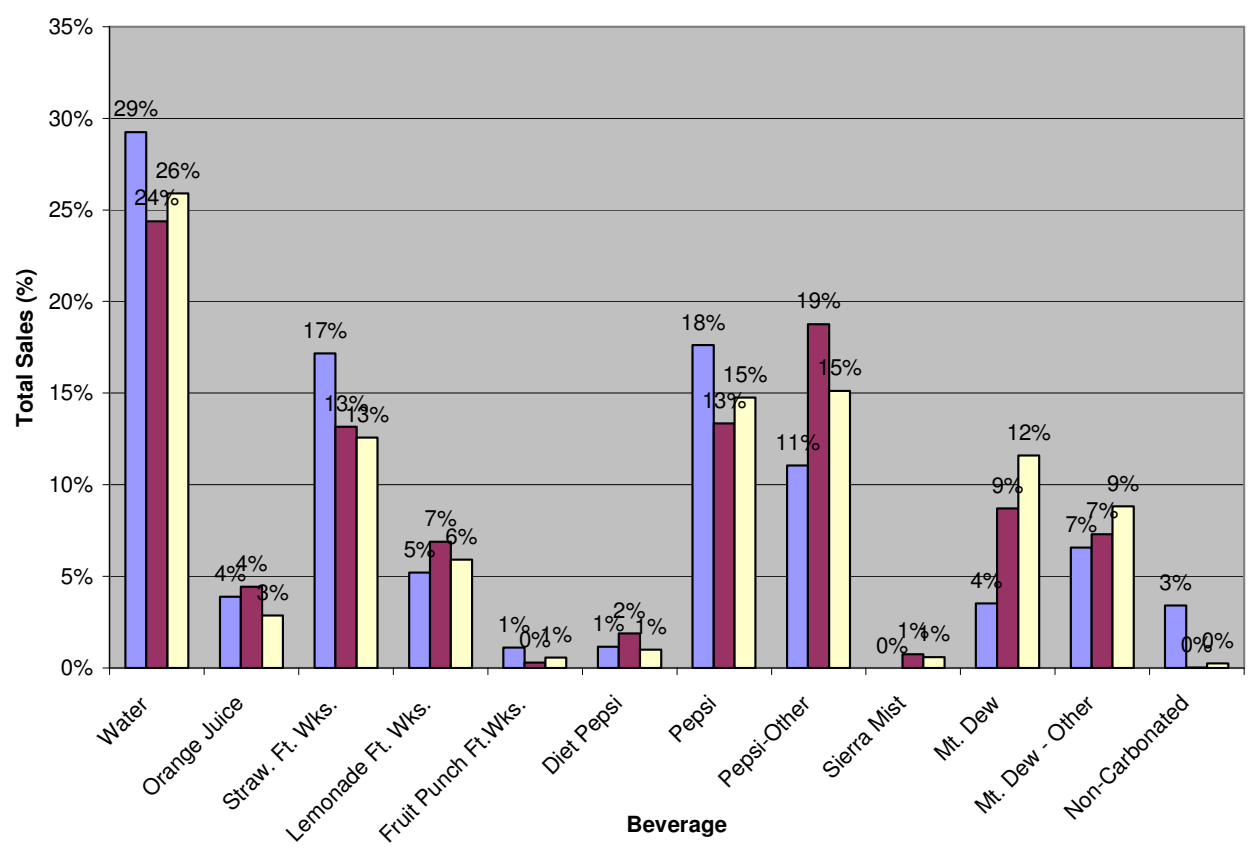

Figure 4: Breakdown of Beverages Purchased From Vending Machines (Percentage) 
Water versus Pepsi. Figure 5 shows a direct comparison of the percentage of sales from the vending machines of water and original-flavor Pepsi.

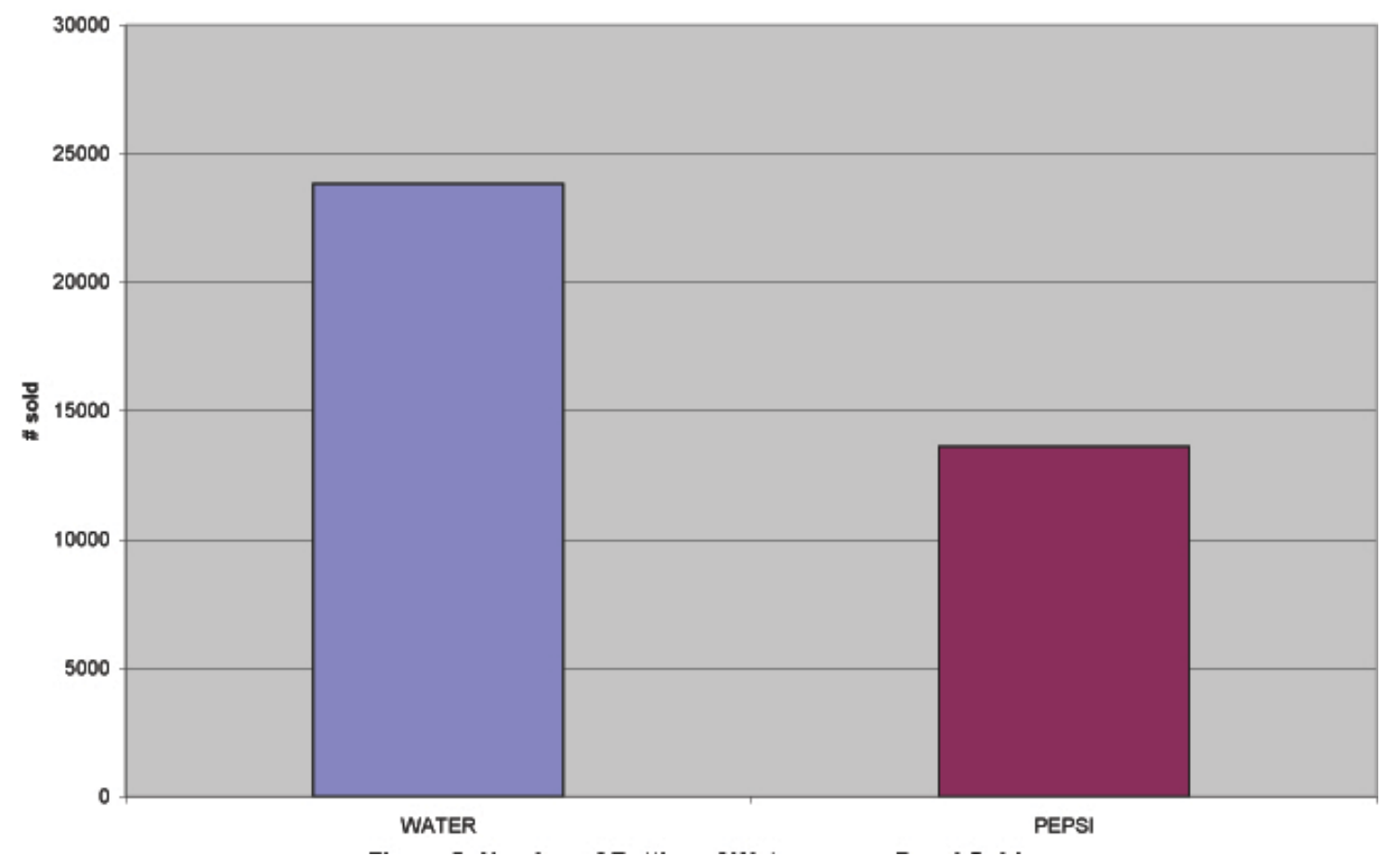

Figure 5: Number of Bottles of Water versus Pepsi Sold

Intended Healthy Beverages. Because students may have been under the impression that orange juice, Fruitworks ${ }^{\circledR}$ beverages, diet Pepsi, and the non-carbonated choices (iced teas, and a Sobe ${ }^{\mathrm{TM}}$ beverage called Mr. Green) were healthy options, the sales of these beverages are shown in Figure 6 in juxtaposition to water and known unhealthy choices. 


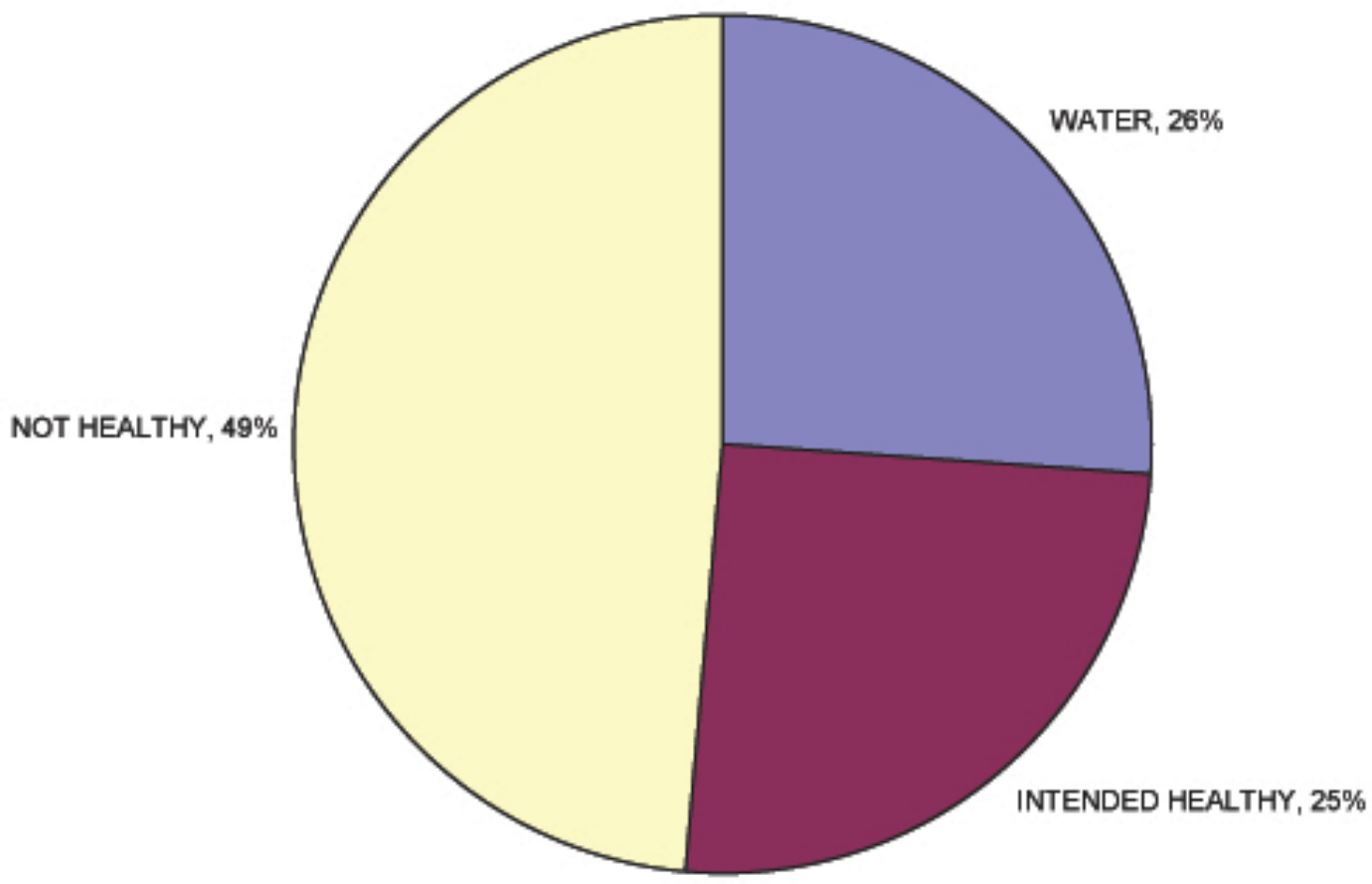

Figure 6: Percentage of Water, Intended Healthy Choices, and Known Not Healthy Choices (Total Bottles: 91,238)

\section{Financial Impact Data}

Data extrapolation was somewhat difficult due to the fact school districts do not have reporting regulations on incoming funds such as these (vendor), nor do they have restrictions for how they can be spent. Fortunately, in March 2005, a change in school district business administration provided data that illustrated a $\$ 7,300$ shortfall of the $\$ 60.000$, which equated to 18,250 less beverages being dispensed, or rather sold, as reflected in actual vendor commission checks. This accounting excerpt is included in Appendix E.

\section{Energy Calculation}

Vending machines normally operate at 750 watts. A 0.50 duty cycle factor was applied to account for the vending units' internal thermostats to maintain temperatures of 
35 to 36 degrees in varying locations. Using the following formula, it was determined that each machine uses $270 \mathrm{kWh} / \mathrm{month}$ :

750 watts $\times 24$ hours/day $\times 30$ days $/$ month $\times .50$ duty cycle $=270 \mathrm{kWh} / \mathrm{mo}$. The Santa Maria Unified High School District is subject to Pacific Gas and Electric Company's E-19 energy rates of $\$ 0.14728 / \mathrm{kWh}$. Therefore the estimate of the cost to operate 45 vending machines for one year is $\$ 21,473$. 


\section{CHAPTER V \\ DISCUSSION AND CONCLUSIONS}

\section{Hypothesis}

The data support the hypothesis "By an environmental change in high school vending machines, making water available, students will choose water over sugar sweetened sodas." Preliminary data analysis results released in August 2005 highlighted that within the first six months when water was introduced it became the number one beverage of choice for the high school students by a margin of more than $10 \%$.

\section{Intended Health Beverages}

Data analyzed in this study revealed not only the quick response in water sales, but favorable selection processes with other beverages that were placed in the top halves of the vending machines. These beverages, by virtue of placement and deceptive labeling, have been notated in this study as "Intended Healthy Choices" and include beverages that do not qualify per the SB-19 standards.

The only qualifying beverage included in the "Intended Healthy" category of choices was a 16 ounce Tropicana orange juice that had a shelf life of 45 days and was not designed for dispensing from the subject vending machine and required a "shim" retrofit feature since the bottle was a different size than the standard 20 ounce plastic bottle vending size. Ironically, a potentially serious health problem did occur relating to the Tropicana orange juice. For reasons unexplained, the Tropicana product developed significant mold in each bottle and was actually dispensed prior to detection. This most likely had a negative impact on subsequent summer term sales. The mold problem occurred again at the beginning of the Fall term and dampened orange juice consumption 
for the entire semester. Of final note here is the fact diet drinks were not introduced in this program study due to 45-day shelf-life concerns and are not allowable by the nutritional guidelines.

\section{Unhealthy Beverage Options}

Water outsold each individual unhealthy beverage flavor during the study period. Introduction of brand new flavors by the vendor of two primary signature beverages could have been a determining factor for luring away this small percentage of "maintenance stage" water drinkers. Another unforeseen problem was the subject vending machines were built with carbonation, as a load factor for dispensing and water did not always drop down, thereby creating a loss of actual water sales, which could not be accurately measured. Neither the eventual implementation of the three-slot allocation for vending dispersal nor the student complaints that "water was always out" were sufficient to eradicate this project shortcoming.

\section{Differential Cost of Beverages}

In so far as pricing contributed to not meeting the vendor's guaranteed commission, this rate of .40 cents per beverage was calculated using case price outlined in the RFP bid submitted in August 2002. All beverages case prices were listed as $\$ 4.75$ for 20 ounce vending bottles, with the exception of $100 \%$ orange juice, since it was only available in 16 ounce bottles for the same case price. The total amount of refill bottles needed was 150,000 for the vendor to "break even" on the competitive bidding proposal of $\$ 60,000$, which was listed as the "Annual Guaranteed Commission" (Appendix D). The calculation breakdown shows with 0.40 cents as the net profit per bottle, the school district actually "earns" this commission by direct sales. 
Regarding insufficient sales as a limiting factor, in this data analysis of 45 machines from February 3, 2003 through January 21, 2004, there was a shortfall of bottles sold by summation of the weekly refill data. Between the two high schools, 90,306 bottles were sold as of the three quarter point timeframe of the subject trial, in which only two of the three time periods were actually part of the contract. The shortfall at this three quarter mark was 59,694 bottles less than the target of 150,000. Although these results were initially discouraging, a promising outcome was discovered that water was the highest single selling beverage flavor by a margin of $11.58 \%$ over the signature cola flavor. These data represent an identifiable change in negative behavior.

\section{Ramifications of Revenue Shortfall on School District}

Because of the guaranteed commission (signing bonus) payout, replacing $50 \%$ of the high-sugar beverages with qualifying healthy drinks in the vending machines on two Santa Maria Joint Union High School campuses did not adversely impact the income earned by the school district even though a shortfall in projected revenues was experienced.

Notwithstanding the fact the revenue shortfall reported herein, the deficiency in targeted sales should not be viewed in a negative manner. This assertion is based on several distinct factors. First, due to intense and prolonged competition between two vendors vying for the 50:50 school district contract, it is very likely the signing bonus was excessive and had somewhat unrealistic sales expectations. Second, a 2006 study conducted by the CSPI and the Boston PHAI (Johanson, Smith \& Wooton, 2006) analyzed 120 contracts in 16 states finding that the beverage contracts raised, on average, less than $\$ 20$ per student annually In addition to underscoring the possibility that local 
expectations may have indeed been set too high this study would also, at a minimum, lend credence to the postulate that school districts should not undertake any for-profit business venture at the expense of the health and well-being of its student body, particularly when such an activity is not altogether that lucrative. When local vending machine energy requirements and other hidden costs are considered, usually after the fact contractually speaking, such commitments to the soda industry seem much less palatable, if not somewhat ill advised. Indeed, such logic has prompted numerous school systems to purchase and operate their own beverage-vending units, which not only gives them total control of content but affords larger profit margins as well.

As previously mentioned, the data analyzed compare beverage sales ratios based upon the partial implementation of a 50:50 ratio compromise between healthy beverages and those high in added sugar content. Consideration should be given to the possibility that the project would have met its targeted goals were it not for initial inconsistencies in formulating policy and subsequent delays implementing approved actions. Vending machine anomalies also contributed to less than optimal timeliness in executing choices for healthier lifestyles. The fact that 50:50 ratios were not implemented, in either same or separate vending machine scenarios, had the effect of being a direct impediment to attaining hypothesis goals.

Data results were also somewhat skewed by the fact the actual contract implementation was begun three months late. This was due to a threat from a competing vendor to sue since their signing bonus offer was $\$ 10,000$ per year higher than that of the awarded vendor. This thesis analyzed an academic year of refill data, yet the contract was not in full force until May 8, 2003 and this fact was not revealed until March 2005. It was 
also not a single academic year; the second performance evaluation period coincided with summer school, having only $10 \%$ of the customer (student) base available.

\section{Healthy Beverage Replacement Concerns}

Considerable time and effort was required to overcome concerns that vending machine revenues would undergo substantial decline due to replacing familiar, highly marketed brands with healthy alternatives that were decidedly low profile in both popularity as well as name recognition. At that period in time, bottled water was the major concern among such items. The vendor was just as worried as the school administrators, particularly inasmuch as he was guaranteeing a base payout to the school district via the signing bonus. Both groups advocated a 30:70 healthy/unhealthy beverage ratio as opposed to the 50:50 pilot approved earlier by the District School Board. The School District's Business Superintendent remained adamant about his 30:70 stance despite the School Board's public vote for the 50:50 policy. This Superintendent and the beverage vendor would, in fact, later increase the $30 \%$ requirement to $33 \%$. By design, this action was done verbally and directed to the Health Educator, during the August 29, 2003 Superintendent's Nutrition Advisory Council meeting. After many months of negotiation the issue was still never totally resolved; instead, the Business Superintendent chose to maintain a lower price for bottled water throughout the program's five-year contract life than prices for the other beverages. From their perspective, this approach would entice more purchases of bottled water while, at the same time, generate more revenue from sales of sugar-enhanced beverages in order to compensate from perceived shortfalls expected from healthy beverage sales. As the study data would later confirm, these concerns were unfounded. Water outsold 
ALL other beverage flavors by a margin of $10 \%$, including the signature brand cola beverage. This information was presented to a local Assemblyperson representative before a timely legislative vote (SB965) to include high schools in the statewide nutrition standards.

\section{Program Accomplishments}

Teen Choices. Foremost among the program positives was the fact a substantial percentage of high school teens did not hesitate in making intelligent decisions when given the opportunity. This program also allowed students to actually have a say in what choices their peers could make regarding healthy alternatives to personal dietary habits and the data elucidated their responsive maturity. Student participation in numerous health programs other than those associated with vending beverages was also commendable. They gave their time unselfishly for the benefit of their fellow students.

Student Activities at Righetti High School Prior to the 50:50 Program. In addition to their willingness to learn and apply new principles, the students' primary successes were a trial period of offering alternative lunch entrees. i.e., Subway sandwiches, special school breakfast promos, and establishment of a body conditioning class, which included weight lifting for girls. The students enhanced these successful services via coupons and fortune cookie messages they had produced, as they baked the cookies themselves, to pass out to interested parties. They also created a humorous video to feature the low cost of breakfast availability on campus to highlight that it was not just appropriate or enjoyable to free and reduced lunch program students.

Within the first few days of school in August 2001, a mobile breakfast cart service was initiated to increase consumption, positively impact student health, reduce poor 
student stigmas, and increase school revenue at the labor expense of Project L.E.A.N. for the first 45- 90 days. A true partnership and institutional change on the Righetti High School campus occurred, as did the publicity elicited statewide for the school district. A local School Board member was asked to speak about this mobile food services success at a subsequent San Diego conference.

A Springboard for Change. The acceptance and success of the 50:50 (healthy to unhealthy) beverage ratio for vending machine marketing was a rewarding culmination to an important and worthwhile cause. Granted, this author is extremely prejudiced here in that she created the concept, albeit an idea that could not possibly have been remotely successful without the hard work, support, and enthusiasm of many people. Participation by the students was, of course, paramount. The better points of the program have been emulated on many school campuses, both nationally and internationally. The 50:50 ratio has been adopted by municipalities for use in public venues where vending services are present.

Preliminary data analysis information was released in August 2005 to the local NBC affiliate (KSBY) emphasizing that high school students were already demonstrating the "Action" phase in the Stages of Readiness for Change Trans-theoretical Behavior model with the clever media sound bite of "students being thirsty for a change".

Development of this local project would have undoubtedly been exposed to a much greater probability for failure had it not been for the guidance and major access to resources availed from many governmental agencies at local, state, and federal levels. As just one example, early local use of L.E.A.N.'s guidebook for negotiating school soda contracts (California Project L.E.A.N., 2002) was indispensable. It was gratifying indeed to have some of our 'lessons learned' subsequently adopted by L.E.A.N. and incorporated 
into their expanded and widely distributed documentation for community action in this specific arena.

Such reciprocity between grassroots entities, school districts, and regulatory agencies were commonplace and, obviously, invaluable. Less frequent, but just as vital, were communications between such groups and legislative bodies. Fortunately, this has allowed great strides to be realized in establishing policies and laws relating to healthier lifestyle opportunities. The media, both locally and statewide, played a major and positive role throughout every stage of this undertaking and most definitely expedited and elevated matters when asked to play such a role.

Affirming Behavioral Science Theory. Behavior change models were affirmed by student actions in this program. Students responded to the new environmental change offering with the immediate purchasing of water, demonstrating the $4^{\text {th }}$ of five distinct stages of readiness for behavior change as "Action" following the principles of Dr. Prochaska and Dr. Di Clemete's Trans-Theoretical model (see Appendix L). This model outlines different levels toward sustained behavior change and typical timelines of each relative stage of change. The research based average for such behavior change movement from pre-contemplation, or even contemplation, to action is typically six months. Following this model, the data illustrated that students were already in the "preparation" stage, which involves about an average 30-day time frame before a new behavior action is taken.

This is one of the reasons more time was sought for implementation, monitoring, and adapting to the 50:50 beverage project, particularly since it was not only delayed but also not deployed in a forthright manner in accordance with the School Board's original vote mandate. 
These results prompted the media sound bite of local high school students being "thirsty for a change." This was an unexpected behavioral outcome early in the data analysis as the initial concern by the vendor and school district was a drop in sales revenue due to the introduction of healthier beverages.

Adolescent Elective Behavior. In some respects, whether adult or adolescent, making healthier choices in dietary habits is a much more complex change in behavior than, say, contemplation of smoking or alcohol consumption. Even when discounting food addictions or the narcotic-like power of processed sugar, positive dietary behavior in adolescents is still quite difficult and should be commended and reinforced at all turns. After all, everyone has an on-going requirement for food intake as opposed to choosing not to smoke or drink alcohol. Throw teenage peer pressure into this behavioral equation and the complexity increases exponentially. Peer pressure is acutely invasive on virtually every aspect of adolescent behavior. A NIH news release in June 2002, cites a study showing teenage girls are so concerned about their weight and obsessed with staying thin that they are subject to increased risk of becoming daily smokers by the time they become 18 to 19 years of age.

The intensity of adolescent peer pressure was precisely why the Health Educator fought against the "side by side, separate machines" beverage vending approach in favor of the original, and Board approved, proposal of single machine/top slots for healthy choices. The side-by-side protocol resulted in "healthy" and "unhealthy" lines that could create peer pressure from the increased social risk, whether real or perceived, associated with being seen in an "un-cool" line, if you will. Such affinity marketing breaks buyers into two groups: Aspiration groups where buyers want to belong; and Disassociate groups where buyers do not want to belong. 
While side-by-side vending may have unintentionally contributed to certain behavior patterns, the students were unfortunately subjected to behavioral controls that were purposely designed. False labeling tactics, deliberate placement of unhealthy beverages in slots represented as healthy choices, and the inclusion of several new "energy" drinks that, in most cases, were worse than the high added-sugar sodas they were meant to replace. All these tactics have had, and continue to have, ill effects on the health and well being of the students. It is disheartening that such behavior has more or less wiped out many of the program's intended benefits.

\section{First Beverage Compromise in California}

The internationally acclaimed Los Angeles Unified School District soda ban occurred subsequent to local (Santa Maria) School Board adoption of the 50:50 beverage ratio program. The positive press of the Win-Win- WEAN agreement was excellent local closure to the initial L.E.A.N. grant efforts. It was a model for the nation that was emulated in countless other school systems and legislatively adopted in many states as well as followed in overseas areas. The program prompted San Jose, CA to become the first U.S. city to establish a 50:50 beverage ratio in its public vending machines.

\section{Conclusions}

The Ongoing Need for Education and Application. There are many reasons for the necessity to continue programs that are concerned with healthier lifestyle pursuits. The intended, never-ending matriculation of school students and the high degree of mobility in American society are both virtual mandates for continuous education in dietary health practices. Advances in pertinent fields of science would, alone, be sufficient reason for on-going education even if schools and society at large somehow became far more 
stationary. As critical as education and knowledge are in helping to develop healthier lifestyle choices, other kinds of responsive, if not preventive, actions may prove more valuable in certain circumstances.

Slogans such as "If you can't legislate then litigate" have appeared in several states over the past few years in response to the obesity epidemic. It has been suggested by some in the media, among others, that States should file class action lawsuits against softdrink makers to recover Medicaid money spent treating obesity-related diseases. A "sin" tax on soda is an idea that was broached several years ago. The soda manufacturing and distribution industries have, of course, not been sitting idly by twiddling their thumbs, although they may have been actively "Twittering". They have steadfastly increased their lobbying efforts in direct response to healthy choice inroads upon their hitherto captive turf, a.k.a. the school campus. The industry has long mirrored the advertising tactics so successfully deployed by the tobacco cartel, i.e., relentless pursuit of the youth market to build brand loyalty.

The 'games' have long since begun and it is incumbent on us all to prevent, as best we can, their playing out in the detrimental fashion exhibited thus far. The stakes in the obesity epidemic are so high as to dwarf the associative costs of cigarette related diseases. This is well known in the soda industry and has only strengthened their resolve to fashion responses in much the same manner and attitude as did the tobacco sector. It would be safe to assume the soda troops have learned well the legal mistakes of their corporate cigarette brethren.

To say that problems still exist would, of course, be an understatement. Although a 2008 CDC report does reveal a flat rate of increase in obesity among American adults has occurred over the years between 2005 and 2007 no such promising data has yet 
appeared regarding adolescents. On the contrary, a 2009 Trend sheet issued by the CDC highlights increases in obesity rates for both male and female adolescents during this same time period. Within the past six years, for the first time in world history, the number of overweight people and the number of undernourished are equal (Creager, 2003). Obviously, the need exists for continuous stimulation to create and maintain beneficial lifestyle choices for people of all ages.

Taking Responsibility. Many School Board members were, and likely still are, unaware of the fact that local high schools are not in compliance with SB-19 or hardly any other State health mandates regarding healthy lifestyle choices, whether those guidelines are legislative, adopted policy, or merely trial programs. Some School Board members are aware of these failures but remain indifferent or otherwise impeded to take corrective action. In any event, the multitude of healthy dietary programs, tendered by qualified governmental entities at all levels, are simply not being followed, at least not in the subject school district.

As stated elsewhere in this document herein, the 50:50 ratio concept was never truly implemented at any time during this unique pilot program. Worse still, several 'new and improved' product permutations have come to be passed off as healthier alternatives to regular sodas but, in fact, are either just as laden with excessive added sugars, have critical caffeine levels, or contain sugar substitutes that are not approved in accordance with SB-19. As if not adhering to the intent of an equal ratio of healthy to unhealthy beverages was not harmful enough, providing beverages with even greater health risk potential than the regular sodas they displace. Actions such as these can only worsen the 
obesity epidemic among adolescents while increasing the incidence of diseases related to poor dietary habits.

Perhaps this kind of misrepresentation, ineptitude, or indifference can be expected or even tolerated in the private sector, but it should certainly not be accepted in taxsupported school environments. Not only are the school systems entrusted guardians and mentors of their wards, they are also legally and ethically bound to pursue and administer all county, state, and federal policies, regulations, and laws pertaining to the health, safety, and well being of their students at all times, in all campus circumstances. Local boards or on-campus administrations simply do not, or should not, have the legal latitude to ignore, circumvent, or oppose directives or mandates from agencies whose function it is to scientifically evaluate beneficial changes for school environments.

Many local School Board members, prior to their appointment or election, have previously served as volunteers in some capacity for the betterment of the schools in their neighborhood. It is, hopefully, this civic pride that has driven them to become more involved. The desire to change or disallow specific activities or policies underscores their concerns and raises their interest in school regulation.

A plethora of reasons exist as to why School Board members sometimes do not exercise the influence or control they might have initially intended over their respective school administrations at the district and campus levels. The fact that many board members have other careers commanding most of their attention is an impediment to potential board accomplishments, particularly as they relate to sustainability and feedback mechanisms of targeted goals after board voting has occurred to implement the desired activity. 
It is in this follow-up phase many School Boards do not have or do not take the time and effort to ensure their approved policies or mandates are applied in the spirit and manner intended. Boards all too frequently assume if a policy or program was successfully initiated (insofar as adherence to or compliance with board-approved dictates) that it somehow does not require on-going and diligent oversight to ensure positive, long-term application of the board's original objectives.

The inability to enforce and monitor board-approved programs or policies is a common shortcoming and this subject School Board was no exception. This is not to say some of the local board members did not actively seek to remedy or rectify the pitfalls in this subject program, usually at dear personal cost as a consequence. No matter how intense or correct their initial actions may therefore be, unless and until board members are inclined to focus on enforcement issues, there is no undertaking, beneficial or otherwise, that will enjoy either success or longevity.

Civic accountability is essential to ensure the integrity of environmental change on school campuses; unfortunately many good laws and regulations are ignored, manipulated, or go un-enforced. 


\section{REFERENCES}

Amador, M., Ramos, L.T., Morono, M. \& Hermelo, M.P. (1990). Growth rate reduction during energy restriction in obese adolescents. Experimental and Clinical Endocrinology, $96,73-82$.

American Medical Association. (1942). Some nutritional aspects of sugar, candy and sweetened carbonated beverages. Journal of American Medicine, 120, 763-765.

Ballew, C., Kuester, S. \& Gillespie, C. (2000). Beverage choices affect adequacy of children's nutrient intakes. Archives of Pediatric Adolescent Medicine, 154, 1148-1153.

Barlow, S. E. \& Dietz, W. H. (1998). Obesity evaluation and treatment: Expert committee recommendations. Pediatrics, 102, 29-40.

Bener, A. (2006). Prevalence of obesity, overweight, and underweight in Qatari adolescents. Food Nutrition Bulletin, 27, 39-45.

Berends, V., Gonzalez, M., Purcell, A. \& Robertson, J. (2003). Successful Students Through Healthy Food Policies: A partnership with the California School Boards Association. Paper presented at the Annual Meeting of the American Public Health Association, November 17, 2003. http://apha/confex.com/apha/131am/techprogram/paper_73367.htm.

California Center for Public Health Advocacy. (2002). An epidemic: Overweight and unfit children in California Assembly Districts. Davis, CA: California Center for Public Health Advocacy. (Legislative District Policy Brief \#1).

California Endowment. (2004). Survey of Californians about the problem of childhood obesity. Retrieved July 17, 2004 from http://www.calendow.org/ uploaded Files/survey_of_ca_childhood_obesity.pdf 
California Project L.E.A.N. (2002). Taking the fizz out of soda contracts: A guide to community action. Retrieved February 3, 2003 from http://www.cspinet.org/ nutritionpolicy/fizz_out.pdf

Carmona R. H. (2003). Remarks to the 2003 California Childhood Obesity Conference, January 6, 2003. http.//www.surgeongeneral.gov/news/speeches/califobesity.htm Center for Disease Control and Prevention. (CDCP). National Center for Health Statistics. Questionnaires, Data Sets, and Related Documents. Retrieved September 2009 from www.cdc.gov/nchs/nhanes/nhanes_questionnaires.htm

Center for Science in the Public Interest. (1999). America: Drowning in Sugar._Retrieved May 2, 2003 from http://www.cspinet.org/new/sugar.html Center for Weight and Health. (1999). The California Children's Healthy Eating and Exercise Practices Survey (CalCHEEPS). Retrieved June 16, 2003 from http://www.cnr.berkeley.edu/cwh/surveys/surveys_ca.shtml\#calcheeps

Centers for Disease Control. (1996). Guidelines for school health programs to promote lifelong healthy eating. Morbidity and Mortality Weekly Report, 45(RR-9), 1-41. Centers for Disease Control. (2006). About BMI for Children and Teens. Retrieved May 3, 2006 from http://www.cdc.gov/healthyweight/assessing/bmi/childrens_bmi/ about_childrens_bmi.html

Centers for Disease Control and Prevention. (CDCP). Questionnaires, Data Sets, and related Documents. Retrieved Sept. 2009 from http://www.cdc.gov/nchs/nhanes/nhanes questionnaires.htm

Clark, C. (1998). Osteoporosis hits young folks, too, professor warns. San Diego UnionTribune, p. 4. 
Cole TJ, Bellizzi MC, Flegal K.M. \& Dietz, WH. (2000) Establishing a standard definition for child overweight and obesity worldwide: international survey. British Medical Journal 320 (7244): 1240-3.

Committee on Communications. (1995). Children, Adolescents and Advertising. Pediatrics, 95, 295-297.

Committee on Food Marketing \& the Diets of Children \& Youth. (2006). Food Marketing to Children \& Youth: Threat or Opportunity? Washington DC:The National Academic Press.

Craypo, L. Purcell, A., Samuels, S.E, Agron, P., Bell, E. \& Takada E. (2002). Fast food sales on high school campuses: Results from the 2000 California High School Fast Food Survey. Journal of School Health, 72, 78-82.

Creager, E. (2003). Western-Style consumption fuels "globesity". Santa Barbara News Press, June 3, 2003.

Damery, H. (2004). Santa Barbara County Children's Scorecard. Santa Barbara CA: Santa Barbara County Department of Social Services. pg. 52-53.

Derenzy, T. (2005). Obesity rose everywhere but Oregon last year. USA Today. August 23.

Eaton, D.K, Kann, L., Kinchen, S., Shanklin, S., Ross, J., Hawkins, J. \& Wechsler, H. (2007). Youth Risk Behavior Surveillance : United States. MMWR Surveillance Summaries 57 (SS04), 1-131.

Epstein, L.H., Wing, R.B. \& Valoski, A. (1985). Childhood Obesity. Pediatric Clinics of North America, 32, 363-370.

Escutia, M. (2001). The Pupil Nutrition, Health, and Achievement Act. California Senate Bill 19. Adopted into law October 14, 2001. Retrievable at http://www.publichealthadvocacy.org/PDFs/SB_19_Summary.pdf 
Escutia, M. (2005). Pupil Nutrition: Beverages. California Senate Bill 965 - Adopted into law September 15, 2005. Retrievable at http://www.nojunkfood.org/policy/sb_965.pdf

Fleming M., Towey, K. \& Jarosik, J. (2000). Healthy Youth 2010- Supporting the 21 Critical Adolescent Objectives. Chicago: American Medical Association.

Fogelholm, M. \& Kukkonen-Harjula, K. (2000). Does physical activity prevent weight gain: A systematic review. Obesity Reviews, 1, 95-111.

French, S.A., Lin, B.-H. \& Guthrie, J.F. (2003) National trends in soft drink consumption among children and adolescents age 6 to 17 years: Prevalence, amounts, and sources, 1977/1978 to 1994/1998. Journal of the American Dietetic Association, 103, 1326-1331

Giammattei J., Blix G., Marshak, H.H., Wollitzer, A.O. \& Pettitt, D. J. (2003). Television watching and soft drink consumption: Association with obesity in 11-13 year old school children. Archive of Pediatrics and Adolescent Medicine, 157, 882-886.

Gift, H.C., Reisine, S.T. \& Larach, D. C. (1992). The social impact of dental problem and visits. American Journal of Public Health, 82, 1663-1668.

Glanz, K. P. \& Rimer, B. K. (1997). Theory at a glance: A guide for health promotion practice. Bethesda: National Cancer Institute (NIH Publication Number 97-3896).

Gold Coast Collaborative. (2003). Policy Brief: A Health Crisis in Paradise. Ventura CA: Ventura County Public Health Department.

Harnack, L., Stang, J. \& Story, M. (1999). Soft drink consumption among U.S. children and adolescents: National consequences. Journal of the American Dietetic Association, 99, 436-441.

Harris K.J., Paine-Andrews, A., Richter K.P. \& Lewis, R.K. (1997). Reducing elementary school children's risk for chronic disease through school lunch modification, nutrition 
education, and physical activity interventions. Journal of Nutrition Education, 29, 196202.

Harvard School of Public Health. (2001). Study finds increased consumption of sugarsweetened beverages promotes childhood obesity. Retrieved May 12, 2003 from http://www.hsph.harvard.edu/press/releases/press02152001.html.

Hastert, T. A., Babey, S.H., Diamant, A. L. \& Brown, E. R. (2008). Low-income adolescents face more barriers to healthy weight. UCLA Health Policy Research Brief. Los Angeles.

Helm, J. (2005). Some studies point to high fructose corn syrup as a culprit in the obesity crisis. Chicago: Chicago Tribune.

Himes, J. H. \& Dietz, W. H. (1994). Guidelines for overweight in adolescent preventive services: Recommendations from an expert committee. American Journal of Clinical Nutrition, 59, 307-316.

Institute of Medicine. (2002). Dietary reference intakes (DRIs) for Energy, Carbohydrates, Fiber, Fat, Fatty Acids, Proteins, and Amino Acids. http://www.iom.edu.

International Association for the Study of Obesity Force. (2008). Childhood Overweight \% (including obesity). Retrieved October 4, 2008 from http://www.iotf.org/database/index.asp.

Jacobson, M. F. (2005). Liquid candy: How soft drinks are harming Americans' health. Washington, D.C.: Center for Science in the Public Interest.

Johanson, J., Smith, J. \& Wooton, M.G. (2006). Raw Deal: School beverage contracts less lucrative than they seem. Washington DC: Center for Science in the Public Interest \& Public Health Advocacy Institute. http://www.cspinet.org/ beveragecontracts.pdf Kraak, V. \& Pelletier, D.L. (1998). The influence of commercialism on the food purchasing behavior of children and teenage youth. Family Economics \& Nutrition Review, 11, 15-24. 
Kuczmarski, R. J., Ogden, C.L., Guo, S.S., Grummer-Strawn, L.M., Flegal, K. M., Mei, Z. \& Johnson, C.L. (2002). 2000 CDC growth charts for the United States: Methods and development. Vital Health Statistics, 246, 1-190.

Lefebvre R.C. \& Rochlin L. (1997). Social Marketing. In Glanz, K., Lewis, F.M., Rimer, B.K. (eds). Health Behavior and Health Education: Theory, Research and Practice ( $2^{\text {nd }}$ ed.). San Francisco: Jossey Bass.

Ludwig, D., Peterson K.E. \& Gortmaker S.L. (2001). Relation between consumption of sugar sweetened drinks and childhood obesity: A prospective, observational analysis. Lancet, 357, 505-508.

McConnell, P.E. \& Shaw, J.B. (1996). Position of The Dietetic Association: Child and adolescent food and nutrition programs. Journal of the American Dietetic Association, 96, 913-917.

McGartland, C., Robson, P.J., Murray, L., Cran, G., Savage, M.J., Watkins, D. \& Boreham, C. (2003). Carbonated soft drink consumption and bone mineral density in adolescence: The Northern Ireland Young Hearts Project. Journal of Bone and Mineral Research 18(9): 1563-1569.

Medical News Today. (2006). California Nutrition Network celebrates ten year of fighting the State's 'Battle of the Bulge.' Medical News Today, August 11, 2006. http://www.medicalnewstoday.com.

Mokdad, A.H., Marks, J.S., Stroup, D.F. \& Gerberding, J.I. (2004). Actual causes of death in the United States. Journal of the American Medical Association, 291, 1238-1245.

Mrdjenovic, G. \& Levitsky, D.A. (2003). Nutritional and energetic consequences of sweetened drink consumption in 6- to 13-year old children. Journal of Pediatrics, 142, 604-610. 
Nestle, M. (2002). Food politics; How the food industry influences nutrition and health. Berkeley, CA, University of California Press.

Nestle, M. \& Jacobson, M.F. (2000). Halting the obesity epidemic: A Public Health Policy Approach. Public Health Reports, 115, 12-23.

Neumark-Sztainer, D., Story, M., Perry, C. \& Casey, M.A. (1999). Factors influencing food choices of adolescents: Findings from focus-group discussions with adolescents. Journal of the American Dietetic Association, 937, 929-934.

Newswise. (2003). Obesity Prevention Program Aimed at Second Graders. Retrieved 4/15/03. www.newswise.com

Ni Mhurchu, C., Margetts, B.M. \& Speller, V.M. (1997). Applying stages -of-change model to dietary change. Nutrition Reviews, 55, 10-16.

Obesity Education Initiative. (1998). Clinical Guidelines on the identification, evaluation, and treatment of overweight and obesity in adults: The evidence report. Washington, D.C.: National Institutes of Health. (NIH Publication \#98-4083).

Ogden, C.L., Kuczmarski, R.J., Flegal, K. M., Mei, Z., Guo, S, Wei \& Johnson, C.L. (2002). Centers for Disease Control and Prevention 2000 Growth Charts for the United States: Improvements to the 1977 National Center for Health Statistics Version. Pediatrics, 109, 45-60.

O'Keefe, L. (Feb. 2003). Soft drink sales benefit schools, not kid's health. AAP News, 22, 72. Olshansky, S.J., Passaro, D.J., Hershow, R.C., Layden, J., Carnes, B.A., Brody J. \& Ludwig, D.S. (2005). A Potential Decline in Life Expectancy in the United States in the 21st Century. The New England Journal of Medicine, 352, 1138-1145.

Prochaska, J.O. \& DiClemente, C.C. (1992). Transtheoretical therapy: toward a more integrative model of change. Psychotherapy Theory Research and Practice, 2, 176-288. 
Public Health Institute. (2006). Captive Kids: Selling Obesity at Schools. An ACTION GUIDE to stop the marketing of unhealthy foods and beverages in schools. Document available at http://www.asu.edu/educ/epsl/CERU/Articles/CERU-0603-172-OWI.pdf

Purcell, A. (2002). The Prevalence and Specifics of School District-wide Soda Contracts in California's Largest School Districts. Public Health Institute. Retrieved May 15, 2004, from http://www.phi.org/pdf-library/sodastudy.pdf

Reaney, P. (2003). Obesity epidemic set to get worse. Reuters Health. Retrieved May 29, 2003, from http://www.reutershealth.com/en/obesity.html.

Reynolds, L.M. \& Finke M. S. (2002). The influence of sweetened drink consumption on the likelihood of meeting the recommended dietary allowance from vitamins and minerals. Family and Consumer Sciences Research Journal, 31, 195-205.

Rooks, A. (2003). Local schools put the cap on sodas. Santa Maria SUN, , February 13, 2003, p. $10-11$.

Samuels and Associates. (2000). 2000 California high school fast food survey: Findings and recommendations. Sacramento, CA: Public Health Institute. Retrieved May 17, 2004, from http://www.phi.org/pdf-library/fastfoodsurvey2000.pdf

Samuels and Associates. (2006). Food and beverage marketing on California high school campuses survey: Findings and recommendations. Sacramento CA: Public Health Institute. Retrieved August 4, 2007 from http://www.phi.org/news_LEAN/ marketing_report.pdf

Shields M. \& Tremblay, M.S (2010). Canadian childhood obesity estimates based on WHO, IOTF and CDC cut-points. International Journal of Pediatric Obesity, 5, 265-273. 
Schwimmer, J.B., Burwinkle T.M. \& Varni, J.W. (2003) Health-related quality of life of severely obese children and adolescents. Journal of the American Medical Association, 289, 1813-1819.

Society for Nutrition Education. (1995). Joint Position of the Society for Nutrition Education (SNE), The American Dietetic Association (ADA), and American School Food Service Association (ASFSA): School-based nutrition programs and services. Journal of the American Dietetic Association, 95, 367-9.

Society for Nutrition Education. (2000). BMI poor indicator of body fat in individual kids. Journal of American Dietetic Association, 100, 628.

Stein, R. (2004). CDC Study Overestimated Deaths from obesity. Washington Post, November 24, 2004, A11.

Steiner, A. (2002) Fat Nation. UTNE Reader March-April 2002. http://www.utne.com/ 200203-01/fat-nation.aspx.

Trager, S. (2004). The Obesity Epidemic: What Schools Can Do. Preventing Weight Problems Before they Become Too Hard to Solve. Retrieved December 2004, from http://www.nasbe.org/index.php/standard/276-ses-oe-v52

UCLA Center for Health Policy Research. (2005). 2003 California Health Interview Survey. Los Angeles: University of California Los Angeles.

U.S. Department of Agriculture. (2005). Dietary Guidelines for Americans. Washington, DC: US Dept of Health and Human Services. www.healthierus.gov/dietaryguidelines.

Wadden T.A. \& Strunkard, A.J. (1985). Social and psychological consequences of obesity. Annals of Internal Medicine, 103, 1062-1067

Wang, Y. C., Gortmaker, G. L., Sobol, A.M. \& Kuntz, K.M. (2006). Estimating the energy gap among U.S. children: A Counterfactual approach. Pediatrics, 11, 1721-1733. 
Wechsler, H., Brener, N.D., Kuester, S. \& Miller, C. (2001). Food Service and Foods and Beverages Available at School: Results from the School Health Policies and Programs Study 2000. Journal of School Health, 71, 313-324.

Weiss, M. (2005). Sansum-Santa Barbara Medical Foundation Clinic CHAMP Pilot Program. Personal Communication, Santa Barbara, July 16.

Whitaker, RC, Wright, J.A., Pepe, M.S, Seidel, K.D. \& Dietz, W.H. (1997). Predicting obesity in young adulthood from childhood and parental obesity. New England Journal of Medicine, 337, 869-873.

Wright, J.D., Wang, C.Y., Kennedy-Stephenson, J. \& Ervin, R.B. (2003). Dietary intake of ten key nutrients for public health, United States: 1999-2000 Advance data from vital and health statistics, 334. http://www.cdc.gov/nchs/data/ad/ad334.pdf. 


\section{ACRONYMS}

AAP American Academy of Pediatrics

ABA American Beverage Association

AMA American Medical Association

BMI Body Mass Index

CDC Center(s) for Disease Control

CHAMP Childhood Health Awareness Mentoring Program

CHDP Child Health \& Disability Program

CHEEPS Ca Children's Healthy Eating and Exercise Priorities Survey

CRV California Redemption Value

CSFII Continuing Survey of Food Intake by Individuals (USDA’s)

CSPI Center for Science in the Public Interest

DRI Dietary Reference Intakes

FDA Food \& Drug Administration

fMRI functional Magnetic Resonance Imaging

GAO General Accounting Office

HBM Health Belief Model

HMO Health Maintenance Organization

HSPH Harvard School of Public Health

IASO International Assoc. for the Study of Obesity

IMB Information, Motivation Behavior theory

IOTF International Obesity Task Force

JAMA Journal of the American Medical Association 


$\begin{array}{ll}\text { L.E.A.N. } & \text { Leaders Encouraging Activity and Nutrition } \\ \text { LEAN } & \text { Low-fat Eating for America Now } \\ \text { MSV } & \text { Message Sensation Value } \\ \text { NCCSH } & \text { National Coordinating Committee on School Health } \\ \text { NHANES } & \text { National Health and Nutrition Examination Survey } \\ \text { NIDA } & \text { National Institute on Drug Abuse } \\ \text { NIH } & \text { National Institute of Health } \\ \text { PHI } & \text { Public Health Institute } \\ \text { RDA } & \text { Recommended Daily Allowance } \\ \text { RFP } & \text { Request for Proposal } \\ \text { SB-19 } & \text { Senate Bill-19 (CA) Pupil Nutrition, Health Achievement Act, 2001 } \\ \text { SHPPS } & \text { School Health and Policies Program } \\ \text { SJR } & \text { Senate Joint Resolution (CA) } \\ \text { SMJUHSD } & \text { Santa Maria Joint Union High School District } \\ \text { USDA } & \text { U.S. Department of Agriculture } \\ \text { World Health Organization }\end{array}$


APPENDICES 


\section{APPENDIX A \\ "Is Your Child's Health for Sale?" \\ Paid Advertisement, April 14, 2002}

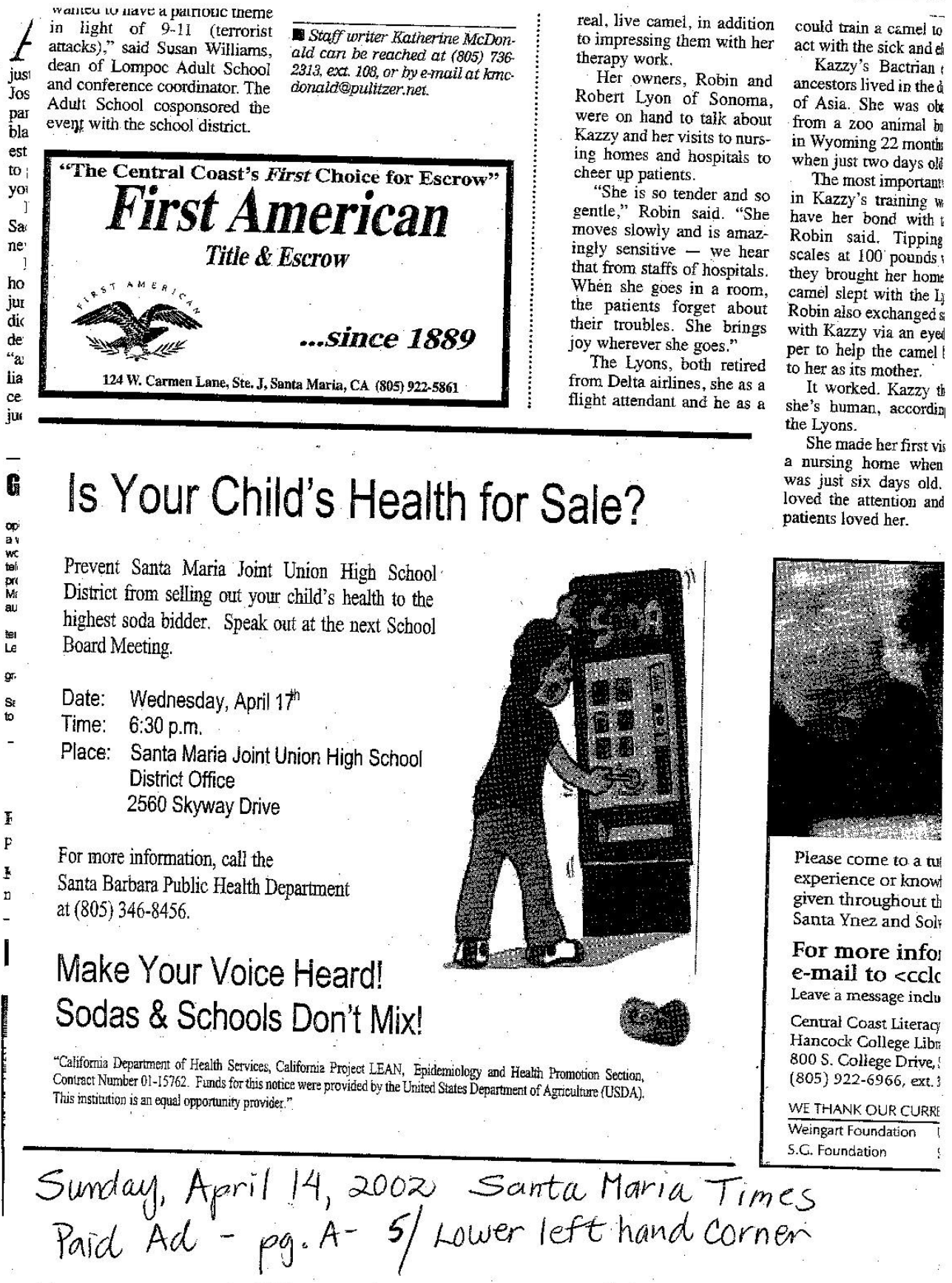




\author{
APPENDIX B \\ "Where's The School Soda?" \\ Santa Maria Times, January 20, 2003
}

FS: RAIDERS, BUCS SECURE BERTHS IN 'GRUDEN BOWL' se B1

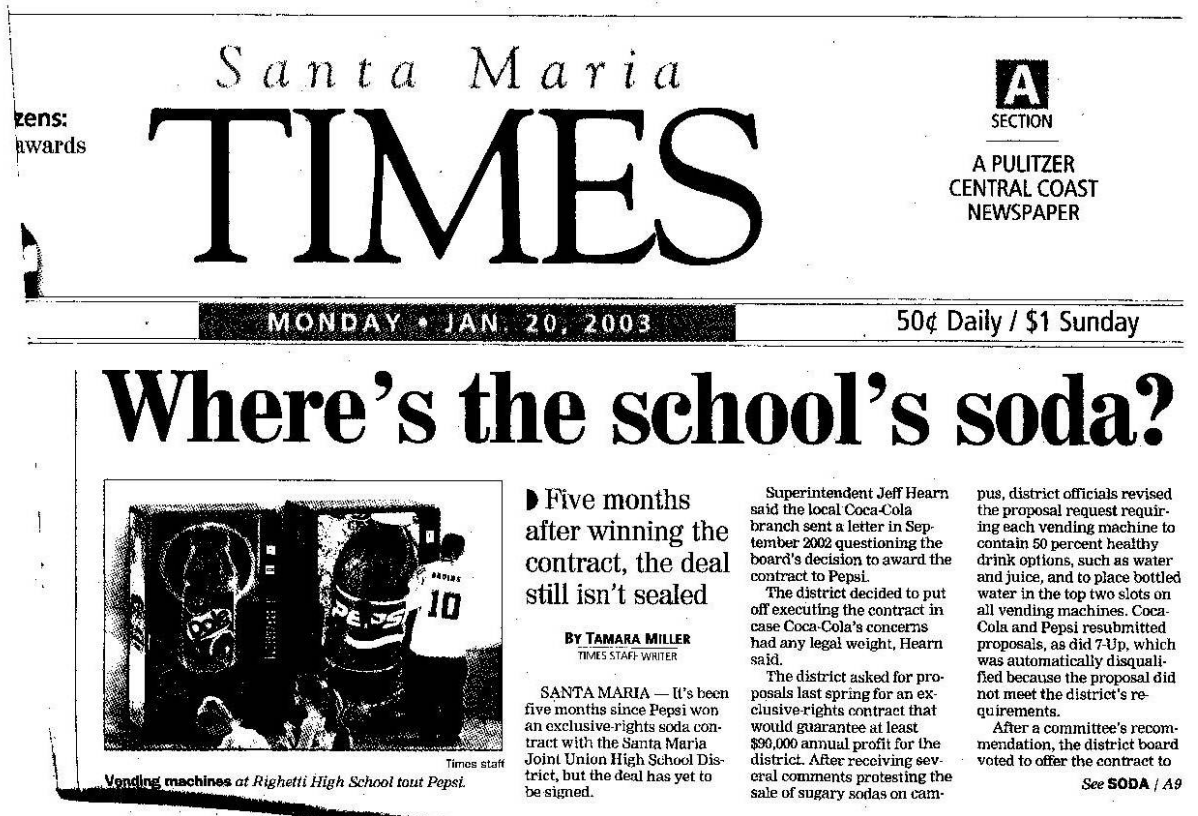




\section{APPENDIX C \\ "Local Schools Put the Cap on Sodas" \\ Santa Maria Sun, February 6-13, 2003}

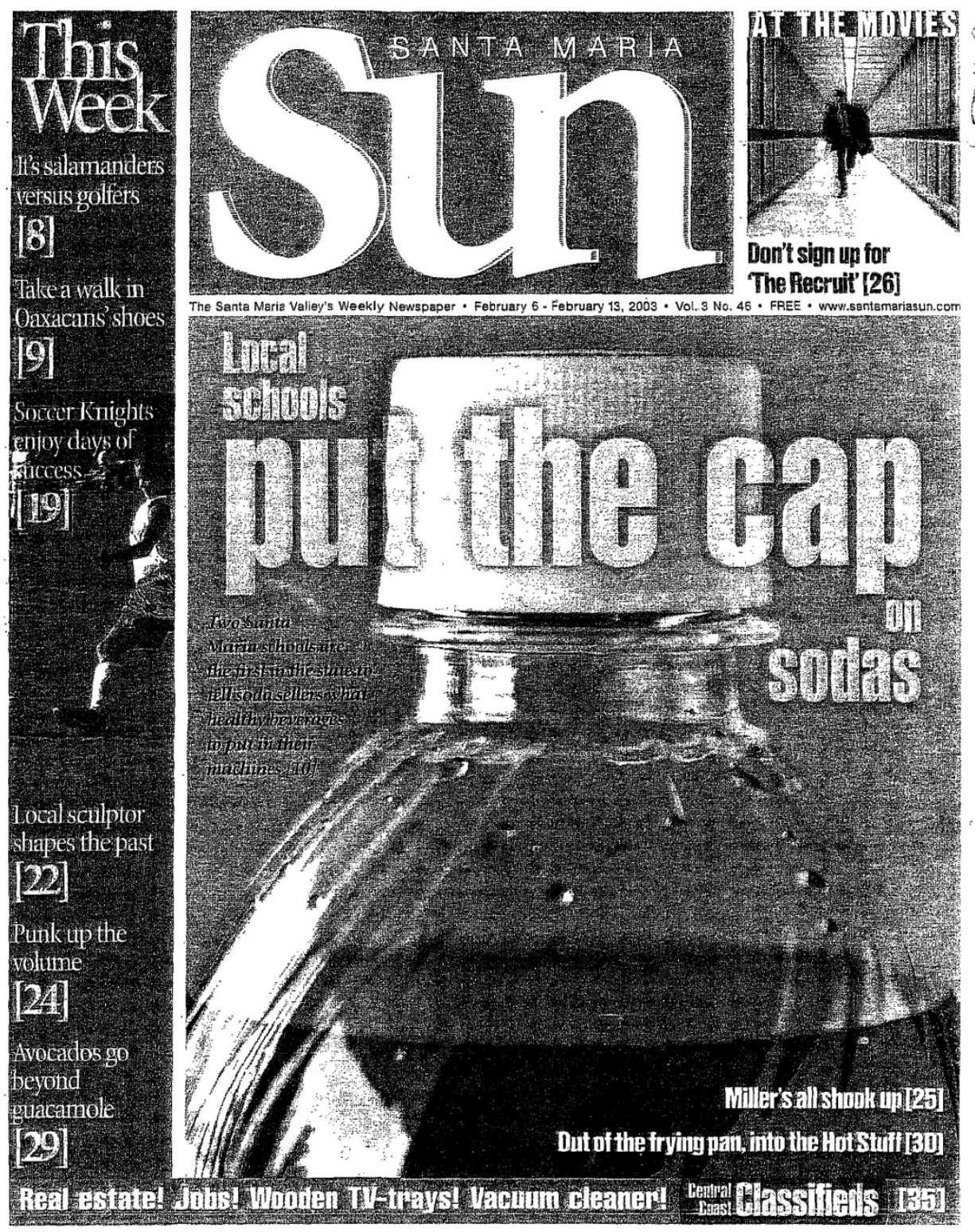




\section{APPENDIX D \\ Annual Guaranteed Commission Calculations}

$\$ 60,000$ - Actual sales quota for vendor to break even on guaranteed signing bonus @ $\$ .40$ per 20 oz. vended beverages sold $=150,000$ bottles

\section{ORIGINAL VENDOR GOAL:} \$60,000 EARNED UNDER NEW BEVERAGE SCHEME.

School district did NOT reach $\$ 60,000$ for total sales for all beverages sold during the 2003-2004 initial contract year, including water and 100\% Orange Juice.

\section{Unexpected Outcomes:}

Water outsold ALL other beverage flavors by a margin of $10 \%$, including the signature brand cola beverage. This information was presented to local Assemblyperson representative before a timely legislative vote (SB965) to include high schools in the statewide nutrition standards.

$\$ 60,000$

$-\quad 7,300$

\$52,700 - Amount Actually earned by school district direct sales

$\underline{52,700}$

$.40=131,750$ Actual Bottles Sold

Adjusted Quarterly Ratio:

$\underline{60,000}$

$4=\$ 15,000$ Projected Sales $=37,500$ Bottles Sold per quarter

Actual Refill Data ONLY available for 8 months:

$\$ 45,000$

- 7,300 - Shortfall amount provided by School District in March 2005

$\$ 37,700=94,250$ Total Bottles sold per adjustment for 8 months. 
APPENDIX E

Shortfall Vending Machines

\begin{tabular}{|c|c|c|c|c|c|c|c|c|}
\hline \multirow{3}{*}{$\begin{array}{c}\text { School } \\
\text { Year }\end{array}$} & & \multirow{3}{*}{ Total } & \multirow{3}{*}{ Check Total } \\
\hline & & & SMHS & RHS & DHS & DISTRI & & \\
\hline & Check & Check \# & Amount & Amount & \multicolumn{2}{|c|}{ Amount Amount } & & \\
\hline $02 / 03$ & $05 \overline{/ 2} 8 / 03$ & 62998772 & & 327.06 & & & 327.06 & 327.06 \\
\hline $02 / 03$ & $05 / 28 / 03$ & 62998776 & & 108.44 & & & 108.44 & 108.44 \\
\hline $02 / 03$ & $05 / 28 / 03$ & 62998770 & 81.38 & & & & 81.38 & 81.38 \\
\hline $02 / 03$ & $0.5 / 28 / 03$ & 62998769 & 64.11 & & & & 64.11 & 64.11 \\
\hline $02 / 03$ & $05 / 28 / 03$ & 62998777 & 51921 & 1.128 .03 & & & 1.647 .24 & 1.647 .24 \\
\hline $02 / 03$ & $06 / 27 / 0$ & 63062271 & 938.23 & 688.29 & & & 1.626 .52 & 1.626 .52 \\
\hline $02 / 03$ & $06 / 30 / 0$ & 63062265 & & 594.31 & & & 594.31 & 594.31 \\
\hline $02 / 03$ & $06 / 30 / 0$ & 63062268 & & 77.82 & & & 77.82 & 77.82 \\
\hline $02 / 03$ & $06 / 30 / 0$ & 63062258 & 54.15 & & & & 54.15 & 54.15 \\
\hline $02 / 03$ & $06 / 30 / 0$ & 63062257 & 166.05 & & & & 166.05 & 166.05 \\
\hline $03 / 04$ & $07 / 28 / 0$ & 63116321 & 726.80 & 135.78 & & & 862.58 & 862.58 \\
\hline $03 / 04$ & $07 / 28 / 0$ & 63116314 & 51.60 & & & & 51.60 & 51.60 \\
\hline $03 / 04$ & $07 / 28 / 0$ & 63116316 & & 260.43 & & & 260.43 & 260.45 \\
\hline $03 / 04$ & $07 / 28 / 0$ & 63116319 & & 46.32 & & & 46.32 & 46.32 \\
\hline $03 / 04$ & $08 / 25 / 0$ & 63163536 & 94.12 & 463.95 & & & 558.07 & 558.07 \\
\hline $03 / 04$ & $08 / 25 / 0$ & 63163531 & & 93.92 & & & 93.92 & 93.92 \\
\hline $03 / 04$ & $08 / 25 / 0$ & 63163534 & & 11.36 & & & 11.36 & 11.36 \\
\hline $03 / 04$ & 09/18/0 & 63203045 & 769.51 & 292.10 & & & 1.061 .61 & 1.061 .61 \\
\hline 03/04 & $09 / 18 / 0$ & 63197498 & & 4.423 .15 & & & 4.423 .15 & 4.423 .15 \\
\hline $03 / 04$ & $09 / 18 / 0$ & 63197499 & 850.05 & & & & 850.05 & 850.05 \\
\hline $03 / 04$ & $09 / 19 / 0$ & 63203042 & & 41.16 & & & 41.16 & 41.16 \\
\hline $03 / 04$ & $09 / 19 / 0$ & 63203040 & & 1.806 .42 & & & 1.806 .42 & 1.806 .42 \\
\hline $03 / 04$ & $09 / 19 / 0$ & 63203038 & & & & 16.20 & 16.20 & 16.20 \\
\hline $03 / 04$ & $10 / 17 / 0$ & 63272586 & 3.098 .31 & 323.04 & & & 3.419 .35 & 3.419 .35 \\
\hline $03 / 04$ & $10 / 17 / 0$ & 63272583 & 380.46 & 2.891 .54 & & & 3.272 .00 & 3.272 .00 \\
\hline $03 / 04$ & $10 / 17 / 0$ & 63272581 & & 79.79 & & & 79.79 & 79.79 \\
\hline 03/04 & $11 / 15 / 0$ & 63325431 & 1.918 .91 & 294.87 & & & 2.213 .78 & 2.213 .78 \\
\hline $03 / 04$ & $11 / 17 / 0$ & 63325429 & 284.87 & 2866.89 & & & 3.151 .76 & 3.151 .76 \\
\hline $03 / 04$ & $11 / 17 / 0$ & 63325426 & & 132.93 & & & 132.93 & 132.93 \\
\hline $03 / 04$ & $12 / 15 / 0$ & 63371013 & 143.33 & 1.433 .31 & & & 1.576 .64 & 1.576 .64 \\
\hline $03 / 04$ & $12 / 15 / 0$ & 63371010 & & 25.75 & & & 25.75 & 25.75 \\
\hline $03 / 04$ & $12 / 15 / 03$ & 63371016 & 1.215 .38 & 230.73 & & & 1.446 .11 & 1.446 .11 \\
\hline $03 / 04$ & $01 / 13 / 04$ & 63429574 & & & & 30.88 & 30.88 & 30.88 \\
\hline $03 / 04$ & $01 / 13 / 04$ & 63429573 & & 79.13 & & & 79.13 & 79.13 \\
\hline $03 / 04$ & $01 / 13 / 04$ & 63429577 & 1.267 .45 & 69.25 & & & 1.336 .70 & 1.336 .70 \\
\hline $03 / 04$ & $01 / 13 / 04$ & 63429572 & & & 93.94 & & 93.94 & 93.94 \\
\hline $03 / 04$ & $01 / 13 / 04$ & 63429581 & 730.60 & 163.57 & & & 894.17 & 894.17 \\
\hline $03 / 04$ & $02 / 06 / 04$ & 63471301 & 93.70 & 54209 & & & 63579 & 635.79 \\
\hline $03 / 04$ & $02 / 06 / 04$ & 63471303 & 810.95 & 80.25 & & & 891.20 & 891.20 \\
\hline $03 / 04$ & $03 / 04 / 04$ & 63510441 & 77.60 & 1.735 .34 & & & 1.812 .94 & 1.812 .94 \\
\hline $03 / 04$ & $03 / 04 / 04$ & 63510443 & 1.121 .36 & 181.79 & & & 1.303 .15 & 1.303 .15 \\
\hline $03 / 04$ & $04 / 01 / 04$ & 63557728 & 191.88 & 1.861 .47 & & & 2.053 .35 & 2.053 .35 \\
\hline $03 / 04$ & $04 / 01 / 04$ & 63557732 & 1.286 .03 & 245.42 & & & 1.531 .45 & 1.531 .45 \\
\hline $03 / 04$ & $04 / 29 / 04$ & 63604982 & $68 \mathrm{~A} 3$ & 1.643 .04 & & & 1.711 .47 & 1.711 .47 \\
\hline $03 / 04$ & $04 / 29 / 04$ & 63604984 & 831.37 & 170.69 & & & 1.002 .06 & 1.002 .06 \\
\hline $03 / 04$ & $05 / 27 / 04$ & 63646792 & 263.70 & 1.900 .25 & & & 2.163 .95 & 2.163 .95 \\
\hline $03 / 04$ & $05 / 27 / 04$ & 63646794 & 1.526 .55 & 350.71 & & & 1.677 .26 & 1.877 .26 \\
\hline & Contract & Totals & 19.624 .09 & 27.800 .39 & 93.94 & 47.08 & 47.565.50 & $(60.000 .00)$ \\
\hline 03/04 & 06/25/04 & 63697946 & $1,376.99$ & 112.05 & & & $1,489.04$ & $1,489.04$ \\
\hline 03/04 & $06 / 25 / 04$ & 63697941 & 113.37 & $2,325.79$ & & & $2,439.16$ & $2,439.18$ \\
\hline $03 / 04$ & $10 / 18 / 04$ & 63868407 & 316.75 & & & & 316.75 & 316.75 \\
\hline 03/04 & $10 / 22 / 04$ & 63873083 & & 888.08 & & & 888.08 & 888.08 \\
\hline & & & & & & & $(7,301.47)$ & $\underset{\substack{\text { Rev. Balance } \\
\text { nus }}}{ }$ \\
\hline
\end{tabular}


APPENDIX F

Santa Maria High School Refill Data (2/2/03-5/31/03)

February 2, 2003 through May 31, 2003

\begin{tabular}{|c|c|c|c|c|c|c|c|c|c|c|c|c|}
\hline $\begin{array}{c}\text { machine } \\
\#\end{array}$ & $\begin{array}{l}\text { First } \\
\text { Data } \\
\text { Date } \\
\end{array}$ & Water & $\begin{array}{l}\text { Orang } \\
\text { e Juice }\end{array}$ & $\begin{array}{c}\text { Straw } \\
\text {. Ft. } \\
\text { Wks. }\end{array}$ & $\begin{array}{l}\text { Lemonad } \\
\text { e Ft. Wks. }\end{array}$ & $\begin{array}{c}\text { Fruit } \\
\text { Punch } \\
\text { Ft.Wks. }\end{array}$ & $\begin{array}{c}\text { Diet } \\
\text { Pepsi }\end{array}$ & $\begin{array}{c}\text { Peps } \\
\text { i }\end{array}$ & $\begin{array}{c}\text { Pepsi } \\
\text { Othe } \\
\text { r } \\
\end{array}$ & $\begin{array}{l}\text { Mt. } \\
\text { Dew }\end{array}$ & $\begin{array}{c}\text { Mt. } \\
\text { Dew } \\
\text { Other }\end{array}$ & $\begin{array}{c}\text { Isotonic } \\
\mathrm{S} \\
\end{array}$ \\
\hline \multirow[t]{6}{*}{5271877} & $\begin{array}{c}3 / 13 / 200 \\
3\end{array}$ & 16 & 0 & 10 & N/A & N/A & N/A & 16 & 28 & N/A & & \\
\hline & & 28 & 24 & 35 & N/A & N/A & N/A & 17 & 12 & N/A & & \\
\hline & & 6 & 12 & 6 & N/A & N/A & N/A & 10 & 18 & N/A & & \\
\hline & & 12 & 4 & 14 & N/A & N/A & N/A & 12 & 28 & N/A & & \\
\hline & & 4 & 0 & 4 & N/A & N/A & N/A & 4 & 6 & N/A & & \\
\hline & & 14 & 0 & 24 & N/A & N/A & N/A & 12 & 24 & N/A & & \\
\hline \multirow[t]{4}{*}{5273268} & $\begin{array}{c}4 / 10 / 200 \\
3\end{array}$ & 42 & 12 & 34 & N/A & N/A & N/A & 56 & 28 & N/A & & 30 \\
\hline & & 16 & 9 & 10 & N/A & N/A & N/A & 28 & 14 & N/A & & 0 \\
\hline & & 0 & 0 & 16 & N/A & N/A & N/A & 38 & 24 & N/A & & 0 \\
\hline & & 0 & 0 & 48 & N/A & N/A & N/A & 20 & 16 & N/A & & 0 \\
\hline \multirow[t]{6}{*}{5272762} & $\begin{array}{c}2 / 21 / 200 \\
3\end{array}$ & 0 & N/A & 54 & 0 & 0 & N/A & N/A & N/A & N/A & N/A & 18 \\
\hline & & 56 & N/A & 46 & 0 & 56 & N/A & N/A & N/A & N/A & N/A & 24 \\
\hline & & 30 & N/A & 26 & 0 & 20 & N/A & N/A & N/A & N/A & N/A & 24 \\
\hline & & 47 & N/A & 8 & 0 & 44 & N/A & N/A & N/A & N/A & N/A & 28 \\
\hline & & 54 & 0 & 27 & 5 & 14 & N/A & N/A & N/A & N/A & N/A & 0 \\
\hline & & 30 & 0 & 30 & 0 & 24 & N/A & N/A & N/A & N/A & N/A & 27 \\
\hline 5273237 & $2 / 27 / 200$ & 22 & N/A & N/A & 18 & N/A & N/A & 0 & 0 & 16 & 24 & 0 \\
\hline
\end{tabular}




\begin{tabular}{|c|c|c|c|c|c|c|c|c|c|c|c|c|}
\hline & 3 & & & & & & & & & & & \\
\hline & & 16 & N/A & N/A & 0 & N/A & N/A & 25 & 0 & 25 & 28 & 28 \\
\hline & & 12 & N/A & N/A & 30 & N/A & N/A & 0 & 0 & 11 & 16 & 10 \\
\hline & & 20 & N/A & N/A & 16 & N/A & N/A & 0 & 0 & 10 & 20 & 10 \\
\hline & & 38 & N/A & N/A & 28 & N/A & N/A & 0 & 0 & 20 & 24 & 0 \\
\hline & & 38 & N/A & N/A & 12 & N/A & N/A & 0 & 0 & 10 & 18 & 0 \\
\hline $\begin{array}{c}\text { machine } \\
\#\end{array}$ & $\begin{array}{l}\text { First } \\
\text { Data } \\
\text { Date } \\
\end{array}$ & Water & $\begin{array}{l}\text { Orang } \\
\text { e Juice }\end{array}$ & $\begin{array}{c}\text { Straw } \\
\text {. Ft. } \\
\text { Wks. }\end{array}$ & $\begin{array}{l}\text { Lemonad } \\
\text { e Ft. Wks. }\end{array}$ & $\begin{array}{c}\text { Fruit } \\
\text { Punch } \\
\text { Ft.Wks. }\end{array}$ & $\begin{array}{l}\text { Diet } \\
\text { Pepsi }\end{array}$ & $\begin{array}{c}\text { Peps } \\
\text { i }\end{array}$ & $\begin{array}{l}\text { Pepsi } \\
\text { Othe } \\
\text { r }\end{array}$ & $\begin{array}{l}\text { Mt. } \\
\text { Dew }\end{array}$ & $\begin{array}{c}\text { Mt. } \\
\text { Dew } \\
\text { Other }\end{array}$ & $\begin{array}{c}\text { Isotonic } \\
\mathrm{S}\end{array}$ \\
\hline 5273386 & $\begin{array}{c}3 / 13 / 200 \\
3 \\
\end{array}$ & 58 & N/A & N/A & 0 & N/A & N/A & 42 & 0 & 34 & 0 & 56 \\
\hline & & 56 & N/A & N/A & 0 & N/A & N/A & 54 & 0 & 28 & 0 & 34 \\
\hline & & 84 & N/A & N/A & 28 & N/A & N/A & 0 & 0 & 0 & 28 & 38 \\
\hline & & 44 & N/A & N/A & 0 & N/A & N/A & 0 & 0 & 0 & 4 & 0 \\
\hline & & 41 & N/A & N/A & 0 & N/A & N/A & 0 & 0 & 0 & 0 & 0 \\
\hline & & 56 & N/A & N/A & 58 & N/A & N/A & 0 & 0 & 28 & 28 & 0 \\
\hline 5272778 & $\begin{array}{c}2 / 21 / 200 \\
3\end{array}$ & 60 & 36 & 56 & N/A & N/A & N/A & 48 & 34 & N/A & 0 & \\
\hline & & 22 & 0 & 12 & N/A & N/A & N/A & 0 & 0 & N/A & 0 & \\
\hline & & 58 & 18 & 64 & N/A & N/A & N/A & 36 & 14 & N/A & 66 & \\
\hline & & 36 & 3 & 34 & N/A & N/A & N/A & 30 & 0 & N/A & 16 & \\
\hline & & 32 & 0 & 20 & N/A & N/A & N/A & 36 & 0 & N/A & 18 & \\
\hline & & 36 & 0 & 52 & N/A & N/A & N/A & 44 & 0 & N/A & 32 & \\
\hline & & & & & & & & & & & & \\
\hline 5271927 & $\begin{array}{c}2 / 21 / 200 \\
3\end{array}$ & 28 & N/A & 32 & N/A & N/A & 0 & 22 & 36 & N/A & N/A & N/A \\
\hline & & 68 & N/A & 56 & N/A & N/A & 14 & 42 & 36 & N/A & N/A & N/A \\
\hline & & 14 & N/A & 10 & N/A & N/A & 0 & 4 & 16 & N/A & N/A & N/A \\
\hline & & 59 & N/A & 56 & N/A & N/A & 8 & 50 & 53 & N/A & N/A & N/A \\
\hline & & 0 & N/A & 0 & N/A & N/A & 0 & 1 & 0 & N/A & N/A & N/A \\
\hline
\end{tabular}




\begin{tabular}{|c|c|c|c|c|c|c|c|c|c|c|c|c|}
\hline & & 12 & N/A & 8 & N/A & N/A & 0 & 14 & 22 & N/A & N/A & N/A \\
\hline & & 68 & N/A & 4 & N/A & N/A & 0 & 29 & 32 & N/A & N/A & N/A \\
\hline \multirow[t]{7}{*}{5272794} & $\begin{array}{c}2 / 21 / 200 \\
3\end{array}$ & 28 & 0 & 24 & N/A & N/A & N/A & 24 & 20 & N/A & 26 & N/A \\
\hline & & 36 & 0 & 34 & N/A & N/A & N/A & 48 & 36 & N/A & 22 & N/A \\
\hline & & 8 & 0 & 12 & N/A & N/A & N/A & 16 & 12 & N/A & 6 & N/A \\
\hline & & 44 & 12 & 32 & N/A & N/A & N/A & 52 & 28 & N/A & 12 & N/A \\
\hline & & 22 & 12 & 22 & N/A & N/A & N/A & 26 & 14 & N/A & 18 & N/A \\
\hline & & 32 & 0 & 38 & N/A & N/A & N/A & 40 & 36 & N/A & 16 & N/A \\
\hline & & 22 & 12 & 16 & N/A & N/A & N/A & 14 & 14 & N/A & 10 & N/A \\
\hline $\begin{array}{c}\text { machine } \\
\#\end{array}$ & $\begin{array}{l}\text { First } \\
\text { Data } \\
\text { Date }\end{array}$ & Water & $\begin{array}{l}\text { Orang } \\
\text { e Juice }\end{array}$ & $\begin{array}{l}\text { Straw } \\
\text {. Ft. } \\
\text { Wks. }\end{array}$ & $\begin{array}{l}\text { Lemonad } \\
\text { e Ft. Wks. }\end{array}$ & $\begin{array}{c}\text { Fruit } \\
\text { Punch } \\
\text { Ft.Wks. }\end{array}$ & $\begin{array}{l}\text { Diet } \\
\text { Pepsi }\end{array}$ & $\begin{array}{c}\text { Peps } \\
\text { i }\end{array}$ & $\begin{array}{l}\text { Pepsi } \\
\text { Othe } \\
\text { r }\end{array}$ & $\begin{array}{l}\text { Mt. } \\
\text { Dew }\end{array}$ & $\begin{array}{l}\text { Mt. } \\
\text { Dew } \\
\text { Other }\end{array}$ & $\begin{array}{c}\text { Isotonic } \\
\mathrm{s}\end{array}$ \\
\hline \multirow[t]{6}{*}{5273243} & $\begin{array}{c}3 / 13 / 200 \\
3\end{array}$ & 62 & 0 & 40 & N/A & N/A & N/A & 70 & 32 & N/A & N/A & 38 \\
\hline & & 44 & 12 & 0 & N/A & N/A & N/A & 60 & 36 & N/A & N/A & 26 \\
\hline & & 10 & 0 & 12 & N/A & N/A & N/A & 10 & 2 & N/A & N/A & 2 \\
\hline & & 17 & 0 & 26 & N/A & N/A & N/A & 34 & 6 & N/A & N/A & 0 \\
\hline & & 26 & 0 & 48 & N/A & N/A & N/A & 20 & 12 & N/A & N/A & 0 \\
\hline & & 52 & 0 & 60 & N/A & N/A & N/A & 56 & 32 & N/A & N/A & 0 \\
\hline \multirow[t]{3}{*}{5271907} & $5 / 8 / 2003$ & 54 & N/A & N/A & 40 & N/A & N/A & N/A & 52 & 20 & 24 & N/A \\
\hline & & 84 & N/A & N/A & 52 & N/A & N/A & N/A & 50 & 14 & 32 & N/A \\
\hline & & 42 & N/A & N/A & 20 & N/A & N/A & N/A & 28 & 10 & 16 & N/A \\
\hline \multirow[t]{3}{*}{738864} & $\begin{array}{c}4 / 10 / 200 \\
3\end{array}$ & 12 & 28 & 56 & N/A & N/A & 28 & 56 & 56 & N/A & N/A & N/A \\
\hline & & 0 & 12 & 24 & N/A & N/A & 0 & 32 & 16 & N/A & N/A & N/A \\
\hline & & 0 & 0 & 20 & N/A & N/A & 4 & 18 & 0 & N/A & N/A & N/A \\
\hline
\end{tabular}




\begin{tabular}{|c|c|c|c|c|c|c|c|c|c|c|c|c|}
\hline 5271926 & $\begin{array}{c}3 / 13 / 200 \\
3\end{array}$ & 36 & 12 & 26 & N/A & N/A & 0 & 28 & 24 & N/A & 10 & 0 \\
\hline & & 28 & 36 & 48 & N/A & N/A & 0 & 45 & 38 & N/A & 26 & 0 \\
\hline & & 56 & 0 & 56 & N/A & N/A & 0 & 0 & 0 & N/A & 0 & 28 \\
\hline & & 10 & 0 & 2 & N/A & N/A & 0 & 0 & 0 & N/A & 0 & 0 \\
\hline & & 12 & 0 & 4 & N/A & N/A & 0 & 0 & 0 & N/A & 0 & 0 \\
\hline & & 22 & 0 & 20 & N/A & N/A & 0 & 0 & 0 & N/A & 0 & 0 \\
\hline \multirow[t]{6}{*}{709274} & $3 / 6 / 2003$ & 48 & 24 & N/A & 32 & N/A & 0 & 20 & N/A & 14 & N/A & N/A \\
\hline & & 30 & 0 & N/A & 50 & N/A & 0 & 32 & N/A & 0 & N/A & N/A \\
\hline & & 53 & 30 & N/A & 30 & N/A & 0 & 40 & N/A & 20 & N/A & N/A \\
\hline & & 50 & 10 & N/A & 20 & N/A & 4 & 28 & $\mathrm{~N} / \mathrm{A}$ & 4 & N/A & N/A \\
\hline & & 38 & 12 & N/A & 14 & N/A & 4 & 34 & N/A & 2 & N/A & N/A \\
\hline & & 56 & 12 & N/A & 32 & N/A & 0 & 52 & N/A & 14 & N/A & N/A \\
\hline $\begin{array}{c}\text { machine } \\
\#\end{array}$ & $\begin{array}{l}\text { First } \\
\text { Data } \\
\text { Date }\end{array}$ & Water & $\begin{array}{l}\text { Orang } \\
\text { e Juice }\end{array}$ & $\begin{array}{c}\text { Straw } \\
\text {. Ft. } \\
\text { Wks. }\end{array}$ & $\begin{array}{l}\text { Lemonad } \\
\text { e Ft. Wks. }\end{array}$ & $\begin{array}{c}\text { Fruit } \\
\text { Punch } \\
\text { Ft.Wks. }\end{array}$ & $\begin{array}{l}\text { Diet } \\
\text { Pepsi }\end{array}$ & $\underset{\mathrm{i}}{\text { Peps }}$ & $\begin{array}{c}\text { Pepsi } \\
\text { Othe } \\
\mathbf{r}\end{array}$ & $\begin{array}{l}\text { Mt. } \\
\text { Dew }\end{array}$ & $\begin{array}{c}\text { Mt. } \\
\text { Dew } \\
\text { Other }\end{array}$ & $\begin{array}{c}\text { Isotonic } \\
\mathbf{S}\end{array}$ \\
\hline \multirow[t]{6}{*}{5404744} & $3 / 6 / 2003$ & 66 & N/A & 42 & N/A & N/A & N/A & N/A & 8 & 6 & & \\
\hline & & 92 & N/A & 32 & N/A & N/A & N/A & N/A & 58 & 0 & & \\
\hline & & 108 & N/A & 40 & N/A & N/A & N/A & N/A & 30 & 0 & & \\
\hline & & 108 & N/A & 70 & N/A & N/A & N/A & N/A & 80 & 36 & & \\
\hline & & 58 & N/A & 30 & N/A & N/A & N/A & N/A & 36 & 4 & & \\
\hline & & 108 & N/A & 40 & N/A & N/A & N/A & N/A & 52 & 6 & & \\
\hline \multirow[t]{6}{*}{5271944} & $2 / 6 / 2003$ & 52 & N/A & 0 & 0 & N/A & N/A & 26 & & N/A & 28 & 0 \\
\hline & & 0 & N/A & 0 & 24 & N/A & N/A & 0 & & N/A & 52 & 18 \\
\hline & & 18 & N/A & 0 & 0 & N/A & N/A & 0 & & N/A & 0 & 0 \\
\hline & & 82 & N/A & 0 & 28 & N/A & N/A & 0 & & N/A & 51 & 0 \\
\hline & & 20 & N/A & 0 & 20 & N/A & N/A & 0 & & N/A & 18 & 0 \\
\hline & & 24 & N/A & 0 & 20 & N/A & N/A & 0 & & N/A & 20 & 0 \\
\hline
\end{tabular}




\begin{tabular}{|c|c|c|c|c|c|c|c|c|c|c|c|c|}
\hline 5232681 & $2 / 6 / 2003$ & 10 & 0 & 18 & N/A & N/A & 6 & 32 & 10 & N/A & & \\
\hline & & 8 & 0 & 50 & N/A & N/A & 12 & 54 & 12 & N/A & & \\
\hline & & 28 & 0 & 12 & N/A & N/A & 6 & 16 & 6 & N/A & & \\
\hline & & 6 & 0 & 12 & N/A & N/A & 2 & 6 & 0 & N/A & & \\
\hline & & 0 & 0 & 8 & N/A & N/A & 0 & 12 & 0 & N/A & & \\
\hline \multirow[t]{6}{*}{5444809} & $\begin{array}{c}3 / 13 / 200 \\
3 \\
\end{array}$ & 38 & 0 & 10 & 28 & N/A & 8 & 28 & & 22 & & \\
\hline & & 0 & 0 & 6 & 0 & N/A & 14 & 34 & & 0 & & \\
\hline & & 22 & 20 & 8 & 8 & N/A & 4 & 28 & & 6 & & \\
\hline & & 14 & 7 & 23 & 8 & N/A & 2 & 20 & & 17 & & \\
\hline & & 18 & 0 & 36 & 14 & N/A & 0 & 24 & & 22 & & \\
\hline & & 58 & 12 & 32 & 24 & N/A & 0 & 40 & & 20 & & \\
\hline $\begin{array}{c}\text { machine } \\
\#\end{array}$ & $\begin{array}{l}\text { First } \\
\text { Data } \\
\text { Date }\end{array}$ & Water & $\begin{array}{l}\text { Orang } \\
\text { e Juice }\end{array}$ & $\begin{array}{c}\text { Straw } \\
\text {. Ft. } \\
\text { Wks. }\end{array}$ & $\begin{array}{l}\text { Lemonad } \\
\text { e Ft. Wks. }\end{array}$ & $\begin{array}{c}\text { Fruit } \\
\text { Punch } \\
\text { Ft.Wks. }\end{array}$ & $\begin{array}{l}\text { Diet } \\
\text { Pepsi }\end{array}$ & $\underset{\text { i }}{\text { Peps }}$ & $\begin{array}{l}\text { Pepsi } \\
\text { Othe } \\
\text { r }\end{array}$ & $\begin{array}{l}\text { Mt. } \\
\text { Dew }\end{array}$ & $\begin{array}{c}\text { Mt. } \\
\text { Dew } \\
\text { Other }\end{array}$ & $\begin{array}{c}\text { Isotonic } \\
\mathrm{s}\end{array}$ \\
\hline \multirow[t]{6}{*}{211727} & $\begin{array}{c}3 / 27 / 200 \\
3\end{array}$ & 2 & 0 & 0 & N/A & 10 & 0 & 0 & 0 & 0 & 0 & \\
\hline & & 36 & 12 & 28 & N/A & 0 & 0 & 60 & 24 & 0 & 18 & \\
\hline & & 36 & 20 & 32 & N/A & 0 & 0 & 32 & 26 & 0 & 18 & \\
\hline & & 34 & 0 & 36 & N/A & 0 & 0 & 36 & 18 & 0 & 20 & \\
\hline & & 66 & 0 & 40 & N/A & 0 & 0 & 60 & 34 & 0 & 24 & \\
\hline & & 0 & 12 & 24 & N/A & 0 & 0 & 0 & 0 & 0 & 0 & \\
\hline \multirow[t]{4}{*}{5273517} & $\begin{array}{c}2 / 13 / 200 \\
3 \\
\end{array}$ & 6 & N/A & N/A & N/A & N/A & N/A & N/A & & N/A & & \\
\hline & & 4 & N/A & N/A & N/A & N/A & N/A & N/A & & N/A & & \\
\hline & & 2 & N/A & N/A & N/A & N/A & N/A & N/A & & N/A & & \\
\hline & & 1 & N/A & N/A & N/A & N/A & N/A & N/A & & N/A & & \\
\hline
\end{tabular}




\begin{tabular}{|c|c|c|c|c|c|c|c|c|c|c|c|c|}
\hline & & 2 & N/A & N/A & N/A & N/A & N/A & N/A & & N/A & & \\
\hline & & 2 & N/A & N/A & N/A & N/A & N/A & N/A & & N/A & & \\
\hline 5273262 & $\begin{array}{c}5 / 14 / 200 \\
3\end{array}$ & 0 & N/A & 36 & N/A & N/A & N/A & 44 & 0 & 14 & & \\
\hline & & & & & & & & & & & & \\
\hline $\begin{array}{c}\text { TOTAL } \\
\mathrm{S} \\
\end{array}$ & & 3496 & 425 & 2081 & 659 & 168 & 116 & 2097 & 1379 & 433 & 789 & 439 \\
\hline
\end{tabular}




\section{APPENDIX G}

Santa Maria High School Refill Data (6/1/03-8/30/03)

June 1, 2003 through August 30, 2003

\begin{tabular}{|c|c|c|c|c|c|c|c|c|c|c|c|c|}
\hline $\begin{array}{c}\text { machine } \\
\#\end{array}$ & Water & $\begin{array}{l}\text { Orang } \\
\text { e Juice }\end{array}$ & $\begin{array}{c}\text { Straw. } \\
\text { Ft. } \\
\text { Wks. }\end{array}$ & $\begin{array}{l}\text { Lemonad } \\
\text { e Ft. Wks. }\end{array}$ & $\begin{array}{c}\text { Fruit } \\
\text { Punch } \\
\text { Ft.Wks } \\
\text {. }\end{array}$ & $\begin{array}{l}\text { Diet } \\
\text { Pepsi }\end{array}$ & Pepsi & $\begin{array}{l}\text { Pepsi } \\
\text { Other }\end{array}$ & $\begin{array}{c}\text { Sierra } \\
\text { Mist }\end{array}$ & $\begin{array}{l}\text { Mt. } \\
\text { Dew }\end{array}$ & $\begin{array}{c}\text { Mt.De } \\
\text { w } \\
\text { Other }\end{array}$ & $\begin{array}{c}\text { Isotonic } \\
\mathrm{S} \\
\end{array}$ \\
\hline \multirow[t]{4}{*}{5271877} & 16 & 12 & 20 & N/A & N/A & N/A & 16 & 22 & & N/A & & \\
\hline & 24 & 12 & 28 & N/A & N/A & N/A & 16 & 50 & & N/A & & \\
\hline & 4 & 12 & 0 & N/A & N/A & N/A & 6 & 14 & & N/A & & \\
\hline & 12 & 0 & 0 & N/A & N/A & N/A & 0 & 0 & & N/A & & \\
\hline \multirow[t]{6}{*}{5273268} & 0 & 0 & 24 & 0 & 0 & N/A & 26 & 16 & & 0 & 0 & 0 \\
\hline & 0 & 18 & 20 & 0 & 0 & N/A & 32 & 28 & & 0 & 0 & 0 \\
\hline & 0 & 0 & 16 & 0 & 0 & N/A & 6 & 0 & & 32 & 32 & 0 \\
\hline & 10 & 0 & 22 & 0 & 0 & N/A & 6 & 12 & & 0 & 6 & 0 \\
\hline & 52 & 0 & 48 & 28 & 44 & N/A & 0 & 0 & & 0 & 0 & 0 \\
\hline & 28 & 0 & 42 & 0 & 0 & N/A & 56 & 28 & & 0 & 56 & 0 \\
\hline 5272762 & 29 & 0 & 32 & 11 & 12 & N/A & N/A & N/A & & N/A & N/A & 6 \\
\hline \multirow[t]{4}{*}{5273237} & 38 & N/A & 0 & 20 & N/A & N/A & 0 & 0 & & 10 & 10 & 0 \\
\hline & 46 & N/A & 0 & 24 & N/A & N/A & 0 & 32 & & 18 & 24 & 0 \\
\hline & 84 & N/A & 0 & 48 & N/A & N/A & 0 & 28 & & 42 & 18 & 0 \\
\hline & 0 & N/A & 18 & 10 & N/A & N/A & 0 & 26 & & 10 & 34 & 0 \\
\hline \multirow[t]{3}{*}{5273386} & 78 & N/A & N/A & 44 & N/A & N/A & 0 & 0 & & 20 & 28 & 0 \\
\hline & 17 & N/A & N/A & 24 & N/A & N/A & 0 & 0 & & 4 & 10 & 0 \\
\hline & 30 & N/A & N/A & 0 & N/A & N/A & 0 & 0 & & 38 & 0 & 0 \\
\hline
\end{tabular}




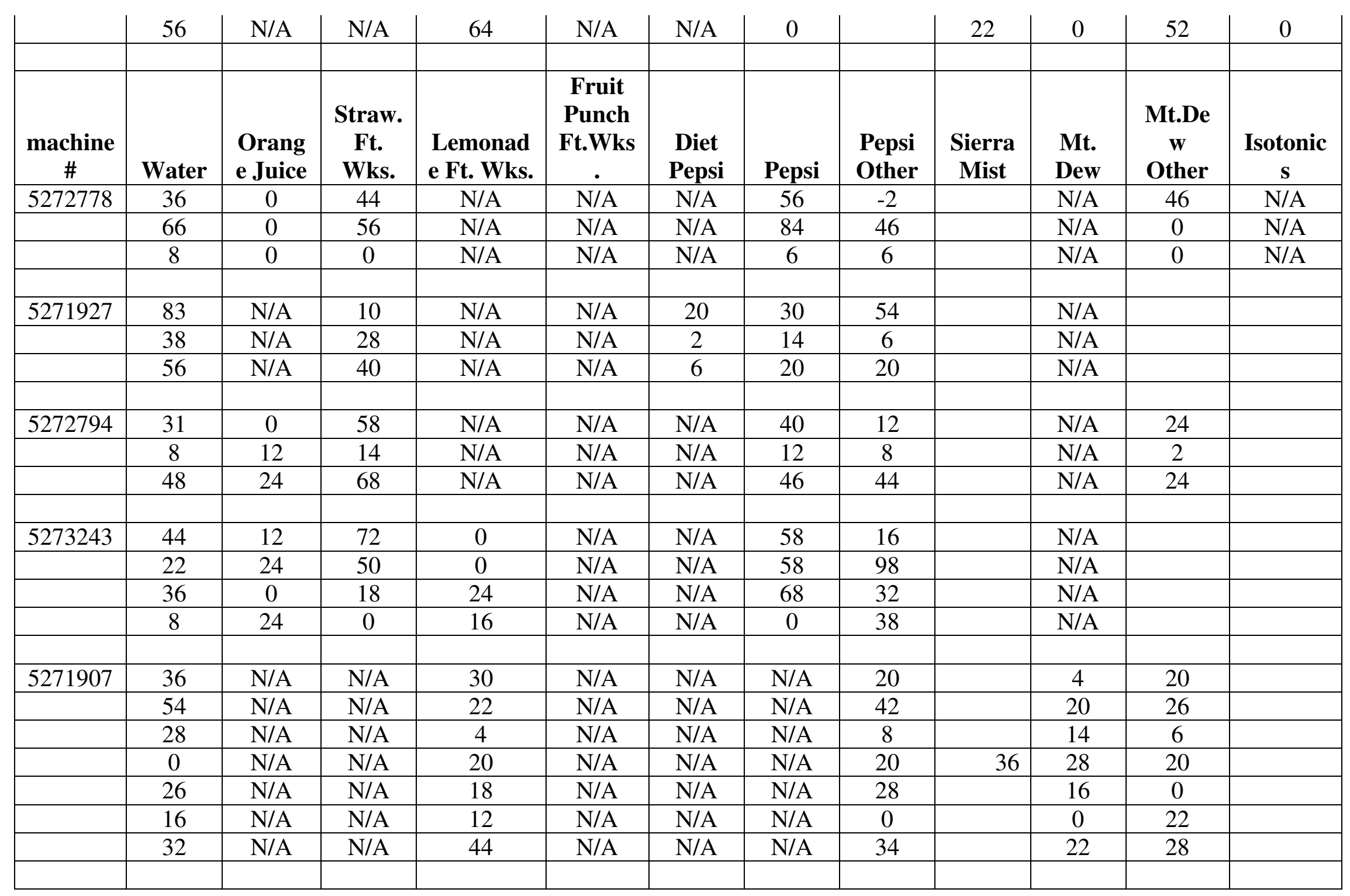




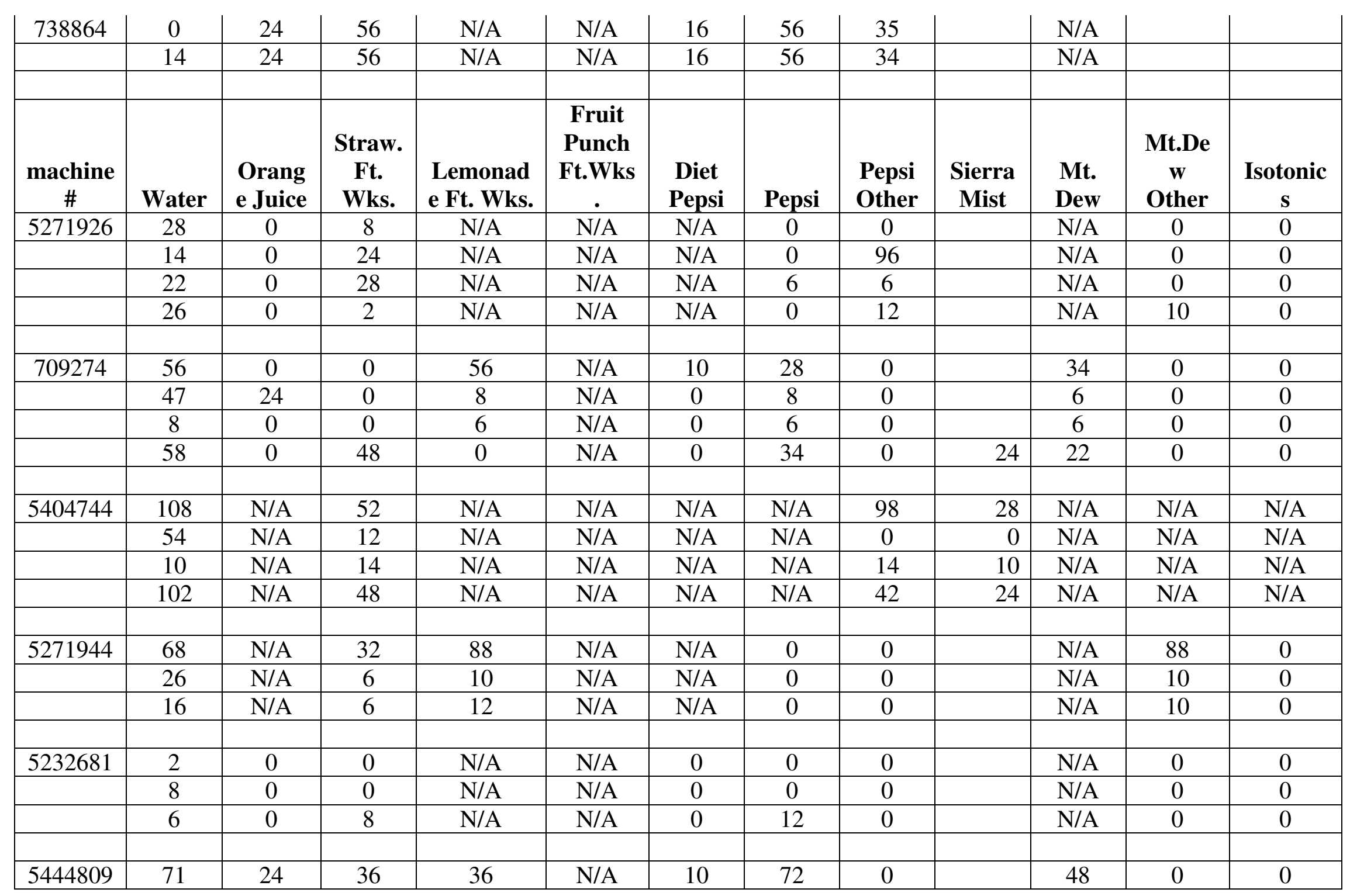




\begin{tabular}{|c|c|c|c|c|c|c|c|c|c|c|c|c|}
\hline & 32 & 12 & 0 & 32 & N/A & 6 & 48 & 0 & & 24 & 0 & 0 \\
\hline & 8 & 0 & 0 & 0 & N/A & 0 & 0 & 0 & & 2 & 0 & 0 \\
\hline & 10 & 0 & 6 & 8 & N/A & 4 & 20 & 0 & & 12 & 0 & 0 \\
\hline & & & & & & & & & & & & \\
\hline $\begin{array}{c}\text { machine } \\
\#\end{array}$ & Water & $\begin{array}{l}\text { Orang } \\
\text { e Juice }\end{array}$ & $\begin{array}{c}\text { Straw. } \\
\text { Ft. } \\
\text { Wks. }\end{array}$ & $\begin{array}{l}\text { Lemonad } \\
\text { e Ft. Wks. }\end{array}$ & $\begin{array}{c}\text { Fruit } \\
\text { Punch } \\
\text { Ft.Wks } \\
\text {. }\end{array}$ & $\begin{array}{l}\text { Diet } \\
\text { Pepsi }\end{array}$ & Pepsi & $\begin{array}{l}\text { Pepsi } \\
\text { Other }\end{array}$ & $\begin{array}{c}\text { Sierra } \\
\text { Mist }\end{array}$ & $\begin{array}{l}\text { Mt. } \\
\text { Dew }\end{array}$ & $\begin{array}{c}\text { Mt.De } \\
\text { w } \\
\text { Other }\end{array}$ & $\begin{array}{c}\text { Isotonic } \\
\mathrm{S}\end{array}$ \\
\hline 211727 & 4 & 0 & 0 & 6 & N/A & 0 & 0 & 0 & & 0 & 0 & 0 \\
\hline & 0 & 16 & 8 & 10 & N/A & 2 & 18 & 0 & & 4 & 0 & 0 \\
\hline & 2 & 0 & 2 & 0 & N/A & 2 & 0 & 0 & & 0 & 0 & 0 \\
\hline & 84 & 0 & 56 & 0 & N/A & 28 & 30 & 56 & & 0 & 0 & 0 \\
\hline 5273517 & 1 & & & & & & & & & & & \\
\hline 3210311 & & & & & & & & & & & & \\
\hline 738864 & 0 & 24 & 56 & & & 16 & 56 & 35 & & & & \\
\hline & 14 & 24 & 56 & & & 16 & 56 & 34 & & & & \\
\hline & & & & & & & & & & & & \\
\hline 5273262 & 22 & & & & & & 28 & 0 & & & & \\
\hline & 0 & & & & & & 12 & 0 & & & & \\
\hline & & & & & & & & & & & & \\
\hline Totals & 2121 & 322 & 1348 & 735 & 56 & 154 & 1202 & 1248 & 144 & 436 & 606 & 6 \\
\hline
\end{tabular}


APPENDIX H

Santa Maria High School Refill Data (9/1/03-1/21/04)

September 1, 2003 through January 21, 2004

\begin{tabular}{|c|c|c|c|c|c|c|c|c|c|c|c|c|c|}
\hline machine \# & First Fill & Water & $\begin{array}{c}\text { Orange } \\
\text { Juice }\end{array}$ & $\begin{array}{c}\text { Straw. } \\
\text { Ft. } \\
\text { Wks. }\end{array}$ & $\begin{array}{l}\text { Lemon- } \\
\text { ade } \\
\text { Ft. Wks. }\end{array}$ & $\begin{array}{c}\text { Fruit } \\
\text { Punch } \\
\text { Ft.Wks. }\end{array}$ & $\begin{array}{c}\text { Diet } \\
\text { Pepsi }\end{array}$ & Pepsi & $\begin{array}{l}\text { Pepsi } \\
\text { Other }\end{array}$ & $\begin{array}{c}\text { Sierra } \\
\text { Mist }\end{array}$ & $\begin{array}{l}\text { Mt. } \\
\text { Dew }\end{array}$ & $\begin{array}{c}\text { Mt. } \\
\text { Dew } \\
\text { Other }\end{array}$ & $\begin{array}{c}\text { Iso- } \\
\text { tonics }\end{array}$ \\
\hline \multirow[t]{7}{*}{5271877} & & 38 & 24 & 40 & 0 & N/A & N/A & 24 & 48 & & N/A & N/A & N/A \\
\hline & & 36 & 12 & 48 & 0 & N/A & N/A & 56 & 58 & & N/A & N/A & N/A \\
\hline & & 12 & 0 & 0 & 0 & N/A & N/A & 0 & 8 & & N/A & N/A & N/A \\
\hline & & 28 & 0 & 32 & 12 & N/A & N/A & 56 & 0 & & 28 & N/A & N/A \\
\hline & & 0 & 0 & 0 & 0 & N/A & N/A & 0 & 2 & & 0 & N/A & N/A \\
\hline & & 30 & 0 & 14 & 0 & N/A & N/A & 14 & 22 & & 0 & N/A & N/A \\
\hline & & 14 & 24 & 50 & 8 & N/A & N/A & 24 & 34 & & 0 & N/A & N/A \\
\hline \multirow[t]{8}{*}{5273237} & & 66 & N/A & 0 & 24 & $\mathrm{~N} / \mathrm{A}$ & N/A & N/A & 0 & & 56 & 54 & N/A \\
\hline & & 84 & N/A & 28 & 28 & N/A & N/A & N/A & 28 & & 56 & 56 & N/A \\
\hline & & 72 & N/A & 28 & 28 & N/A & N/A & N/A & 28 & & 56 & 56 & N/A \\
\hline & & 28 & N/A & 14 & 16 & N/A & N/A & N/A & 24 & & 8 & 10 & N/A \\
\hline & & 12 & N/A & 4 & 4 & N/A & N/A & N/A & 6 & & 10 & 0 & N/A \\
\hline & & 22 & N/A & 0 & 12 & N/A & N/A & N/A & 6 & & 8 & 12 & N/A \\
\hline & & 22 & N/A & 8 & 8 & N/A & N/A & N/A & 0 & & 40 & 12 & N/A \\
\hline & & 40 & N/A & 18 & 6 & N/A & N/A & N/A & 0 & & 48 & 12 & N/A \\
\hline \multirow[t]{7}{*}{5273268} & & 84 & N/A & 28 & 0 & 0 & N/A & 26 & 28 & & 56 & 56 & N/A \\
\hline & & 28 & N/A & 30 & 0 & 0 & N/A & 32 & 14 & & 0 & 16 & N/A \\
\hline & & 72 & N/A & 36 & 36 & 0 & N/A & 64 & 0 & & 48 & 0 & N/A \\
\hline & & 28 & N/A & 52 & 0 & 0 & N/A & 56 & 28 & & 0 & 56 & N/A \\
\hline & & 28 & N/A & 30 & 0 & 0 & N/A & 30 & 28 & & 30 & 26 & N/A \\
\hline & & 28 & N/A & 48 & 0 & 0 & N/A & 34 & 24 & & 0 & 32 & N/A \\
\hline & & 6 & N/A & 12 & 0 & 0 & N/A & 8 & 12 & & 0 & 6 & N/A \\
\hline
\end{tabular}




\begin{tabular}{|c|c|c|c|c|c|c|c|c|c|c|c|c|c|}
\hline & & 24 & N/A & 12 & 0 & 0 & N/A & 22 & 18 & & 0 & 16 & N/A \\
\hline & & 20 & N/A & 12 & 0 & N/A & N/A & 24 & 12 & & 0 & 8 & N/A \\
\hline \multirow[t]{3}{*}{ machine \# } & First Fill & Water & $\begin{array}{c}\text { Orange } \\
\text { Juice }\end{array}$ & $\begin{array}{c}\text { Straw. } \\
\text { Ft. } \\
\text { Wks. }\end{array}$ & $\begin{array}{c}\text { Lemonade } \\
\text { Ft. Wks. }\end{array}$ & $\begin{array}{c}\text { Fruit } \\
\text { Punch } \\
\text { Ft.Wks. }\end{array}$ & $\begin{array}{l}\text { Diet } \\
\text { Pepsi }\end{array}$ & Pepsi & $\begin{array}{l}\text { Pepsi } \\
\text { Other }\end{array}$ & $\begin{array}{c}\text { Sierra } \\
\text { Mist }\end{array}$ & $\begin{array}{l}\text { Mt. } \\
\text { Dew }\end{array}$ & $\begin{array}{c}\text { Mt. } \\
\text { Dew } \\
\text { Other }\end{array}$ & Isotonics \\
\hline & & 6 & N/A & 26 & 0 & N/A & N/A & 36 & 0 & & 30 & 0 & N/A \\
\hline & & 6 & N/A & 2 & 0 & N/A & N/A & 0 & 2 & & 2 & 0 & N/A \\
\hline \multirow[t]{9}{*}{5272762} & & 42 & 0 & 40 & 31 & 42 & N/A & N/A & 0 & & N/A & N/A & 14 \\
\hline & & 56 & 0 & 56 & 0 & 56 & N/A & N/A & 0 & & N/A & N/A & 24 \\
\hline & & 56 & 0 & 56 & 0 & 24 & N/A & N/A & 0 & & N/A & N/A & 24 \\
\hline & & 18 & 0 & 44 & 0 & 28 & N/A & N/A & 0 & & N/A & N/A & 14 \\
\hline & & 17 & 0 & 56 & 0 & 28 & N/A & N/A & 0 & & N/A & N/A & 28 \\
\hline & & 36 & N/A & 0 & 0 & 56 & N/A & 0 & 0 & & 0 & 0 & 28 \\
\hline & & 28 & N/A & 56 & 6 & 56 & N/A & 0 & 0 & & 0 & 0 & 14 \\
\hline & & 34 & N/A & 54 & 0 & 0 & N/A & 56 & 32 & & 22 & 12 & 0 \\
\hline & & 49 & N/A & 0 & 18 & 0 & N/A & 0 & 0 & & 37 & 12 & 0 \\
\hline \multirow[t]{13}{*}{5273386} & & 84 & N/A & N/A & 56 & N/A & N/A & N/A & 0 & & 56 & 0 & 0 \\
\hline & & 28 & N/A & N/A & 0 & N/A & N/A & N/A & 0 & & 56 & 4 & 0 \\
\hline & & 28 & N/A & N/A & 12 & N/A & N/A & N/A & 0 & & 8 & 2 & 0 \\
\hline & & 28 & N/A & N/A & 28 & N/A & N/A & N/A & 0 & & 56 & 0 & 0 \\
\hline & & 28 & N/A & N/A & 0 & N/A & N/A & N/A & 0 & & 56 & 0 & 0 \\
\hline & & 12 & N/A & N/A & 0 & N/A & N/A & N/A & 0 & & 14 & 8 & 0 \\
\hline & & 28 & N/A & N/A & 0 & N/A & N/A & N/A & 0 & & 56 & 0 & 0 \\
\hline & & 28 & N/A & N/A & 0 & N/A & N/A & N/A & 0 & & 56 & 0 & 0 \\
\hline & & 28 & N/A & N/A & 0 & N/A & N/A & N/A & 0 & & 56 & 6 & 0 \\
\hline & & 20 & N/A & N/A & 0 & N/A & N/A & N/A & 0 & & 28 & 0 & 0 \\
\hline & & 16 & N/A & N/A & 0 & N/A & N/A & N/A & 0 & & 30 & 4 & 0 \\
\hline & & 2 & N/A & N/A & 0 & N/A & N/A & N/A & 0 & 0 & 0 & 0 & 0 \\
\hline & & & & & & & & & & & & & \\
\hline
\end{tabular}




\begin{tabular}{|c|c|c|c|c|c|c|c|c|c|c|c|c|c|}
\hline 5273517 & & 20 & N/A & 43 & N/A & N/A & N/A & 20 & 34 & & N/A & 0 & 0 \\
\hline & & 4 & N/A & 0 & N/A & N/A & N/A & 0 & 0 & & N/A & 0 & 0 \\
\hline & & 4 & N/A & 0 & N/A & N/A & N/A & 0 & 0 & & N/A & 0 & 0 \\
\hline machine \# & First Fill & Water & $\begin{array}{c}\text { Orange } \\
\text { Juice }\end{array}$ & $\begin{array}{c}\text { Straw. } \\
\text { Ft. } \\
\text { Wks. }\end{array}$ & $\begin{array}{c}\text { Lemonade } \\
\text { Ft. Wks. }\end{array}$ & $\begin{array}{c}\text { Fruit } \\
\text { Punch } \\
\text { Ft.Wks. }\end{array}$ & $\begin{array}{l}\text { Diet } \\
\text { Pepsi }\end{array}$ & Pepsi & $\begin{array}{l}\text { Pepsi } \\
\text { Other }\end{array}$ & $\begin{array}{c}\text { Sierra } \\
\text { Mist }\end{array}$ & $\begin{array}{l}\text { Mt. } \\
\text { Dew }\end{array}$ & $\begin{array}{c}\text { Mt. } \\
\text { Dew } \\
\text { Other }\end{array}$ & Isotonics \\
\hline \multirow[t]{7}{*}{5272778} & & 29 & 0 & 24 & N/A & N/A & N/A & 72 & 0 & & N/A & 32 & N/A \\
\hline & & 32 & 12 & 20 & N/A & N/A & N/A & 44 & 16 & & N/A & 12 & N/A \\
\hline & & 20 & 0 & 24 & N/A & N/A & N/A & 36 & 0 & & N/A & 20 & N/A \\
\hline & & 20 & 0 & 16 & N/A & N/A & N/A & 24 & 0 & & N/A & 6 & N/A \\
\hline & & 14 & 0 & 18 & N/A & N/A & N/A & 54 & 16 & & N/A & 6 & N/A \\
\hline & & 18 & 0 & 0 & N/A & N/A & N/A & 48 & 0 & & N/A & 0 & N/A \\
\hline & & 14 & 0 & 32 & N/A & N/A & N/A & 18 & 12 & & N/A & 16 & N/A \\
\hline \multirow{9}{*}{5271927} & & 78 & $\mathrm{~N} / \mathrm{A}$ & 28 & 0 & 0 & 14 & 0 & 28 & & $N / \Delta$ & $\mathrm{N} / \mathrm{A}$ & $\mathrm{N} / \mathrm{A}$ \\
\hline & & 80 & N/A & 56 & 0 & 0 & 12 & 27 & 56 & & N/A & N/A & N/A \\
\hline & & 58 & N/A & 32 & 0 & 0 & 14 & 34 & 28 & & N/A & N/A & N/A \\
\hline & & 2 & N/A & 2 & 0 & 0 & 0 & 4 & 0 & & N/A & N/A & N/A \\
\hline & & 28 & N/A & 56 & 12 & 42 & 0 & 0 & 0 & & N/A & N/A & N/A \\
\hline & & 84 & N/A & 28 & 0 & 0 & 28 & 28 & 56 & & N/A & N/A & N/A \\
\hline & & 84 & N/A & 56 & 0 & 0 & 28 & 28 & 56 & & N/A & N/A & N/A \\
\hline & & 84 & N/A & 56 & 0 & 0 & 28 & 50 & 56 & & N/A & N/A & N/A \\
\hline & & 52 & N/A & 44 & 0 & 0 & 6 & 24 & 20 & & N/A & N/A & N/A \\
\hline \multirow[t]{6}{*}{5272794} & & 64 & 36 & 71 & N/A & N/A & N/A & 72 & 56 & & N/A & 29 & N/A \\
\hline & & 48 & 12 & 40 & N/A & N/A & N/A & 56 & 32 & & N/A & 23 & N/A \\
\hline & & 40 & 0 & 30 & N/A & N/A & N/A & 32 & 0 & & N/A & 14 & N/A \\
\hline & & 6 & 12 & 0 & N/A & N/A & N/A & 14 & 0 & & N/A & 6 & N/A \\
\hline & & 2 & 0 & 6 & N/A & N/A & N/A & 0 & 0 & & N/A & 0 & N/A \\
\hline & & 14 & 24 & 16 & N/A & N/A & N/A & 14 & 30 & & N/A & 0 & N/A \\
\hline
\end{tabular}




\begin{tabular}{|c|c|c|c|c|c|c|c|c|c|c|c|c|c|}
\hline & & 10 & 0 & 8 & N/A & N/A & N/A & 20 & 6 & & N/A & 8 & N/A \\
\hline & & 34 & 0 & 16 & N/A & N/A & N/A & 30 & 18 & & N/A & 14 & N/A \\
\hline & & 6 & 0 & 18 & N/A & N/A & N/A & 14 & 4 & & N/A & 10 & N/A \\
\hline & & 18 & 12 & 8 & N/A & N/A & N/A & 36 & 12 & & N/A & 16 & N/A \\
\hline \multirow[t]{4}{*}{ machine \# } & First Fill & Water & $\begin{array}{c}\text { Orange } \\
\text { Juice }\end{array}$ & $\begin{array}{c}\text { Straw. } \\
\text { Ft. } \\
\text { Wks. }\end{array}$ & $\begin{array}{c}\text { Lemonade } \\
\text { Ft. Wks. }\end{array}$ & $\begin{array}{c}\text { Fruit } \\
\text { Punch } \\
\text { Ft.Wks. }\end{array}$ & $\begin{array}{l}\text { Diet } \\
\text { Pepsi }\end{array}$ & Pepsi & $\begin{array}{l}\text { Pepsi } \\
\text { Other }\end{array}$ & $\begin{array}{c}\text { Sierra } \\
\text { Mist }\end{array}$ & $\begin{array}{l}\text { Mt. } \\
\text { Dew }\end{array}$ & $\begin{array}{l}\text { Mt. } \\
\text { Dew } \\
\text { Other }\end{array}$ & Isotonics \\
\hline & & 28 & 0 & 0 & N/A & N/A & N/A & 20 & 0 & & N/A & 10 & N/A \\
\hline & & 36 & 24 & 54 & N/A & N/A & N/A & 54 & 14 & & N/A & 16 & N/A \\
\hline & & 44 & 0 & 56 & N/A & N/A & N/A & 64 & 0 & & N/A & 30 & N/A \\
\hline \multirow[t]{16}{*}{5271907} & & 28 & N/A & N/A & 56 & N/A & N/A & 0 & 40 & & 26 & 22 & N/A \\
\hline & & 28 & N/A & N/A & 16 & N/A & N/A & 44 & 0 & & 20 & 12 & N/A \\
\hline & & 28 & N/A & N/A & 22 & N/A & N/A & 8 & 0 & & 28 & 20 & N/A \\
\hline & & 28 & N/A & N/A & 30 & N/A & N/A & 14 & 0 & & 28 & 40 & N/A \\
\hline & & 28 & N/A & N/A & 28 & N/A & N/A & 0 & 0 & & 20 & 16 & N/A \\
\hline & & 4 & N/A & N/A & 0 & N/A & N/A & 0 & 4 & & 2 & 2 & N/A \\
\hline & & 28 & N/A & N/A & 40 & N/A & N/A & 0 & 0 & & 28 & 36 & N/A \\
\hline & & 28 & N/A & N/A & 22 & N/A & N/A & 8 & 0 & & 20 & 24 & N/A \\
\hline & & 54 & N/A & N/A & 56 & N/A & N/A & 28 & 0 & & 26 & 56 & N/A \\
\hline & & 0 & N/A & N/A & 0 & N/A & N/A & 0 & 0 & & 12 & 0 & N/A \\
\hline & & 60 & N/A & N/A & 14 & N/A & N/A & 0 & 0 & & 10 & 24 & N/A \\
\hline & & 38 & N/A & N/A & 20 & N/A & N/A & 0 & 0 & & 12 & 22 & N/A \\
\hline & & 24 & N/A & N/A & 24 & N/A & N/A & 8 & 0 & & 24 & 24 & N/A \\
\hline & & 32 & N/A & N/A & 22 & N/A & N/A & 0 & 0 & & 10 & 12 & N/A \\
\hline & & 40 & N/A & N/A & 28 & N/A & N/A & 0 & 0 & & 16 & 26 & N/A \\
\hline & & 44 & N/A & N/A & 38 & N/A & N/A & 0 & 0 & & 24 & 26 & N/A \\
\hline \multirow[t]{3}{*}{5273243} & & 72 & 0 & 72 & 0 & N/A & N/A & 72 & 72 & & N/A & N/A & N/A \\
\hline & & 44 & 12 & 40 & 0 & N/A & N/A & 36 & 60 & & N/A & N/A & N/A \\
\hline & & 72 & 0 & 58 & 0 & N/A & N/A & 60 & 58 & & N/A & N/A & N/A \\
\hline
\end{tabular}




\begin{tabular}{|c|c|c|c|c|c|c|c|c|c|c|c|c|c|}
\hline & & 62 & 0 & 70 & 0 & N/A & N/A & 64 & 36 & & N/A & N/A & N/A \\
\hline & & 60 & 0 & 40 & 0 & N/A & N/A & 44 & 36 & & N/A & N/A & N/A \\
\hline & & 64 & 0 & 72 & 0 & N/A & N/A & 72 & 36 & & N/A & N/A & N/A \\
\hline & & 58 & 0 & 62 & 0 & N/A & N/A & 56 & 74 & & N/A & N/A & N/A \\
\hline & & 42 & 0 & 54 & N/A & N/A & N/A & 56 & 50 & & N/A & N/A & N/A \\
\hline \multirow[t]{9}{*}{ machine \# } & First Fill & Water & $\begin{array}{l}\text { Orange } \\
\text { Juice }\end{array}$ & $\begin{array}{c}\text { Straw. } \\
\text { Ft. } \\
\text { Wks. }\end{array}$ & $\begin{array}{l}\text { Lemonade } \\
\text { Ft. Wks. }\end{array}$ & $\begin{array}{c}\text { Fruit } \\
\text { Punch } \\
\text { Ft.Wks. }\end{array}$ & $\begin{array}{l}\text { Diet } \\
\text { Pepsi }\end{array}$ & Pepsi & $\begin{array}{l}\text { Pepsi } \\
\text { Other }\end{array}$ & $\begin{array}{l}\text { Sierra } \\
\text { Mist }\end{array}$ & $\begin{array}{l}\text { Mt. } \\
\text { Dew }\end{array}$ & $\begin{array}{l}\text { Mt. } \\
\text { Dew } \\
\text { Other }\end{array}$ & Isotonics \\
\hline & & 4 & 0 & 8 & N/A & N/A & N/A & 12 & 14 & & N/A & N/A & N/A \\
\hline & & 38 & 0 & 46 & N/A & N/A & N/A & 48 & 64 & & N/A & N/A & N/A \\
\hline & & 30 & 12 & 30 & N/A & N/A & N/A & 32 & 50 & & N/A & N/A & N/A \\
\hline & & 26 & 0 & 24 & N/A & N/A & N/A & 48 & 32 & & N/A & N/A & N/A \\
\hline & & 22 & 12 & 28 & N/A & N/A & N/A & 28 & 68 & & N/A & N/A & N/A \\
\hline & & 20 & 12 & 32 & N/A & N/A & N/A & 28 & 32 & & N/A & N/A & N/A \\
\hline & & 26 & 0 & 32 & N/A & N/A & N/A & 58 & 56 & & N/A & N/A & N/A \\
\hline & & 28 & 0 & 64 & N/A & N/A & N/A & 72 & 76 & & N/A & N/A & N/A \\
\hline \multirow[t]{6}{*}{5232681} & & 51 & 0 & 40 & N/A & N/A & 10 & 52 & 42 & & N/A & N/A & N/A \\
\hline & & 20 & 0 & 22 & N/A & N/A & 0 & 26 & 0 & & N/A & N/A & N/A \\
\hline & & 36 & 12 & 0 & N/A & N/A & 4 & 36 & 0 & & N/A & N/A & N/A \\
\hline & & 8 & 0 & 8 & N/A & N/A & 0 & 8 & 40 & & N/A & N/A & N/A \\
\hline & & 6 & 0 & 4 & N/A & N/A & 0 & 12 & 6 & & N/A & N/A & N/A \\
\hline & & 22 & 0 & 30 & N/A & N/A & 0 & 32 & 16 & & N/A & N/A & N/A \\
\hline \multirow[t]{7}{*}{5271944} & & 48 & N/A & 12 & 0 & N/A & N/A & N/A & 18 & & N/A & 0 & N/A \\
\hline & & 14 & N/A & 6 & 10 & N/A & N/A & N/A & 0 & & N/A & 14 & N/A \\
\hline & & 24 & N/A & 32 & 0 & N/A & N/A & N/A & 14 & & N/A & 0 & N/A \\
\hline & & 22 & N/A & 9 & 20 & N/A & N/A & N/A & 0 & & N/A & 26 & N/A \\
\hline & & 20 & N/A & 12 & 12 & N/A & N/A & N/A & 0 & & N/A & 22 & N/A \\
\hline & & 0 & N/A & 12 & 12 & N/A & N/A & N/A & 0 & 26 & N/A & 10 & N/A \\
\hline & & & & & & & & & & & & & \\
\hline
\end{tabular}




\begin{tabular}{|c|c|c|c|c|c|c|c|c|c|c|c|c|c|}
\hline 1111 & $10 / 9 / 2003$ & 158 & N/A & 148 & 74 & 0 & N/A & N/A & N/A & & N/A & N/A & N/A \\
\hline 5273262 & & 0 & N/A & 26 & N/A & N/A & N/A & 29 & 0 & & 22 & N/A & N/A \\
\hline \multirow[t]{2}{*}{5238719} & $9 / 11 / 2003$ & 56 & 0 & N/A & 56 & N/A & N/A & N/A & 55 & & 28 & 55 & N/A \\
\hline & & 32 & 0 & N/A & 56 & N/A & N/A & N/A & 55 & & 28 & 50 & N/A \\
\hline \multirow[t]{7}{*}{ machine \# } & First Fill & Water & $\begin{array}{c}\text { Orange } \\
\text { Juice }\end{array}$ & $\begin{array}{c}\text { Straw. } \\
\text { Ft. } \\
\text { Wks. }\end{array}$ & $\begin{array}{c}\text { Lemonade } \\
\text { Ft. Wks. }\end{array}$ & $\begin{array}{c}\text { Fruit } \\
\text { Punch } \\
\text { Ft.Wks. }\end{array}$ & $\begin{array}{c}\text { Diet } \\
\text { Pepsi }\end{array}$ & Pepsi & $\begin{array}{l}\text { Pepsi } \\
\text { Other }\end{array}$ & $\begin{array}{c}\text { Sierra } \\
\text { Mist }\end{array}$ & $\begin{array}{l}\text { Mt. } \\
\text { Dew }\end{array}$ & $\begin{array}{c}\text { Mt. } \\
\text { Dew } \\
\text { Other }\end{array}$ & Isotonics \\
\hline & & 20 & 24 & N/A & 0 & N/A & N/A & N/A & 28 & & 28 & 56 & N/A \\
\hline & & 54 & 24 & N/A & 56 & N/A & N/A & N/A & 30 & & 28 & 30 & N/A \\
\hline & & 0 & 16 & N/A & 22 & N/A & N/A & N/A & 46 & & 23 & 24 & N/A \\
\hline & & 50 & 0 & N/A & 26 & N/A & N/A & N/A & 30 & & 6 & 60 & N/A \\
\hline & & 12 & 24 & N/A & 22 & N/A & N/A & N/A & 24 & & 8 & 24 & N/A \\
\hline & & 48 & 0 & N/A & 56 & N/A & N/A & N/A & 56 & & 28 & 56 & N/A \\
\hline \multirow[t]{13}{*}{5404744} & & 18 & N/A & 2 & 8 & N/A & N/A & N/A & 0 & & N/A & 4 & N/A \\
\hline & & 0 & N/A & 2 & 6 & N/A & N/A & N/A & 0 & & N/A & 0 & N/A \\
\hline & & 108 & N/A & 56 & 0 & N/A & N/A & N/A & 56 & 24 & N/A & 0 & N/A \\
\hline & & 42 & N/A & 40 & 0 & N/A & N/A & N/A & 34 & 24 & N/A & 0 & N/A \\
\hline & & 22 & N/A & 4 & 12 & N/A & N/A & N/A & 0 & 20 & N/A & 10 & N/A \\
\hline & & 66 & N/A & 60 & 0 & N/A & N/A & N/A & 30 & 8 & N/A & 0 & N/A \\
\hline & & 38 & N/A & 32 & 0 & N/A & N/A & N/A & 18 & 12 & N/A & 0 & N/A \\
\hline & & 26 & N/A & 6 & 0 & N/A & N/A & N/A & 0 & & N/A & 0 & N/A \\
\hline & & 34 & N/A & 22 & 0 & N/A & N/A & N/A & 6 & 10 & N/A & 0 & N/A \\
\hline & & 44 & N/A & 22 & 0 & N/A & N/A & N/A & 4 & 24 & N/A & 0 & N/A \\
\hline & & 36 & N/A & 0 & 0 & N/A & N/A & N/A & 10 & & N/A & 0 & N/A \\
\hline & & 28 & N/A & 34 & 0 & N/A & N/A & N/A & 32 & & N/A & 0 & N/A \\
\hline & & 36 & N/A & 20 & 0 & N/A & N/A & N/A & 32 & & N/A & 0 & N/A \\
\hline
\end{tabular}




\begin{tabular}{|c|c|c|c|c|c|c|c|c|c|c|c|c|c|}
\hline 5272773 & $9 / 11 / 2003$ & 83 & N/A & 56 & N/A & N/A & N/A & 84 & 28 & & N/A & N/A & N/A \\
\hline & & 84 & N/A & 56 & N/A & N/A & N/A & 84 & 0 & & N/A & N/A & N/A \\
\hline & & 48 & N/A & 56 & N/A & N/A & N/A & 84 & 0 & & N/A & N/A & N/A \\
\hline & & 68 & N/A & 56 & N/A & N/A & N/A & 84 & 56 & & N/A & $\mathrm{N} / \mathrm{A}$ & N/A \\
\hline & & 0 & N/A & 20 & N/A & N/A & N/A & 54 & 24 & & N/A & N/A & N/A \\
\hline & & 72 & N/A & 0 & N/A & N/A & N/A & 84 & 0 & & N/A & N/A & N/A \\
\hline & & 18 & N/A & 56 & N/A & N/A & N/A & 50 & 0 & & N/A & N/A & N/A \\
\hline \multirow[t]{2}{*}{ machine \# } & First Fill & Water & $\begin{array}{c}\text { Orange } \\
\text { Juice }\end{array}$ & $\begin{array}{c}\text { Straw. } \\
\text { Ft. } \\
\text { Wks. }\end{array}$ & $\begin{array}{c}\text { Lemonade } \\
\text { Ft. Wks. }\end{array}$ & $\begin{array}{c}\text { Fruit } \\
\text { Punch } \\
\text { Ft.Wks. }\end{array}$ & $\begin{array}{l}\text { Diet } \\
\text { Pepsi }\end{array}$ & Pepsi & $\begin{array}{l}\text { Pepsi } \\
\text { Other }\end{array}$ & $\begin{array}{l}\text { Sierra } \\
\text { Mist }\end{array}$ & $\begin{array}{l}\text { Mt. } \\
\text { Dew }\end{array}$ & $\begin{array}{l}\text { Mt. } \\
\text { Dew } \\
\text { Other }\end{array}$ & Isotonics \\
\hline & & 18 & N/A & 22 & N/A & N/A & N/A & 48 & 0 & & N/A & N/A & N/A \\
\hline \multirow[t]{9}{*}{5444809} & & 0 & 0 & 0 & 0 & N/A & 0 & 1 & N/A & & 0 & N/A & N/A \\
\hline & & 72 & 36 & 36 & 36 & N/A & 27 & 52 & N/A & & 72 & N/A & N/A \\
\hline & & 72 & 24 & 34 & 36 & N/A & 36 & 64 & N/A & & 72 & N/A & N/A \\
\hline & & 42 & 0 & 26 & 6 & N/A & 0 & 44 & N/A & & 38 & N/A & N/A \\
\hline & & 61 & 0 & 36 & 30 & N/A & 0 & 72 & N/A & & 48 & N/A & N/A \\
\hline & & 72 & 0 & 0 & 14 & N/A & 12 & 68 & N/A & & 36 & N/A & N/A \\
\hline & & 16 & 24 & 36 & 12 & N/A & 0 & 46 & N/A & & 42 & N/A & N/A \\
\hline & & 16 & 0 & 22 & 14 & N/A & 16 & 30 & N/A & & 28 & N/A & N/A \\
\hline & & 35 & 0 & 20 & 16 & N/A & 16 & 64 & N/A & & 18 & N/A & N/A \\
\hline \multirow[t]{8}{*}{5272794} & & 64 & 36 & 71 & N/A & N/A & N/A & 72 & & & N/A & N/A & N/A \\
\hline & & 48 & 12 & 40 & N/A & N/A & N/A & 56 & & & N/A & $\mathrm{N} / \mathrm{A}$ & N/A \\
\hline & & 40 & 0 & 30 & N/A & N/A & N/A & 32 & & & N/A & N/A & N/A \\
\hline & & 6 & 12 & 0 & N/A & N/A & N/A & 14 & & & N/A & N/A & N/A \\
\hline & & 2 & 0 & 6 & N/A & N/A & N/A & 0 & & & N/A & N/A & N/A \\
\hline & & 14 & 24 & 16 & N/A & N/A & N/A & 14 & & & N/A & N/A & N/A \\
\hline & & 10 & 0 & 8 & N/A & N/A & N/A & 20 & & & N/A & N/A & N/A \\
\hline & & 34 & 0 & 16 & N/A & N/A & N/A & 30 & & & N/A & N/A & N/A \\
\hline
\end{tabular}




\begin{tabular}{|c|c|c|c|c|c|c|c|c|c|c|c|c|c|}
\hline & & 6 & 0 & 18 & N/A & N/A & N/A & 14 & & & N/A & N/A & N/A \\
\hline & & 18 & 12 & 8 & N/A & N/A & N/A & 32 & & & N/A & N/A & N/A \\
\hline & & & & & & & & & & & & & \\
\hline \multirow[t]{4}{*}{738864} & & 0 & 0 & 0 & 14 & N/A & 0 & 26 & 0 & & N/A & N/A & N/A \\
\hline & & 0 & 24 & 56 & 0 & N/A & 24 & 56 & 56 & & N/A & N/A & N/A \\
\hline & & 0 & 0 & 56 & 0 & N/A & 12 & 28 & 13 & & N/A & N/A & N/A \\
\hline & & 0 & 24 & 34 & 0 & N/A & 0 & 26 & 56 & & N/A & N/A & N/A \\
\hline & & & & & & & & & & & & & \\
\hline machine \# & First Fill & Water & $\begin{array}{c}\text { Orange } \\
\text { Juice }\end{array}$ & $\begin{array}{c}\text { Straw. } \\
\text { Ft. } \\
\text { Wks. }\end{array}$ & $\begin{array}{l}\text { Lemonade } \\
\text { Ft. Wks. }\end{array}$ & $\begin{array}{c}\text { Fruit } \\
\text { Punch } \\
\text { Ft.Wks. }\end{array}$ & $\begin{array}{c}\text { Diet } \\
\text { Pepsi }\end{array}$ & Pepsi & $\begin{array}{l}\text { Pepsi } \\
\text { Other }\end{array}$ & $\begin{array}{l}\text { Sierra } \\
\text { Mist }\end{array}$ & $\begin{array}{l}\text { Mt. } \\
\text { Dew }\end{array}$ & $\begin{array}{c}\text { Mt. } \\
\text { Dew } \\
\text { Other }\end{array}$ & Isotonics \\
\hline \multirow[t]{6}{*}{5271926} & & 36 & N/A & 4 & N/A & N/A & N/A & N/A & 26 & & N/A & 18 & N/A \\
\hline & & 60 & N/A & 16 & N/A & N/A & N/A & N/A & 8 & & N/A & 4 & N/A \\
\hline & & 34 & N/A & 0 & N/A & N/A & N/A & N/A & 0 & & N/A & 0 & N/A \\
\hline & & 36 & N/A & 10 & N/A & N/A & N/A & N/A & 0 & & N/A & 0 & N/A \\
\hline & & 71 & N/A & 0 & N/A & N/A & N/A & N/A & 0 & & N/A & 0 & N/A \\
\hline & & 20 & N/A & 0 & N/A & N/A & N/A & N/A & 56 & & N/A & 14 & N/A \\
\hline \multirow[t]{12}{*}{709274} & $9 / 11 / 2003$ & 56 & & & 36 & & 0 & 40 & N/A & & 24 & N/A & N/A \\
\hline & & 56 & & & 54 & & 0 & 28 & N/A & & 42 & N/A & N/A \\
\hline & & 56 & & & 56 & & 0 & 56 & N/A & & 56 & N/A & N/A \\
\hline & & 88 & & & 35 & & 14 & 0 & N/A & & 32 & N/A & N/A \\
\hline & & 38 & & & 20 & & 0 & 32 & N/A & & 20 & N/A & N/A \\
\hline & & 66 & & & 12 & & 0 & 24 & N/A & & 16 & N/A & N/A \\
\hline & & 66 & & & 20 & & 0 & 24 & N/A & & 16 & N/A & N/A \\
\hline & & 48 & & & 10 & & 0 & 16 & N/A & & 10 & N/A & N/A \\
\hline & & 18 & & & 12 & & 0 & 26 & N/A & & 12 & N/A & N/A \\
\hline & & 14 & & & 0 & & 0 & 10 & N/A & & 0 & N/A & N/A \\
\hline & & 24 & & & 14 & & 0 & 24 & N/A & & 10 & N/A & N/A \\
\hline & & 42 & & & 16 & & 0 & 28 & N/A & & 14 & N/A & N/A \\
\hline
\end{tabular}




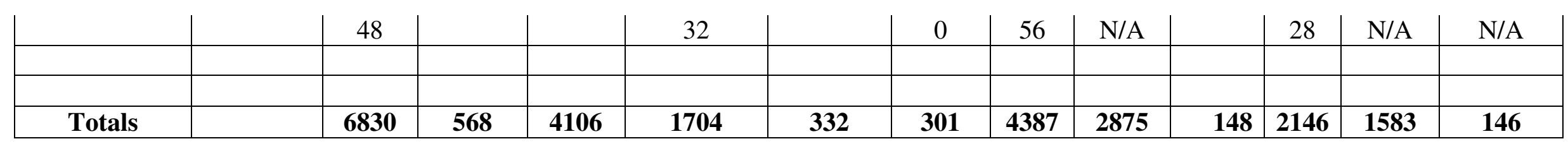


APPENDIX I

Righetti High School Refill Data (2/2/03-5/31/03)

February 2, 2003 through May 31, 2003

\begin{tabular}{|c|c|c|c|c|c|c|c|c|c|c|c|c|}
\hline $\begin{array}{c}\text { Machine } \\
\#\end{array}$ & \begin{tabular}{|c|} 
First \\
Data \\
Available
\end{tabular} & Water & $\begin{array}{c}\text { Orange } \\
\text { Juice }\end{array}$ & $\begin{array}{c}\text { Straw. } \\
\text { Ft. } \\
\text { Wks. }\end{array}$ & $\begin{array}{c}\text { Lemon } \\
\text { Ft. } \\
\text { Wks. }\end{array}$ & $\begin{array}{c}\text { Fruit } \\
\text { Punch } \\
\text { Ft.Wks. }\end{array}$ & $\begin{array}{l}\text { Diet } \\
\text { Pepsi }\end{array}$ & Pepsi & $\begin{array}{c}\text { Pepsi } \\
- \\
\text { Other }\end{array}$ & $\begin{array}{l}\text { Mt. } \\
\text { Dew }\end{array}$ & $\begin{array}{l}\text { Mt. } \\
\text { Dew - } \\
\text { Other }\end{array}$ & Isotonics \\
\hline 5405167 & 6/9/2003 & $\mathrm{N} / \mathrm{A}$ & N/A & N/A & N/A & N/A & N/A & N/A & N/A & N/A & N/A & \\
\hline 5404570 & $6 / 4 / 2003$ & N/A & N/A & N/A & N/A & N/A & N/A & N/A & N/A & N/A & N/A & \\
\hline \multirow[t]{5}{*}{5272754} & $4 / 30 / 2003$ & 12 & N/A & 23 & N/A & N/A & N/A & 22 & N/A & N/A & 22 & \\
\hline & & 16 & N/A & 18 & N/A & N/A & N/A & 36 & N/A & N/A & 24 & \\
\hline & & 20 & N/A & 24 & N/A & N/A & N/A & 22 & N/A & N/A & 20 & \\
\hline & & 54 & N/A & 32 & N/A & N/A & N/A & 56 & N/A & N/A & 55 & \\
\hline & & 2 & N/A & 6 & N/A & N/A & N/A & 8 & N/A & N/A & 8 & \\
\hline \multirow[t]{2}{*}{5272731} & $5 / 23 / 2003$ & 36 & 0 & 56 & 0 & $\mathrm{~N} / \mathrm{A}$ & N/A & 0 & N/A & N/A & N/A & \\
\hline & & 83 & 24 & 28 & 0 & N/A & N/A & 56 & N/A & N/A & N/A & \\
\hline \multirow[t]{6}{*}{5215113} & $4 / 1 / 2003$ & 56 & 0 & 56 & 0 & N/A & 0 & 56 & N/A & N/A & N/A & \\
\hline & & 2 & 0 & 0 & 0 & N/A & 0 & 0 & N/A & N/A & N/A & \\
\hline & & 30 & 12 & 12 & 0 & N/A & 0 & 44 & N/A & N/A & N/A & \\
\hline & & 24 & 24 & 60 & 0 & N/A & 14 & 38 & 20 & N/A & N/A & \\
\hline & & 58 & 0 & 0 & 28 & N/A & 0 & 0 & 0 & N/A & N/A & \\
\hline & & 28 & 24 & 0 & 0 & N/A & 0 & 0 & 0 & N/A & N/A & \\
\hline 5242244 & $6 / 2 / 2003$ & $\mathrm{~N} / \mathrm{A}$ & $\mathrm{N} / \mathrm{A}$ & N/A & N/A & N/A & N/A & N/A & N/A & N/A & N/A & \\
\hline 5237012 & $5 / 27 / 2003$ & 38 & N/A & N/A & 20 & N/A & N/A & N/A & 54 & N/A & N/A & \\
\hline
\end{tabular}




\begin{tabular}{|c|c|c|c|c|c|c|c|c|c|c|c|c|}
\hline 5404991 & $6 / 2 / 2003$ & N/A & N/A & N/A & N/A & N/A & N/A & N/A & N/A & N/A & N/A & \\
\hline $\begin{array}{c}\text { Machine } \\
\#\end{array}$ & $\begin{array}{c}\text { First } \\
\text { Data } \\
\text { Available }\end{array}$ & Water & $\begin{array}{c}\text { Orange } \\
\text { Juice }\end{array}$ & $\begin{array}{c}\text { Straw. } \\
\text { Ft. } \\
\text { Wks. }\end{array}$ & $\begin{array}{c}\text { Lemon } \\
\text { Ft. } \\
\text { Wks. }\end{array}$ & $\begin{array}{c}\text { Fruit } \\
\text { Punch } \\
\text { Ft.Wks. }\end{array}$ & $\begin{array}{l}\text { Diet } \\
\text { Pepsi }\end{array}$ & Pepsi & $\begin{array}{c}\text { Pepsi } \\
- \\
\text { Other }\end{array}$ & $\begin{array}{l}\text { Mt. } \\
\text { Dew }\end{array}$ & $\begin{array}{l}\text { Mt. } \\
\text { Dew - } \\
\text { Other }\end{array}$ & Isotonics \\
\hline 5272950 & $6 / 4 / 2003$ & N/A & N/A & N/A & N/A & N/A & N/A & N/A & N/A & N/A & N/A & \\
\hline 5272945 & $5 / 20 / 2003$ & 28 & 24 & 32 & N/A & N/A & 14 & 40 & 14 & N/A & N/A & \\
\hline & & 55 & 0 & 46 & N/A & N/A & 28 & 56 & 56 & N/A & N/A & \\
\hline 5272953 & $5 / 27 / 2003$ & 12 & N/A & N/A & 0 & 0 & N/A & N/A & 24 & 0 & N/A & \\
\hline 5237140 & $2 / 3 / 2003$ & 96 & N/A & N/A & N/A & $\mathrm{N} / \mathrm{A}$ & N/A & 0 & N/A & 64 & 64 & \\
\hline 5279493 & $3 / 26 / 2003$ & 96 & N/A & N/A & 64 & N/A & N/A & 0 & N/A & 32 & $\mathrm{~N} / \mathrm{A}$ & 24 \\
\hline & & 0 & N/A & N/A & 0 & N/A & N/A & 0 & N/A & 0 & N/A & 48 \\
\hline & & 26 & N/A & N/A & 8 & N/A & N/A & 0 & N/A & 0 & N/A & 0 \\
\hline 5275001 & $3 / 26 / 2003$ & 76 & 36 & 76 & N/A & N/A & N/A & 76 & 76 & N/A & N/A & \\
\hline & & 2 & 0 & 0 & N/A & N/A & N/A & 0 & 0 & N/A & N/A & \\
\hline & & 20 & 12 & 14 & N/A & N/A & N/A & 24 & 28 & N/A & N/A & \\
\hline Totals & & 870 & 156 & 483 & 120 & 0 & 56 & 534 & 272 & 96 & 193 & 72 \\
\hline
\end{tabular}




\section{APPENDIX J}

\section{Righetti High School Refill Data (6/1/03-8/30/03)}

June 1, 2003 through August 30, 2003

\begin{tabular}{|c|c|c|c|c|c|c|c|c|c|c|c|c|}
\hline $\begin{array}{c}\text { Machine } \\
\#\end{array}$ & Water & $\begin{array}{c}\text { Orange } \\
\text { Juice }\end{array}$ & $\begin{array}{c}\text { Straw. } \\
\text { Ft. } \\
\text { Wks. }\end{array}$ & $\begin{array}{c}\text { Lemonade } \\
\text { Ft. Wks. }\end{array}$ & $\begin{array}{c}\text { Fruit } \\
\text { Punch } \\
\text { Ft.Wks. }\end{array}$ & $\begin{array}{l}\text { Diet } \\
\text { Pepsi }\end{array}$ & Pepsi & $\begin{array}{l}\text { Pepsi - } \\
\text { Other }\end{array}$ & $\begin{array}{l}\text { Mt. } \\
\text { Dew }\end{array}$ & $\begin{array}{l}\text { Mt. } \\
\text { Dew - } \\
\text { Other }\end{array}$ & Isotonics & $\begin{array}{c}\text { Sierra } \\
\text { Mist }\end{array}$ \\
\hline \multirow[t]{10}{*}{5405167} & 10 & 0 & 36 & N/A & N/A & N/A & 24 & 72 & N/A & N/A & & \\
\hline & 18 & 0 & 26 & N/A & N/A & N/A & 18 & 26 & N/A & N/A & & \\
\hline & 20 & 36 & 36 & N/A & N/A & N/A & 46 & 72 & N/A & N/A & & \\
\hline & 0 & 0 & 0 & N/A & N/A & N/A & 16 & 10 & N/A & N/A & & \\
\hline & 4 & 4 & 4 & N/A & N/A & N/A & 2 & 18 & N/A & N/A & & \\
\hline & 0 & 2 & 4 & N/A & N/A & N/A & 2 & 26 & N/A & N/A & & \\
\hline & 2 & 0 & 2 & N/A & N/A & N/A & 2 & 18 & N/A & N/A & & \\
\hline & 6 & 0 & 8 & N/A & N/A & N/A & 10 & 18 & N/A & N/A & & \\
\hline & 6 & 24 & 42 & N/A & N/A & N/A & 32 & 30 & N/A & N/A & & \\
\hline & 0 & 12 & 22 & N/A & N/A & N/A & 30 & 66 & N/A & N/A & & \\
\hline \multirow[t]{10}{*}{5404570} & 18 & N/A & N/A & N/A & N/A & N/A & 0 & N/A & 28 & 28 & & \\
\hline & 30 & N/A & N/A & N/A & N/A & N/A & 0 & N/A & 24 & 18 & & \\
\hline & 51 & N/A & N/A & N/A & N/A & N/A & 0 & $\mathrm{~N} / \mathrm{A}$ & 70 & 60 & & \\
\hline & 4 & N/A & N/A & N/A & N/A & N/A & 10 & N/A & 0 & 0 & & \\
\hline & 8 & N/A & N/A & N/A & N/A & N/A & 0 & N/A & 12 & 16 & & \\
\hline & 8 & N/A & N/A & N/A & N/A & N/A & 0 & N/A & 4 & 6 & & \\
\hline & 6 & N/A & N/A & N/A & N/A & N/A & 0 & N/A & 6 & 6 & & \\
\hline & 20 & N/A & N/A & N/A & N/A & N/A & 0 & N/A & 12 & 16 & & \\
\hline & 16 & N/A & N/A & N/A & N/A & N/A & 0 & N/A & 44 & 36 & & \\
\hline & 28 & N/A & N/A & N/A & N/A & N/A & 0 & N/A & 24 & 26 & & \\
\hline & & & & & & & & & & & & \\
\hline & & & & & & & & & & & & \\
\hline
\end{tabular}




\begin{tabular}{|c|c|c|c|c|c|c|c|c|c|c|c|c|}
\hline $\begin{array}{c}\text { Machine } \\
\#\end{array}$ & Water & $\begin{array}{l}\text { Orange } \\
\text { Juice }\end{array}$ & $\begin{array}{c}\text { Straw. } \\
\text { Ft. } \\
\text { Wks. }\end{array}$ & $\begin{array}{l}\text { Lemonade } \\
\text { Ft. Wks. }\end{array}$ & $\begin{array}{c}\text { Fruit } \\
\text { Punch } \\
\text { Ft.Wks. }\end{array}$ & $\begin{array}{l}\text { Diet } \\
\text { Pepsi }\end{array}$ & Pepsi & $\begin{array}{l}\text { Pepsi - } \\
\text { Other }\end{array}$ & $\begin{array}{l}\text { Mt. } \\
\text { Dew }\end{array}$ & $\begin{array}{l}\text { Mt. } \\
\text { Dew - } \\
\text { Other }\end{array}$ & Isotonics & $\begin{array}{c}\text { Sierra } \\
\text { Mist }\end{array}$ \\
\hline \multirow[t]{6}{*}{5272754} & 2 & N/A & 0 & N/A & N/A & N/A & 0 & N/A & 0 & 0 & & \\
\hline & 12 & 0 & 8 & N/A & N/A & N/A & 20 & N/A & 1 & 8 & & \\
\hline & 2 & 0 & 8 & N/A & N/A & N/A & 14 & N/A & 0 & 10 & & \\
\hline & 22 & 0 & 35 & N/A & N/A & N/A & 42 & N/A & 0 & 25 & & \\
\hline & 0 & 0 & 14 & N/A & N/A & N/A & 42 & N/A & 0 & 20 & & \\
\hline & 30 & 12 & 46 & N/A & N/A & N/A & 56 & N/A & 0 & 56 & & \\
\hline \multirow[t]{8}{*}{5272731} & 68 & 24 & 28 & 0 & N/A & N/A & 56 & 0 & N/A & N/A & & \\
\hline & 65 & 0 & 28 & 0 & N/A & N/A & 56 & 1 & N/A & N/A & & \\
\hline & 6 & 10 & 0 & 0 & N/A & N/A & 0 & 0 & N/A & N/A & & \\
\hline & 56 & 12 & 28 & 0 & N/A & N/A & 56 & 0 & N/A & N/A & & \\
\hline & 2 & 0 & 0 & 2 & N/A & N/A & 0 & 0 & N/A & N/A & & \\
\hline & 86 & 24 & 56 & 0 & N/A & N/A & 56 & 0 & N/A & N/A & & \\
\hline & 12 & 0 & 22 & 0 & N/A & N/A & 30 & 40 & N/A & N/A & & \\
\hline & 56 & 24 & 0 & 0 & N/A & N/A & 28 & 28 & N/A & N/A & & \\
\hline \multirow[t]{4}{*}{5215113} & 56 & 0 & 0 & 0 & $\mathrm{~N} / \mathrm{A}$ & 0 & 0 & 0 & 0 & 0 & & \\
\hline & 12 & 0 & 0 & 10 & N/A & 0 & 0 & 0 & 22 & 16 & & \\
\hline & 12 & 0 & 12 & 0 & N/A & 0 & 0 & 0 & 8 & 0 & & \\
\hline & 34 & 0 & 0 & 0 & N/A & 0 & 0 & 0 & 18 & 32 & & \\
\hline \multirow[t]{7}{*}{5242244} & 22 & 24 & 26 & N/A & N/A & 20 & 54 & 10 & N/A & N/A & & \\
\hline & 12 & 0 & 18 & N/A & N/A & 22 & 28 & 10 & N/A & N/A & & \\
\hline & 28 & 28 & 28 & N/A & N/A & 24 & 56 & 56 & N/A & N/A & & \\
\hline & 10 & 0 & 10 & N/A & N/A & 0 & 14 & 0 & N/A & N/A & & \\
\hline & 0 & 4 & 0 & N/A & N/A & 10 & 4 & 12 & N/A & N/A & & \\
\hline & 0 & 2 & 4 & N/A & N/A & 4 & 10 & 4 & N/A & N/A & & \\
\hline & 2 & 0 & 0 & N/A & N/A & 0 & 2 & 2 & N/A & N/A & & \\
\hline
\end{tabular}




\begin{tabular}{|c|c|c|c|c|c|c|c|c|c|c|c|c|}
\hline & 2 & 0 & 2 & N/A & N/A & 2 & 2 & 0 & N/A & N/A & \multirow[b]{2}{*}{ Isotonics } & \multirow[b]{2}{*}{$\begin{array}{l}\text { Sierra } \\
\text { Mist }\end{array}$} \\
\hline \multirow[t]{3}{*}{$\begin{array}{c}\text { Machine } \\
\#\end{array}$} & Water & $\begin{array}{l}\text { Orange } \\
\text { Juice }\end{array}$ & $\begin{array}{c}\text { Straw. } \\
\text { Ft. } \\
\text { Wks. }\end{array}$ & $\begin{array}{l}\text { Lemonade } \\
\text { Ft. Wks. }\end{array}$ & $\begin{array}{c}\text { Fruit } \\
\text { Punch } \\
\text { Ft.Wks. }\end{array}$ & $\begin{array}{l}\text { Diet } \\
\text { Pepsi }\end{array}$ & Pepsi & $\begin{array}{l}\text { Pepsi - } \\
\text { Other }\end{array}$ & $\begin{array}{l}\text { Mt. } \\
\text { Dew }\end{array}$ & $\begin{array}{l}\text { Mt. } \\
\text { Dew - } \\
\text { Other }\end{array}$ & & \\
\hline & 6 & 0 & 12 & N/A & N/A & 12 & 28 & 0 & N/A & N/A & & \\
\hline & 26 & 24 & 32 & N/A & N/A & 28 & 56 & 0 & N/A & N/A & & \\
\hline \multirow{9}{*}{5237012} & 48 & $\mathrm{~N} / \mathrm{A}$ & $\mathrm{N} / \mathrm{A}$ & 14 & $\mathrm{~N} / \mathrm{A}$ & N/A & N/A & 54 & 0 & $\mathrm{~N} / \mathrm{A}$ & & \\
\hline & 18 & N/A & N/A & 12 & N/A & N/A & N/A & 48 & 0 & N/A & & \\
\hline & 42 & N/A & N/A & 38 & N/A & N/A & N/A & 82 & 0 & N/A & & \\
\hline & 0 & N/A & N/A & 0 & N/A & $\mathrm{N} / \mathrm{A}$ & N/A & 14 & 76 & N/A & & \\
\hline & 4 & N/A & N/A & 4 & N/A & N/A & N/A & 18 & 8 & N/A & & \\
\hline & 2 & N/A & N/A & 2 & N/A & N/A & $\mathrm{N} / \mathrm{A}$ & 12 & 8 & N/A & & \\
\hline & 0 & N/A & N/A & 2 & N/A & N/A & N/A & 2 & 0 & N/A & & \\
\hline & 18 & N/A & N/A & 0 & N/A & N/A & N/A & 22 & 12 & N/A & & \\
\hline & 64 & N/A & N/A & 51 & N/A & N/A & N/A & 108 & 62 & N/A & & \\
\hline \multirow[t]{10}{*}{5404991} & 24 & 24 & 20 & N/A & N/A & N/A & 28 & 80 & N/A & N/A & & \\
\hline & 30 & 0 & 18 & N/A & N/A & N/A & 32 & 55 & N/A & N/A & & \\
\hline & 14 & 0 & 22 & N/A & N/A & N/A & 32 & 86 & N/A & N/A & & \\
\hline & 16 & 0 & 6 & N/A & N/A & N/A & 21 & 54 & N/A & N/A & & \\
\hline & 60 & 33 & 30 & N/A & N/A & N/A & 28 & 75 & N/A & N/A & & \\
\hline & 38 & 16 & 25 & N/A & N/A & N/A & 24 & 60 & N/A & N/A & & \\
\hline & 12 & 8 & 12 & N/A & N/A & N/A & 6 & 28 & N/A & N/A & & \\
\hline & 14 & 12 & 16 & N/A & N/A & N/A & 20 & 18 & N/A & N/A & & \\
\hline & 20 & 0 & 36 & N/A & N/A & N/A & 36 & 66 & N/A & N/A & & \\
\hline & 18 & 36 & 18 & N/A & N/A & N/A & 36 & 90 & N/A & N/A & & \\
\hline \multirow[t]{3}{*}{5272950} & 34 & N/A & N/A & 16 & N/A & N/A & N/A & N/A & 42 & 18 & & \\
\hline & 18 & N/A & N/A & 16 & N/A & N/A & N/A & $\mathrm{N} / \mathrm{A}$ & 40 & 22 & & \\
\hline & 12 & N/A & N/A & 6 & N/A & N/A & N/A & N/A & 22 & 10 & & \\
\hline
\end{tabular}




\begin{tabular}{|c|c|c|c|c|c|c|c|c|c|c|c|c|}
\hline & 8 & N/A & N/A & 4 & N/A & N/A & N/A & N/A & 4 & 0 & & \\
\hline & 8 & N/A & N/A & 2 & N/A & N/A & N/A & N/A & 0 & 4 & & \\
\hline \multirow[t]{6}{*}{$\begin{array}{c}\text { Machine } \\
\# \\
\end{array}$} & Water & $\begin{array}{c}\text { Orange } \\
\text { Juice }\end{array}$ & $\begin{array}{c}\text { Straw. } \\
\text { Ft. } \\
\text { Wks. }\end{array}$ & $\begin{array}{l}\text { Lemonade } \\
\text { Ft. Wks. }\end{array}$ & $\begin{array}{c}\text { Fruit } \\
\text { Punch } \\
\text { Ft.Wks. }\end{array}$ & $\begin{array}{l}\text { Diet } \\
\text { Pepsi }\end{array}$ & Pepsi & $\begin{array}{l}\text { Pepsi - } \\
\text { Other }\end{array}$ & $\begin{array}{l}\text { Mt. } \\
\text { Dew }\end{array}$ & $\begin{array}{l}\text { Mt. } \\
\text { Dew - } \\
\text { Other }\end{array}$ & Isotonics & $\begin{array}{c}\text { Sierra } \\
\text { Mist }\end{array}$ \\
\hline & 14 & N/A & N/A & 2 & N/A & N/A & N/A & N/A & 4 & 2 & & \\
\hline & 4 & N/A & N/A & 2 & N/A & N/A & N/A & N/A & 2 & 4 & & \\
\hline & 38 & N/A & N/A & 16 & N/A & N/A & N/A & N/A & 22 & 26 & & \\
\hline & 108 & N/A & N/A & 54 & N/A & N/A & N/A & N/A & 72 & 72 & & \\
\hline & 32 & N/A & N/A & 14 & N/A & N/A & N/A & N/A & 36 & 44 & & \\
\hline \multirow[t]{9}{*}{5272945} & 56 & 24 & 56 & N/A & N/A & 28 & 14 & 56 & N/A & N/A & & \\
\hline & 12 & 12 & 13 & N/A & N/A & 4 & 20 & 6 & N/A & N/A & & \\
\hline & 56 & 28 & 50 & N/A & N/A & 28 & 30 & 56 & N/A & N/A & & \\
\hline & 24 & 0 & 0 & N/A & N/A & 0 & 0 & 22 & N/A & N/A & & \\
\hline & 0 & 20 & 10 & N/A & N/A & 10 & 28 & 14 & N/A & N/A & & \\
\hline & 6 & 10 & 22 & N/A & N/A & 0 & 24 & 16 & N/A & N/A & & \\
\hline & 2 & 0 & 0 & N/A & N/A & 0 & 0 & 0 & N/A & N/A & & \\
\hline & 6 & 0 & 16 & N/A & N/A & 8 & 0 & 0 & N/A & N/A & & \\
\hline & 38 & 24 & 50 & 8 & N/A & 0 & 28 & 32 & N/A & N/A & & \\
\hline \multirow[t]{10}{*}{5272953} & 108 & N/A & N/A & 72 & N/A & N/A & N/A & 72 & 0 & N/A & & \\
\hline & 49 & N/A & N/A & 34 & N/A & N/A & N/A & 92 & 53 & N/A & & \\
\hline & 86 & N/A & N/A & 72 & N/A & N/A & N/A & 108 & 72 & N/A & & \\
\hline & 24 & N/A & N/A & 20 & N/A & N/A & N/A & 76 & 44 & N/A & & \\
\hline & 14 & N/A & N/A & 8 & N/A & N/A & N/A & 26 & 26 & N/A & & \\
\hline & 2 & N/A & N/A & 3 & N/A & N/A & N/A & 22 & 20 & N/A & & \\
\hline & 26 & N/A & N/A & 17 & N/A & N/A & N/A & 64 & 58 & N/A & & \\
\hline & 12 & N/A & N/A & 4 & N/A & N/A & N/A & 18 & 24 & N/A & & \\
\hline & 103 & N/A & N/A & 35 & N/A & N/A & N/A & 108 & 72 & N/A & & \\
\hline & & & & & & & & & & & & \\
\hline
\end{tabular}




\begin{tabular}{|c|c|c|c|c|c|c|c|c|c|c|c|c|}
\hline 5233006 & 27 & N/A & 10 & N/A & N/A & N/A & N/A & N/A & 26 & 8 & & \\
\hline & 22 & N/A & 8 & N/A & N/A & N/A & N/A & N/A & 16 & 4 & & \\
\hline & 108 & N/A & 72 & N/A & N/A & N/A & N/A & N/A & 72 & 72 & & \\
\hline $\begin{array}{c}\text { Machine } \\
\text { \# }\end{array}$ & Water & $\begin{array}{c}\text { Orange } \\
\text { Juice }\end{array}$ & $\begin{array}{c}\text { Straw. } \\
\text { Ft. } \\
\text { Wks. }\end{array}$ & $\begin{array}{c}\text { Lemonade } \\
\text { Ft. Wks. }\end{array}$ & $\begin{array}{c}\text { Fruit } \\
\text { Punch } \\
\text { Ft.Wks. }\end{array}$ & $\begin{array}{l}\text { Diet } \\
\text { Pepsi }\end{array}$ & Pepsi & $\begin{array}{l}\text { Pepsi - } \\
\text { Other }\end{array}$ & $\begin{array}{l}\text { Mt. } \\
\text { Dew }\end{array}$ & $\begin{array}{c}\text { Mt. } \\
\text { Dew - } \\
\text { Other }\end{array}$ & Isotonics & $\begin{array}{c}\text { Sierra } \\
\text { Mist }\end{array}$ \\
\hline & 20 & N/A & 20 & N/A & N/A & N/A & N/A & N/A & 36 & 68 & & \\
\hline 5275001 & 2 & N/A & N/A & N/A & N/A & N/A & N/A & 0 & N/A & N/A & & \\
\hline 5279493 & 48 & N/A & N/A & 22 & N/A & N/A & 0 & 0 & 0 & 37 & 0 & \\
\hline & & & & & & & & & & & 0 & \\
\hline Totals & 2465 & 513 & 1127 & 562 & 0 & 200 & 1309 & 2279 & 1202 & 770 & $\mathbf{0}$ & 0 \\
\hline
\end{tabular}




\section{APPENDIX K}

Righetti High School Refill Data (9/1/03-1/21/04)

September 1, 2003 through January 21, 2004

\begin{tabular}{|c|c|c|c|c|c|c|c|c|c|c|c|c|}
\hline Machine \# & Water & $\begin{array}{c}\text { Orange } \\
\text { Juice }\end{array}$ & $\begin{array}{c}\text { Straw. } \\
\text { Ft. } \\
\text { Wks. }\end{array}$ & $\begin{array}{c}\text { Lemonade } \\
\text { Ft. Wks. }\end{array}$ & $\begin{array}{c}\text { Fruit } \\
\text { Punch } \\
\text { Ft.Wks. }\end{array}$ & $\begin{array}{c}\text { Diet } \\
\text { Pepsi }\end{array}$ & Pepsi & $\begin{array}{c}\text { Pepsi } \\
- \\
\text { Other }\end{array}$ & $\begin{array}{c}\text { Sierra } \\
\text { Mist }\end{array}$ & $\begin{array}{l}\text { Mt. } \\
\text { Dew }\end{array}$ & $\begin{array}{l}\text { Mt. } \\
\text { Dew - } \\
\text { Other }\end{array}$ & Isotonics \\
\hline \multirow[t]{20}{*}{5272953} & 18 & N/A & N/A & 12 & N/A & N/A & 0 & 52 & & 40 & N/A & \\
\hline & 96 & N/A & N/A & 60 & N/A & N/A & 0 & 108 & & 72 & N/A & \\
\hline & 24 & N/A & N/A & 6 & N/A & N/A & 0 & 38 & & 48 & N/A & \\
\hline & 22 & N/A & N/A & 0 & N/A & N/A & 0 & 46 & & 40 & N/A & \\
\hline & 30 & N/A & N/A & 20 & N/A & N/A & 0 & 58 & & 52 & N/A & \\
\hline & 24 & N/A & N/A & 0 & N/A & N/A & 14 & 64 & & 60 & N/A & \\
\hline & 30 & N/A & N/A & 18 & N/A & N/A & 0 & 60 & & 70 & N/A & \\
\hline & 58 & N/A & N/A & 57 & N/A & N/A & 0 & 0 & & 72 & 108 & \\
\hline & 66 & N/A & N/A & 22 & N/A & N/A & 0 & 102 & & 72 & 0 & \\
\hline & 68 & N/A & N/A & 38 & N/A & N/A & 0 & 88 & & 72 & 0 & \\
\hline & 48 & N/A & 0 & 20 & N/A & 0 & 0 & 62 & & 72 & & \\
\hline & 32 & N/A & 0 & 8 & N/A & 0 & 0 & 48 & & 49 & & \\
\hline & 40 & N/A & 0 & 16 & N/A & 0 & 0 & 38 & & 70 & & \\
\hline & 52 & N/A & 0 & 12 & N/A & 0 & 0 & 78 & & 68 & & \\
\hline & 66 & N/A & 0 & 16 & N/A & 0 & 0 & 80 & & 68 & & \\
\hline & 38 & N/A & 0 & 10 & N/A & 0 & 0 & 46 & & 56 & & \\
\hline & 18 & N/A & 16 & 0 & N/A & 10 & 20 & 16 & & 0 & & \\
\hline & 42 & N/A & 0 & 10 & N/A & 0 & 0 & 48 & & 47 & & \\
\hline & 56 & N/A & 0 & 0 & N/A & 0 & 32 & 58 & & 0 & & \\
\hline & 26 & N/A & 0 & 4 & N/A & 0 & 0 & 30 & & 46 & & \\
\hline
\end{tabular}




\begin{tabular}{|c|c|c|c|c|c|c|c|c|c|c|c|c|}
\hline Machine \# & Water & $\begin{array}{c}\text { Orange } \\
\text { Juice }\end{array}$ & $\begin{array}{c}\text { Straw. } \\
\text { Ft. } \\
\text { Wks. }\end{array}$ & $\begin{array}{l}\text { Lemonade } \\
\text { Ft. Wks. }\end{array}$ & $\begin{array}{c}\text { Fruit } \\
\text { Punch } \\
\text { Ft.Wks. }\end{array}$ & $\begin{array}{l}\text { Diet } \\
\text { Pepsi }\end{array}$ & Pepsi & $\begin{array}{c}\text { Pepsi } \\
- \\
\text { Other }\end{array}$ & $\begin{array}{c}\text { Sierra } \\
\text { Mist }\end{array}$ & $\begin{array}{l}\text { Mt. } \\
\text { Dew }\end{array}$ & $\begin{array}{l}\text { Mt. } \\
\text { Dew - } \\
\text { Other }\end{array}$ & Isotonics \\
\hline \multirow[t]{26}{*}{5237012} & 12 & N/A & N/A & 10 & N/A & N/A & N/A & 37 & & 19 & N/A & \\
\hline & 70 & N/A & N/A & 53 & N/A & N/A & N/A & 36 & & 0 & N/A & \\
\hline & 44 & N/A & N/A & 0 & N/A & N/A & N/A & 7 & & 53 & N/A & \\
\hline & 24 & N/A & N/A & 0 & N/A & N/A & N/A & 0 & & 28 & N/A & \\
\hline & 54 & N/A & N/A & 0 & N/A & N/A & N/A & 0 & & 36 & N/A & \\
\hline & 43 & N/A & N/A & 0 & N/A & N/A & N/A & 0 & & 36 & N/A & \\
\hline & 40 & N/A & N/A & 38 & N/A & N/A & N/A & 0 & & 10 & N/A & \\
\hline & 44 & N/A & N/A & 46 & N/A & N/A & N/A & 0 & & 0 & N/A & \\
\hline & 48 & N/A & N/A & 36 & N/A & N/A & N/A & 0 & & 0 & N/A & \\
\hline & 96 & N/A & N/A & 34 & N/A & N/A & N/A & 0 & & 36 & N/A & \\
\hline & 44 & N/A & N/A & 46 & N/A & N/A & N/A & 0 & & 0 & N/A & \\
\hline & 48 & N/A & N/A & 36 & N/A & N/A & N/A & 0 & & 0 & N/A & \\
\hline & 96 & N/A & N/A & 34 & N/A & N/A & N/A & 0 & & 36 & N/A & \\
\hline & 72 & N/A & N/A & 50 & N/A & N/A & N/A & 0 & & 0 & N/A & \\
\hline & 73 & N/A & N/A & 42 & N/A & N/A & N/A & 0 & & 34 & & \\
\hline & 40 & N/A & N/A & 10 & N/A & N/A & N/A & 36 & & 12 & & \\
\hline & 30 & N/A & N/A & 32 & N/A & N/A & N/A & 72 & & 0 & & \\
\hline & 12 & N/A & N/A & 0 & N/A & N/A & N/A & 0 & & 6 & & \\
\hline & 28 & N/A & N/A & 0 & N/A & N/A & N/A & 56 & & 0 & & \\
\hline & 20 & N/A & N/A & 8 & N/A & N/A & N/A & 32 & & 0 & & \\
\hline & 24 & N/A & N/A & 16 & N/A & N/A & N/A & 52 & & 0 & & \\
\hline & 102 & N/A & N/A & 72 & N/A & N/A & N/A & 72 & & 0 & & \\
\hline & 24 & N/A & N/A & 14 & N/A & N/A & N/A & 34 & & 0 & & \\
\hline & 16 & N/A & N/A & 12 & N/A & N/A & N/A & 34 & & 0 & & \\
\hline & 36 & N/A & N/A & 14 & N/A & N/A & N/A & 48 & & 0 & & \\
\hline & 40 & N/A & N/A & 10 & N/A & N/A & N/A & 30 & & 2 & & \\
\hline
\end{tabular}




\begin{tabular}{|c|c|c|c|c|c|c|c|c|c|c|c|c|}
\hline Machine \# & Water & $\begin{array}{c}\text { Orange } \\
\text { Juice }\end{array}$ & $\begin{array}{c}\text { Straw. } \\
\text { Ft. } \\
\text { Wks. }\end{array}$ & $\begin{array}{l}\text { Lemonade } \\
\text { Ft. Wks. }\end{array}$ & $\begin{array}{c}\text { Fruit } \\
\text { Punch } \\
\text { Ft.Wks. }\end{array}$ & $\begin{array}{l}\text { Diet } \\
\text { Pepsi }\end{array}$ & Pepsi & $\begin{array}{c}\text { Pepsi } \\
- \\
\text { Other }\end{array}$ & $\begin{array}{c}\text { Sierra } \\
\text { Mist }\end{array}$ & $\begin{array}{l}\text { Mt. } \\
\text { Dew }\end{array}$ & $\begin{array}{l}\text { Mt. } \\
\text { Dew - } \\
\text { Other }\end{array}$ & Isotonics \\
\hline \multirow[t]{14}{*}{5242244} & 28 & 24 & 0 & 0 & N/A & 28 & 56 & 24 & & N/A & N/A & 0 \\
\hline & 28 & 12 & 28 & 0 & N/A & 20 & 56 & 20 & & N/A & N/A & 0 \\
\hline & 26 & 24 & 28 & 0 & N/A & 28 & 56 & 56 & & N/A & N/A & 0 \\
\hline & 22 & 24 & 50 & 0 & N/A & 0 & 56 & 28 & & N/A & N/A & 0 \\
\hline & 0 & 0 & 0 & 12 & N/A & 0 & 6 & 0 & & N/A & N/A & 0 \\
\hline & 0 & 0 & 0 & 0 & N/A & 6 & 18 & 0 & & N/A & N/A & 0 \\
\hline & 0 & 0 & 6 & 0 & N/A & 0 & 8 & 27 & & N/A & N/A & 0 \\
\hline & 0 & 12 & 0 & 0 & N/A & 0 & 28 & 0 & & N/A & N/A & 0 \\
\hline & 8 & 0 & 14 & 0 & N/A & 0 & 62 & 14 & & N/A & & \\
\hline & 6 & 0 & 3 & 0 & N/A & 38 & 6 & 0 & & 0 & & \\
\hline & 12 & 12 & 0 & 0 & N/A & 0 & 18 & 0 & & 0 & & \\
\hline & 0 & 0 & 0 & 0 & N/A & 0 & 10 & 8 & & 0 & & \\
\hline & 10 & 0 & 20 & 0 & N/A & 0 & 32 & 12 & & 16 & & \\
\hline & & & & & & & & $\mathrm{s}$ & & & & \\
\hline \multirow{3}{*}{5215113} & 0 & 0 & 0 & 0 & N/A & 0 & 1 & 0 & & 0 & 0 & \\
\hline & 0 & 0 & 0 & 0 & N/A & 0 & 1 & 0 & & 0 & 0 & \\
\hline & 62 & 24 & 28 & N/A & N/A & N/A & 56 & & & N/A & & \\
\hline \multirow[t]{9}{*}{5272731} & 60 & 0 & 34 & N/A & N/A & N/A & 28 & 4 & & N/A & N/A & N/A \\
\hline & 56 & 36 & 56 & N/A & N/A & N/A & 0 & 56 & & N/A & N/A & N/A \\
\hline & 83 & 36 & 28 & N/A & N/A & N/A & 56 & 28 & & N/A & N/A & N/A \\
\hline & 82 & 12 & 28 & N/A & N/A & N/A & 31 & 9 & & N/A & N/A & N/A \\
\hline & 84 & 24 & 28 & N/A & N/A & N/A & 56 & 30 & & N/A & N/A & N/A \\
\hline & 84 & 24 & 28 & N/A & N/A & N/A & 56 & 0 & & N/A & N/A & N/A \\
\hline & 64 & 12 & 28 & N/A & N/A & N/A & 56 & 28 & & N/A & N/A & N/A \\
\hline & 58 & 24 & 28 & N/A & N/A & N/A & 4 & 32 & & N/A & & \\
\hline & 56 & 24 & 26 & N/A & N/A & N/A & 56 & 30 & & N/A & & \\
\hline
\end{tabular}




\begin{tabular}{|c|c|c|c|c|c|c|c|c|c|c|c|c|}
\hline & 56 & 24 & 28 & N/A & N/A & N/A & 56 & 56 & & N/A & & \multirow[b]{2}{*}{ Isotonics } \\
\hline \multirow[t]{8}{*}{ Machine \# } & Water & $\begin{array}{c}\text { Orange } \\
\text { Juice }\end{array}$ & $\begin{array}{c}\text { Straw. } \\
\text { Ft. } \\
\text { Wks. }\end{array}$ & $\begin{array}{c}\text { Lemonade } \\
\text { Ft. Wks. }\end{array}$ & $\begin{array}{c}\text { Fruit } \\
\text { Punch } \\
\text { Ft.Wks. }\end{array}$ & $\begin{array}{l}\text { Diet } \\
\text { Pepsi }\end{array}$ & Pepsi & $\begin{array}{c}\text { Pepsi } \\
- \\
\text { Other }\end{array}$ & $\begin{array}{c}\text { Sierra } \\
\text { Mist }\end{array}$ & $\begin{array}{l}\text { Mt. } \\
\text { Dew }\end{array}$ & $\begin{array}{l}\text { Mt. } \\
\text { Dew - } \\
\text { Other }\end{array}$ & \\
\hline & 56 & 0 & 54 & N/A & N/A & N/A & 32 & 56 & & $\mathrm{~N} / \mathrm{A}$ & & \\
\hline & 56 & 24 & 32 & N/A & N/A & N/A & 56 & 56 & & N/A & & \\
\hline & 0 & 0 & 0 & N/A & N/A & N/A & 0 & 0 & & N/A & & \\
\hline & 56 & 0 & 0 & N/A & N/A & N/A & 36 & 6 & & N/A & & \\
\hline & 52 & 24 & 0 & N/A & N/A & N/A & 56 & 56 & & N/A & & \\
\hline & 6 & 0 & 0 & N/A & N/A & N/A & 2 & 4 & & N/A & & \\
\hline & 12 & 0 & 0 & N/A & N/A & N/A & 12 & 12 & & N/A & & \\
\hline 5272950 & 48 & $\mathrm{~N} / \mathrm{A}$ & $\mathrm{N} / \mathrm{A}$ & 0 & N/A & N/A & 108 & 116 & & 0 & 0 & \\
\hline & 56 & N/A & N/A & 26 & N/A & N/A & 0 & 0 & & 36 & 100 & \\
\hline & 54 & N/A & N/A & 22 & N/A & N/A & 0 & 0 & & 44 & 56 & \\
\hline & 30 & N/A & N/A & 20 & N/A & N/A & 0 & 0 & & 50 & 42 & \\
\hline & 108 & N/A & N/A & 40 & N/A & N/A & 0 & 0 & & 72 & 108 & \\
\hline & 42 & N/A & N/A & 22 & N/A & N/A & 0 & 0 & & 52 & 49 & \\
\hline & 74 & N/A & N/A & 54 & N/A & N/A & 0 & 0 & & 72 & 108 & \\
\hline & 90 & N/A & N/A & 64 & N/A & N/A & 0 & 0 & & 72 & 108 & \\
\hline & 88 & N/A & N/A & 24 & N/A & N/A & 0 & 0 & & 72 & 108 & \\
\hline & 33 & N/A & N/A & 14 & N/A & N/A & 0 & 0 & & 40 & 40 & \\
\hline & 60 & N/A & N/A & 8 & N/A & N/A & 0 & 0 & & 52 & 64 & \\
\hline & 34 & N/A & N/A & 12 & N/A & N/A & 0 & 0 & & 30 & 20 & \\
\hline & 44 & N/A & N/A & 20 & N/A & N/A & 0 & 0 & & 72 & 92 & \\
\hline & 14 & N/A & N/A & 8 & N/A & N/A & 0 & 0 & & 2 & 2 & \\
\hline & 24 & N/A & N/A & 0 & N/A & N/A & 0 & 0 & & 18 & 20 & \\
\hline & 0 & N/A & N/A & 12 & N/A & N/A & 0 & 0 & & 20 & 14 & \\
\hline & 44 & N/A & N/A & 20 & N/A & N/A & N/A & 0 & & 72 & 92 & \\
\hline & 14 & N/A & N/A & 8 & N/A & N/A & N/A & 0 & & 2 & 2 & \\
\hline
\end{tabular}




\begin{tabular}{|c|c|c|c|c|c|c|c|c|c|c|c|c|}
\hline & 24 & N/A & N/A & 0 & N/A & N/A & N/A & 0 & & 18 & 20 & \\
\hline & 0 & N/A & N/A & 12 & N/A & N/A & N/A & 0 & & 20 & 14 & \\
\hline \multirow[t]{7}{*}{ Machine \# } & Water & $\begin{array}{c}\text { Orange } \\
\text { Juice }\end{array}$ & $\begin{array}{c}\text { Straw. } \\
\text { Ft. } \\
\text { Wks. }\end{array}$ & $\begin{array}{c}\text { Lemonade } \\
\text { Ft. Wks. }\end{array}$ & $\begin{array}{c}\text { Fruit } \\
\text { Punch } \\
\text { Ft.Wks. }\end{array}$ & $\begin{array}{l}\text { Diet } \\
\text { Pepsi }\end{array}$ & Pepsi & $\begin{array}{c}\text { Pepsi } \\
- \\
\text { Other } \\
\end{array}$ & $\begin{array}{c}\text { Sierra } \\
\text { Mist }\end{array}$ & $\begin{array}{l}\text { Mt. } \\
\text { Dew }\end{array}$ & $\begin{array}{l}\text { Mt. } \\
\text { Dew - } \\
\text { Other }\end{array}$ & Isotonics \\
\hline & 30 & N/A & N/A & 16 & N/A & N/A & N/A & 0 & & 24 & 36 & \\
\hline & 72 & N/A & N/A & 26 & N/A & N/A & N/A & 0 & & 70 & 52 & \\
\hline & 36 & N/A & N/A & 16 & N/A & N/A & N/A & 0 & & 48 & 68 & \\
\hline & 24 & N/A & N/A & 8 & N/A & N/A & N/A & 0 & & 16 & 8 & \\
\hline & 36 & N/A & N/A & 16 & N/A & N/A & N/A & 0 & & 28 & 50 & \\
\hline & 34 & N/A & N/A & 16 & N/A & N/A & N/A & 0 & & 32 & 30 & \\
\hline \multirow{18}{*}{5404991} & 66 & 0 & 72 & N/A & N/A & $\mathrm{N} / \mathrm{A}$ & 72 & 108 & & N/A & N/A & \\
\hline & 16 & 0 & 20 & N/A & N/A & N/A & 24 & 70 & & N/A & N/A & \\
\hline & 72 & 36 & 72 & N/A & N/A & N/A & 72 & 72 & & N/A & N/A & \\
\hline & 20 & 0 & 0 & N/A & N/A & N/A & 20 & 26 & & N/A & N/A & \\
\hline & 28 & 24 & 32 & N/A & N/A & N/A & 30 & 46 & & N/A & N/A & \\
\hline & 20 & 0 & 40 & N/A & N/A & N/A & 44 & 48 & & N/A & N/A & \\
\hline & 48 & 0 & 26 & N/A & N/A & N/A & 44 & 58 & & N/A & N/A & \\
\hline & 56 & 0 & 58 & N/A & N/A & N/A & 72 & 108 & & N/A & N/A & \\
\hline & 0 & 24 & 0 & N/A & N/A & N/A & 52 & 102 & & N/A & N/A & \\
\hline & 71 & 36 & 52 & N/A & N/A & N/A & 24 & 70 & & N/A & N/A & \\
\hline & 14 & 12 & 12 & N/A & N/A & N/A & 30 & 96 & & N/A & & \\
\hline & 26 & 0 & 18 & N/A & N/A & $\mathrm{N} / \mathrm{A}$ & 18 & 68 & & N/A & & \\
\hline & 24 & 12 & 14 & N/A & N/A & N/A & 44 & 73 & & N/A & & \\
\hline & 0 & 0 & 0 & N/A & N/A & N/A & 2 & 68 & & N/A & & \\
\hline & 32 & 12 & 12 & N/A & N/A & N/A & 24 & 50 & & N/A & & \\
\hline & 20 & 12 & 20 & N/A & N/A & N/A & 26 & 53 & & N/A & & \\
\hline & 22 & 0 & 14 & N/A & N/A & N/A & 32 & 8 & & N/A & & \\
\hline & 40 & 0 & 40 & N/A & N/A & N/A & 30 & 62 & & N/A & & \\
\hline
\end{tabular}




\begin{tabular}{|c|c|c|c|c|c|c|c|c|c|c|c|c|}
\hline & 12 & 0 & 8 & N/A & N/A & N/A & 34 & 22 & & N/A & & \\
\hline & 2 & 0 & 0 & N/A & N/A & N/A & 0 & 50 & & N/A & & \\
\hline & 20 & 0 & 36 & N/A & N/A & N/A & 48 & 44 & & N/A & & \\
\hline \multirow[t]{10}{*}{ Machine \# } & Water & $\begin{array}{c}\text { Orange } \\
\text { Juice }\end{array}$ & $\begin{array}{c}\text { Straw. } \\
\text { Ft. } \\
\text { Wks. } \\
\end{array}$ & $\begin{array}{c}\text { Lemonade } \\
\text { Ft. Wks. }\end{array}$ & $\begin{array}{c}\text { Fruit } \\
\text { Punch } \\
\text { Ft.Wks. }\end{array}$ & $\begin{array}{l}\text { Diet } \\
\text { Pepsi }\end{array}$ & Pepsi & $\begin{array}{c}\text { Pepsi } \\
- \\
\text { Other }\end{array}$ & $\begin{array}{c}\text { Sierra } \\
\text { Mist }\end{array}$ & $\begin{array}{l}\text { Mt. } \\
\text { Dew }\end{array}$ & $\begin{array}{l}\text { Mt. } \\
\text { Dew - } \\
\text { Other }\end{array}$ & Isotonics \\
\hline & 5 & 0 & 16 & N/A & N/A & N/A & 24 & 42 & & N/A & & \\
\hline & 37 & 12 & 18 & N/A & N/A & N/A & 47 & 66 & & N/A & & \\
\hline & 16 & 0 & 10 & N/A & N/A & N/A & 30 & 0 & & N/A & & \\
\hline & 20 & 0 & 10 & N/A & N/A & N/A & 18 & 44 & & N/A & & \\
\hline & 0 & 12 & 2 & N/A & N/A & N/A & 16 & 40 & & N/A & & \\
\hline & 8 & 12 & 8 & N/A & N/A & N/A & 4 & 38 & & N/A & & \\
\hline & 18 & 0 & 16 & N/A & N/A & N/A & 24 & 58 & & N/A & & \\
\hline & 10 & 0 & 10 & N/A & N/A & N/A & 16 & 28 & & N/A & & \\
\hline & 14 & 0 & 4 & N/A & N/A & N/A & 28 & 0 & & N/A & & \\
\hline \multirow[t]{5}{*}{5290798} & 2 & N/A & N/A & 0 & & 3 & 7 & 0 & & 32 & N/A & \\
\hline & 0 & N/A & N/A & 0 & N/A & 0 & 0 & 2 & & 0 & N/A & \\
\hline & 0 & N/A & N/A & 2 & N/A & 0 & 0 & 0 & & 0 & N/A & \\
\hline & 4 & N/A & N/A & 2 & N/A & 0 & 0 & 4 & & 0 & N/A & \\
\hline & 4 & N/A & N/A & 0 & N/A & 0 & 6 & 0 & & 2 & N/A & \\
\hline \multirow[t]{8}{*}{5272945} & 12 & 12 & 22 & 0 & $\mathrm{~N} / \mathrm{A}$ & 0 & 8 & 0 & & N/A & N/A & \\
\hline & 16 & 24 & 56 & 0 & N/A & 0 & 0 & 28 & & N/A & N/A & \\
\hline & 28 & 36 & 56 & 0 & N/A & 0 & 0 & 28 & & N/A & N/A & \\
\hline & 34 & 36 & 30 & 0 & N/A & 0 & 32 & 30 & & N/A & N/A & \\
\hline & 39 & 0 & 26 & 0 & N/A & 0 & 44 & 0 & & N/A & N/A & \\
\hline & 56 & 0 & 42 & 0 & N/A & 0 & 46 & 0 & & N/A & N/A & \\
\hline & 56 & 12 & 28 & 0 & N/A & 0 & 56 & 58 & & N/A & N/A & \\
\hline & 28 & 36 & 56 & 0 & N/A & 0 & 28 & 56 & & N/A & N/A & \\
\hline
\end{tabular}




\begin{tabular}{|c|c|c|c|c|c|c|c|c|c|c|c|c|}
\hline & 26 & 12 & 20 & N/A & N/A & 0 & 34 & 7 & & N/A & & \\
\hline & 6 & 24 & 6 & N/A & N/A & 0 & 26 & 6 & & N/A & & \\
\hline & 24 & 24 & 26 & N/A & N/A & 0 & 36 & 18 & & N/A & & \\
\hline & 12 & 0 & 12 & N/A & N/A & 0 & 24 & 7 & & N/A & & \\
\hline \multirow[t]{7}{*}{ Machine \# } & Water & $\begin{array}{c}\text { Orange } \\
\text { Juice }\end{array}$ & $\begin{array}{c}\text { Straw. } \\
\text { Ft. } \\
\text { Wks. }\end{array}$ & $\begin{array}{c}\text { Lemonade } \\
\text { Ft. Wks. }\end{array}$ & $\begin{array}{c}\text { Fruit } \\
\text { Punch } \\
\text { Ft.Wks. }\end{array}$ & $\begin{array}{l}\text { Diet } \\
\text { Pepsi }\end{array}$ & Pepsi & $\begin{array}{c}\text { Pepsi } \\
- \\
\text { Other }\end{array}$ & $\begin{array}{c}\text { Sierra } \\
\text { Mist }\end{array}$ & $\begin{array}{l}\text { Mt. } \\
\text { Dew }\end{array}$ & $\begin{array}{l}\text { Mt. } \\
\text { Dew - } \\
\text { Other }\end{array}$ & Isotonics \\
\hline & 24 & 24 & 52 & N/A & N/A & 0 & 36 & 26 & & N/A & & \\
\hline & 44 & 24 & 54 & N/A & N/A & 32 & 24 & 34 & & N/A & & \\
\hline & 38 & 24 & 50 & N/A & N/A & 14 & 28 & 20 & & N/A & & \\
\hline & 20 & 0 & 19 & N/A & N/A & 6 & 26 & 8 & & N/A & & \\
\hline & 2 & 0 & 0 & N/A & N/A & 0 & 0 & 0 & & N/A & & \\
\hline & 42 & 0 & 36 & N/A & N/A & 0 & 28 & 0 & & N/A & & \\
\hline \multirow[t]{16}{*}{5404570} & 26 & N/A & N/A & N/A & N/A & N/A & N/A & N/A & & 34 & 36 & \\
\hline & 70 & N/A & N/A & N/A & N/A & N/A & N/A & & & 108 & 34 & \\
\hline & 12 & N/A & N/A & N/A & N/A & N/A & N/A & & & 26 & 36 & \\
\hline & 58 & N/A & N/A & N/A & N/A & N/A & N/A & & & 98 & 22 & \\
\hline & 14 & N/A & N/A & N/A & N/A & N/A & N/A & & & 16 & 34 & \\
\hline & 8 & N/A & N/A & N/A & N/A & N/A & N/A & & & 22 & 10 & \\
\hline & 12 & N/A & N/A & N/A & N/A & N/A & N/A & & & 18 & 24 & \\
\hline & 36 & N/A & N/A & N/A & N/A & N/A & N/A & & & 60 & 64 & \\
\hline & 72 & N/A & N/A & N/A & N/A & N/A & N/A & & & 108 & 72 & \\
\hline & 4 & N/A & N/A & N/A & N/A & N/A & N/A & & & 0 & 0 & \\
\hline & 8 & N/A & 0 & N/A & N/A & N/A & N/A & & & 22 & 12 & \\
\hline & 40 & N/A & 0 & N/A & N/A & N/A & N/A & & & 36 & 34 & \\
\hline & 18 & N/A & 0 & N/A & N/A & N/A & N/A & & & 22 & 10 & \\
\hline & 34 & N/A & 0 & N/A & N/A & N/A & N/A & & & 54 & 52 & \\
\hline & 8 & N/A & 0 & N/A & N/A & N/A & N/A & & & 6 & 10 & \\
\hline & 16 & N/A & 8 & N/A & N/A & N/A & N/A & & & 34 & 16 & \\
\hline
\end{tabular}




\begin{tabular}{|c|c|c|c|c|c|c|c|c|c|c|c|c|}
\hline & 10 & N/A & 0 & N/A & N/A & N/A & N/A & & & 18 & 12 & \\
\hline & 14 & N/A & 0 & N/A & N/A & N/A & N/A & & & 30 & 16 & \\
\hline & 46 & N/A & 8 & N/A & N/A & N/A & N/A & & & 72 & 48 & \\
\hline & 6 & N/A & 8 & N/A & N/A & N/A & N/A & & & 16 & 12 & \\
\hline & 46 & N/A & 32 & N/A & N/A & N/A & N/A & & & 68 & 68 & \\
\hline \multirow[t]{4}{*}{ Machine \# } & Water & $\begin{array}{c}\text { Orange } \\
\text { Juice }\end{array}$ & $\begin{array}{c}\text { Straw. } \\
\text { Ft. } \\
\text { Wks. }\end{array}$ & $\begin{array}{l}\text { Lemonade } \\
\text { Ft. Wks. }\end{array}$ & $\begin{array}{c}\text { Fruit } \\
\text { Punch } \\
\text { Ft.Wks. }\end{array}$ & $\begin{array}{c}\text { Diet } \\
\text { Pepsi }\end{array}$ & Pepsi & $\begin{array}{c}\text { Pepsi } \\
- \\
\text { Other }\end{array}$ & $\begin{array}{c}\text { Sierra } \\
\text { Mist }\end{array}$ & $\begin{array}{l}\text { Mt. } \\
\text { Dew }\end{array}$ & $\begin{array}{l}\text { Mt. } \\
\text { Dew - } \\
\text { Other }\end{array}$ & Isotonics \\
\hline & 14 & N/A & 16 & N/A & N/A & N/A & N/A & & & 12 & 20 & \\
\hline & 22 & N/A & 12 & N/A & N/A & N/A & N/A & & & 62 & 0 & \\
\hline & 8 & N/A & 16 & N/A & N/A & N/A & N/A & & & 22 & 32 & \\
\hline \multirow{18}{*}{5405167} & 10 & 12 & 0 & N/A & N/A & N/A & 20 & 66 & & N/A & N/A & \\
\hline & 18 & 0 & 18 & N/A & N/A & N/A & 20 & 62 & & N/A & & \\
\hline & 0 & 12 & 0 & N/A & N/A & N/A & 4 & 48 & & N/A & & \\
\hline & 0 & 0 & 0 & N/A & N/A & N/A & 0 & 12 & & N/A & & \\
\hline & 0 & 0 & 6 & N/A & N/A & N/A & 8 & 48 & & N/A & & \\
\hline & 9 & 12 & 12 & N/A & N/A & N/A & 14 & 40 & & N/A & & \\
\hline & 0 & 0 & 0 & N/A & N/A & N/A & 10 & 20 & & N/A & & \\
\hline & 0 & 0 & 20 & N/A & N/A & N/A & 24 & 60 & & N/A & & \\
\hline & 10 & 0 & 26 & N/A & N/A & N/A & 32 & 36 & & N/A & & \\
\hline & 0 & 24 & 0 & N/A & N/A & N/A & 0 & 0 & & N/A & & \\
\hline & 0 & 0 & 0 & N/A & N/A & N/A & 0 & 2 & & N/A & & \\
\hline & 4 & 0 & 14 & N/A & N/A & N/A & 30 & 77 & & N/A & & \\
\hline & 0 & 24 & 16 & N/A & N/A & N/A & 12 & 48 & & N/A & & \\
\hline & 0 & 0 & 8 & N/A & N/A & N/A & 26 & 76 & & N/A & & \\
\hline & 4 & 12 & 12 & N/A & N/A & N/A & 36 & 62 & & N/A & & \\
\hline & 0 & 12 & 20 & N/A & N/A & N/A & 36 & 108 & & N/A & & \\
\hline & 6 & 12 & 10 & N/A & N/A & N/A & 20 & 58 & & N/A & & \\
\hline & 2 & 0 & 2 & N/A & N/A & N/A & 30 & 74 & & N/A & & \\
\hline
\end{tabular}




\begin{tabular}{|c|c|c|c|c|c|c|c|c|c|c|c|c|}
\hline & 0 & 12 & 0 & N/A & N/A & N/A & 14 & 61 & & N/A & & \\
\hline & 0 & 0 & 4 & N/A & N/A & N/A & 0 & 0 & & N/A & & \\
\hline & & & & & & & & $\mathrm{s}$ & & & & \\
\hline \multirow[t]{3}{*}{5233006} & 40 & N/A & 58 & N/A & N/A & N/A & N/A & 0 & & 36 & 72 & \\
\hline & 0 & N/A & 0 & N/A & N/A & N/A & N/A & 0 & & 22 & 32 & \\
\hline & 6 & N/A & 0 & N/A & N/A & N/A & N/A & 0 & & 28 & 14 & \\
\hline \multirow[t]{4}{*}{ Machine \# } & Water & $\begin{array}{c}\text { Orange } \\
\text { Juice }\end{array}$ & $\begin{array}{c}\text { Straw. } \\
\text { Ft. } \\
\text { Wks. }\end{array}$ & $\begin{array}{l}\text { Lemonade } \\
\text { Ft. Wks. }\end{array}$ & $\begin{array}{c}\text { Fruit } \\
\text { Punch } \\
\text { Ft.Wks. }\end{array}$ & $\begin{array}{l}\text { Diet } \\
\text { Pepsi }\end{array}$ & Pepsi & $\begin{array}{c}\text { Pepsi } \\
- \\
\text { Other }\end{array}$ & $\begin{array}{c}\text { Sierra } \\
\text { Mist }\end{array}$ & $\begin{array}{l}\text { Mt. } \\
\text { Dew }\end{array}$ & $\begin{array}{l}\text { Mt. } \\
\text { Dew - } \\
\text { Other }\end{array}$ & Isotonics \\
\hline & 0 & N/A & 0 & N/A & N/A & N/A & N/A & 0 & & 20 & 26 & \\
\hline & 0 & N/A & 0 & N/A & N/A & N/A & N/A & 6 & & 0 & 0 & \\
\hline & 1 & N/A & 0 & N/A & N/A & N/A & N/A & 0 & & 0 & 0 & \\
\hline \multirow[t]{2}{*}{5215113} & 0 & 0 & 0 & 0 & N/A & 0 & 1 & 0 & & 0 & 0 & \\
\hline & 0 & 0 & 0 & 0 & N/A & 0 & 1 & 0 & & 0 & 0 & \\
\hline 5258671 & 96 & N/A & N/A & 64 & N/A & N/A & 32 & 64 & 64 & N/A & & \\
\hline \multirow[t]{5}{*}{ (new) } & 10 & N/A & N/A & 0 & N/A & N/A & 0 & 18 & & N/A & & \\
\hline & 0 & N/A & N/A & 0 & N/A & N/A & 0 & 2 & & N/A & & \\
\hline & 0 & N/A & N/A & 2 & N/A & N/A & 0 & 0 & & N/A & & \\
\hline & 3 & N/A & N/A & 0 & N/A & N/A & 0 & 0 & & N/A & & \\
\hline & 2 & N/A & N/A & 0 & N/A & N/A & 0 & 0 & & N/A & & \\
\hline 5464125 & 114 & $\mathrm{~N} / \mathrm{A}$ & 76 & N/A & N/A & N/A & 0 & 0 & 38 & 76 & 76 & \\
\hline \multirow[t]{6}{*}{ (new) } & 20 & N/A & 0 & N/A & N/A & N/A & 0 & 0 & 0 & 12 & 14 & \\
\hline & 0 & N/A & 0 & N/A & N/A & N/A & 0 & 0 & 16 & 12 & 0 & \\
\hline & 4 & N/A & 16 & N/A & N/A & N/A & 0 & 0 & 0 & 20 & 18 & \\
\hline & 12 & N/A & 8 & N/A & N/A & N/A & 0 & 0 & 0 & 34 & 24 & \\
\hline & 18 & N/A & 0 & N/A & N/A & N/A & 0 & 0 & 32 & 16 & 12 & \\
\hline & 10 & N/A & 16 & N/A & N/A & N/A & 0 & 0 & 16 & 22 & 28 & \\
\hline
\end{tabular}




\begin{tabular}{|c|c|c|c|c|c|c|c|c|c|c|c|c|}
\hline & 28 & N/A & 16 & N/A & N/A & N/A & 0 & 0 & 34 & 50 & 36 & \\
\hline & 4 & N/A & 8 & N/A & N/A & N/A & 2 & 0 & 0 & 0 & 0 & \\
\hline 5404741 & 114 & N/A & 114 & N/A & N/A & N/A & N/A & N/A & & 76 & 76 & \\
\hline \multirow[t]{3}{*}{ (new) } & 28 & N/A & 16 & $\mathrm{~N} / \mathrm{A}$ & $\mathrm{N} / \mathrm{A}$ & N/A & N/A & & & 36 & 34 & \\
\hline & 40 & N/A & 32 & N/A & $\mathrm{N} / \mathrm{A}$ & N/A & N/A & & & 36 & 12 & \\
\hline & 40 & N/A & 40 & N/A & N/A & N/A & N/A & & & 36 & 34 & \\
\hline \multirow[t]{5}{*}{ Machine \# } & Water & $\begin{array}{c}\text { Orange } \\
\text { Juice }\end{array}$ & $\begin{array}{c}\text { Straw. } \\
\text { Ft. } \\
\text { Wks. }\end{array}$ & $\begin{array}{c}\text { Lemonade } \\
\text { Ft. Wks. }\end{array}$ & $\begin{array}{c}\text { Fruit } \\
\text { Punch } \\
\text { Ft.Wks. }\end{array}$ & $\begin{array}{l}\text { Diet } \\
\text { Pepsi }\end{array}$ & Pepsi & $\begin{array}{c}\text { Pepsi } \\
- \\
\text { Other }\end{array}$ & $\begin{array}{c}\text { Sierra } \\
\text { Mist }\end{array}$ & $\begin{array}{l}\text { Mt. } \\
\text { Dew }\end{array}$ & $\begin{array}{l}\text { Mt. } \\
\text { Dew - } \\
\text { Other }\end{array}$ & Isotonics \\
\hline & 18 & N/A & 26 & N/A & N/A & N/A & N/A & & & 22 & 26 & \\
\hline & 70 & N/A & 42 & N/A & N/A & N/A & N/A & & & 44 & 50 & \\
\hline & 52 & $\mathrm{~N} / \mathrm{A}$ & 54 & $\mathrm{~N} / \mathrm{A}$ & $\mathrm{N} / \mathrm{A}$ & N/A & $\mathrm{N} / \mathrm{A}$ & & & 56 & 52 & \\
\hline & 42 & N/A & 60 & N/A & N/A & N/A & N/A & & & 54 & 0 & \\
\hline 5291457 & 160 & N/A & N/A & 96 & N/A & N/A & N/A & 64 & & N/A & N/A & \\
\hline \multirow[t]{2}{*}{ (new) } & 2 & N/A & N/A & 0 & N/A & N/A & N/A & 0 & & N/A & & \\
\hline & 0 & $\mathrm{~N} / \mathrm{A}$ & N/A & 2 & N/A & N/A & N/A & 0 & & N/A & & \\
\hline 709558 & 128 & N/A & 0 & 32 & N/A & 62 & 64 & 62 & & 32 & N/A & \\
\hline \multirow[t]{6}{*}{ (new) } & 0 & N/A & 0 & 0 & N/A & 0 & 0 & 2 & & 0 & N/A & \\
\hline & 0 & $\mathrm{~N} / \mathrm{A}$ & 0 & 2 & $\mathrm{~N} / \mathrm{A}$ & 0 & 0 & 0 & & 0 & N/A & \\
\hline & 2 & N/A & 0 & 0 & N/A & 0 & 0 & 0 & & 0 & N/A & \\
\hline & 96 & N/A & 64 & 0 & N/A & 32 & 0 & 0 & & 64 & 64 & \\
\hline & 0 & N/A & 0 & 0 & N/A & 0 & 0 & 0 & & 0 & 2 & \\
\hline & 0 & N/A & 0 & 0 & N/A & 0 & 0 & 0 & & 0 & 2 & \\
\hline 5237140 & 83 & N/A & N/A & N/A & N/A & N/A & 96 & N/A & & 56 & 54 & \\
\hline \multirow[t]{2}{*}{ (new) } & 4 & N/A & N/A & N/A & N/A & N/A & 14 & N/A & & 4 & 6 & \\
\hline & 0 & N/A & N/A & N/A & N/A & N/A & 4 & N/A & & 2 & 2 & \\
\hline
\end{tabular}




\begin{tabular}{|c|c|c|c|c|c|c|c|c|c|c|c|c|}
\hline & 18 & N/A & N/A & N/A & N/A & N/A & 40 & N/A & & 33 & 30 & \\
\hline & 76 & N/A & N/A & N/A & N/A & N/A & 84 & N/A & & 56 & 56 & \\
\hline & 50 & N/A & N/A & N/A & N/A & N/A & 0 & N/A & & 4 & 2 & \\
\hline & 30 & N/A & N/A & N/A & N/A & N/A & 52 & N/A & & 26 & 26 & \\
\hline & 14 & N/A & N/A & N/A & N/A & N/A & 34 & N/A & & 18 & 22 & \\
\hline 5272754 & 6 & 0 & 0 & N/A & N/A & N/A & 4 & & & 3 & 8 & \\
\hline & 32 & 0 & 24 & N/A & N/A & N/A & 56 & & & 56 & 55 & \\
\hline Machine \# & Water & $\begin{array}{c}\text { Orange } \\
\text { Juice }\end{array}$ & $\begin{array}{c}\text { Straw. } \\
\text { Ft. } \\
\text { Wks. }\end{array}$ & $\begin{array}{l}\text { Lemonade } \\
\text { Ft. Wks. }\end{array}$ & $\begin{array}{c}\text { Fruit } \\
\text { Punch } \\
\text { Ft.Wks. }\end{array}$ & $\begin{array}{c}\text { Diet } \\
\text { Pepsi }\end{array}$ & Pepsi & $\begin{array}{c}\text { Pepsi } \\
- \\
\text { Other }\end{array}$ & $\begin{array}{c}\text { Sierra } \\
\text { Mist }\end{array}$ & $\begin{array}{l}\text { Mt. } \\
\text { Dew }\end{array}$ & $\begin{array}{l}\text { Mt. } \\
\text { Dew - } \\
\text { Other }\end{array}$ & Isotonics \\
\hline & 50 & 0 & 46 & N/A & N/A & N/A & 56 & & & 0 & 56 & \\
\hline & 6 & 0 & 8 & N/A & N/A & N/A & 16 & & & 0 & 8 & \\
\hline & 28 & 0 & 24 & N/A & N/A & N/A & 40 & & & 0 & 40 & \\
\hline & 28 & 0 & 56 & N/A & N/A & N/A & 56 & & & 0 & 56 & \\
\hline & 2 & 8 & 0 & N/A & N/A & N/A & 4 & & & 0 & 4 & \\
\hline & 12 & 0 & 20 & N/A & N/A & N/A & 34 & & & 0 & 36 & \\
\hline & 34 & 0 & 34 & N/A & N/A & N/A & 56 & & & 0 & 44 & \\
\hline & 20 & 0 & 14 & N/A & N/A & N/A & 54 & & & 0 & 32 & \\
\hline 5275001 & 12 & 36 & 72 & N/A & N/A & N/A & 72 & 108 & & 0 & 0 & \\
\hline & 20 & 0 & 0 & N/A & N/A & N/A & 0 & 0 & & 30 & 30 & \\
\hline & 30 & 0 & 20 & N/A & N/A & N/A & 46 & 0 & & 0 & 40 & \\
\hline & 56 & 24 & 72 & N/A & N/A & N/A & 72 & 108 & & 0 & 0 & \\
\hline 5279493 & 37 & & & 32 & & & 64 & 0 & & 0 & 32 & 0 \\
\hline & 44 & & & 0 & & & 30 & 0 & & 0 & 28 & 0 \\
\hline & 6 & & & 16 & & & 0 & 24 & & 0 & 18 & 0 \\
\hline & 8 & & & 2 & & & 0 & 28 & & 0 & 12 & 0 \\
\hline & 0 & & & 2 & & & 0 & 0 & & 2 & 0 & 0 \\
\hline
\end{tabular}




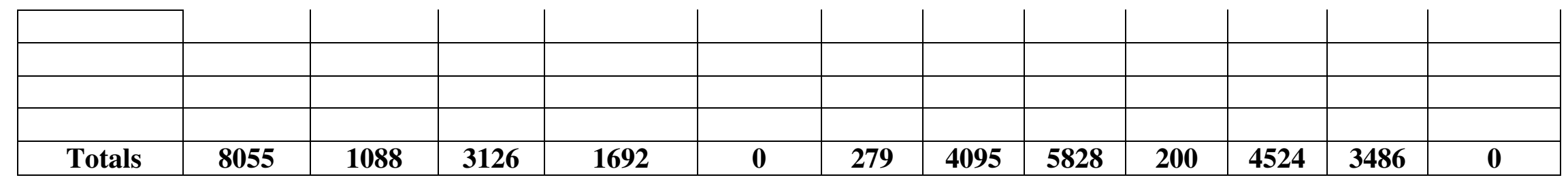


APPENDIX L

Prochaska and DiClemente's Stages of Change Model

\begin{tabular}{|c|c|c|}
\hline Stage of Change & Characteristics & Techniques \\
\hline Pre-contemplation & $\begin{array}{l}\text { Not currently considering } \\
\text { change: "Ignorance is bliss" }\end{array}$ & $\begin{array}{l}\text { Validate lack of readiness } \\
\text { Clarify: decision is theirs } \\
\text { Encourage re-evaluation of } \\
\text { current behavior } \\
\text { Encourage self-exploration, not } \\
\text { action } \\
\text { Explain and personalize the risk }\end{array}$ \\
\hline Contemplation & $\begin{array}{l}\text { Ambivalent about change: } \\
\text { "Sitting on the fence" } \\
\text { Not considering change } \\
\text { within the next month }\end{array}$ & $\begin{array}{l}\text { Validate lack of readiness } \\
\text { Clarify: decision is theirs } \\
\text { Encourage evaluation of pros } \\
\text { and cons of behavior change } \\
\text { Identify and promote new, } \\
\text { positive outcome expectations }\end{array}$ \\
\hline Preparation & $\begin{array}{l}\text { Some experience with } \\
\text { change and are trying to } \\
\text { change: "Testing the } \\
\text { waters" } \\
\text { Planning to act within } \\
\text { 1month }\end{array}$ & $\begin{array}{l}\text { Identify and assist in problem } \\
\text { solving re: obstacles } \\
\text { Help patient identify social } \\
\text { support } \\
\text { Verify that patient has underlying } \\
\text { skills for behavior change } \\
\text { Encourage small initial steps }\end{array}$ \\
\hline Action & $\begin{array}{l}\text { Practicing new behavior for } \\
\text { 3-6 months }\end{array}$ & $\begin{array}{l}\text { Focus on restructuring cues and } \\
\text { social support } \\
\text { Bolster self-efficacy for dealing } \\
\text { with obstacles } \\
\text { Combat feelings of loss and } \\
\text { reiterate long-term benefits }\end{array}$ \\
\hline Maintenance & $\begin{array}{l}\text { Continued commitment to } \\
\text { sustaining new behavior } \\
\text { Post- } 6 \text { months to } 5 \text { years }\end{array}$ & $\begin{array}{l}\text { Plan for follow-up support } \\
\text { Reinforce internal rewards } \\
\text { Discuss coping with relapse }\end{array}$ \\
\hline Relapse & \begin{tabular}{|l|} 
Resumption of old \\
behaviors: "Fall from grace"
\end{tabular} & $\begin{array}{l}\text { Evaluate trigger for relapse } \\
\text { Reassess motivation and } \\
\text { barriers } \\
\text { Plan stronger coping strategies }\end{array}$ \\
\hline
\end{tabular}

